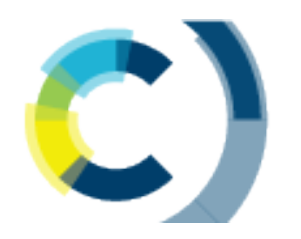

NJC

\title{
Simple dissymmetrical and asymmetrical Tröger's Bases: Photophysical and structural characterization
}

\begin{tabular}{|c|c|}
\hline Journal: & New Journal of Chemistry \\
\hline Manuscript ID & NJ-ART-04-2020-001988.R1 \\
\hline Article Type: & Paper \\
\hline $\begin{array}{r}\text { Date Submitted by the } \\
\text { Author: }\end{array}$ & $\mathrm{n} / \mathrm{a}$ \\
\hline Complete List of Authors: & $\begin{array}{l}\text { Trupp, Leandro; Universidad de Buenos Aires Facultad de Ciencias } \\
\text { Exactas y Naturales, Departamento de Química Inorgánica, Analítica y } \\
\text { Química Física; Instituto de Quimica Fisica de los Materiales Medio } \\
\text { Ambiente y Energia, ; Universidad de Buenos Aires Facultad de Ciencias } \\
\text { Exactas y Naturales, Departamento de Química Orgánica; Unidad de } \\
\text { Microanálisis y Métodos Físicos en Química Orgánica } \\
\text { Bruttomesso, Andrea; Universidad de Buenos Aires Facultad de Ciencias } \\
\text { Exactas y Naturales, Departamento de Química Orgánica; Unidad de } \\
\text { Microanálisis y Métodos Físicos en Química Orgánica } \\
\text { BARJA, BEATRIZ; Universidad de Buenos Aires Facultad de Ciencias } \\
\text { Exactas y Naturales, Departamento de Química Inorgánica, Analítica y } \\
\text { Química Física; Instituto de Quimica Fisica de los Materiales Medio } \\
\text { Ambiente y Energia, }\end{array}$ \\
\hline \multicolumn{2}{|c|}{$\begin{array}{l}\text { Note: The following files were submitted by the author for peer review, but cannot be converted to PDF. } \\
\text { You must view these files (e.g. movies) online. }\end{array}$} \\
\hline $\begin{array}{l}\text { Figure 1.cdx } \\
\text { Chart 1.cdx } \\
\text { Scheme 1.cdx } \\
\text { Figure 2.cdx } \\
\text { Figure 3.cdx }\end{array}$ & \\
\hline
\end{tabular}




\section{Guidelines for Referees}

Thank you very much for agreeing to review this manuscript for New Journal of Chemistry.

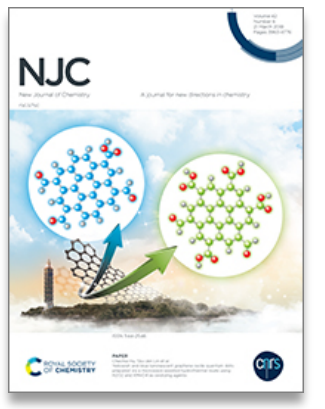

NJC (New Journal of Chemistry) is a broad-based primary journal encompassing all branches of chemistry and its sub-disciplines. It contains full research articles, letters and perspectives and focus articles.

NJC’s Impact Factor is 3.069 (2018 Journal Citation Reports ${ }^{\circledR}$ )

The following manuscript has been submitted for consideration as a

\section{PAPER}

Papers report a complete study that leads to new understanding or gives new insight into the subject under investigation. If preliminary results have been published in a communication, a subsequent full paper should include additional results that justify another publication.

We ask referees to recommend only the most significant work for publication in NJC. When making your recommendation please:

- Comment on the originality, importance, impact and scientific reliability of the work

- Note that routine or incremental work should not be recommended for publication.

- Contact the Editor if there is any conflict of interest, if the work has been previously published or if there is a significant part of the work which you are not able to referee with confidence.

Best regards,

\section{Contact us}

\section{Professor Mir Wais Hosseini}

Dr Andrew Shore

Editor-in-Chief, NJC

Executive Editor, NJC

Please visit our reviewer hub for further details of our processes, policies and reviewer responsibilities as well as guidance on how to review, or click the links below.
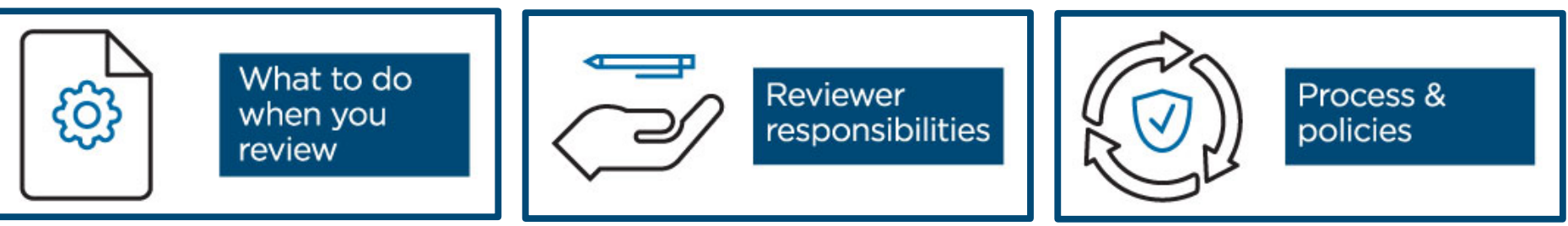
Dr. Beatriz C. Barja

Facultad de Ciencias Exactas y Naturales

University of Buenos Aires

1428 Ciudad Universitaria

Pabellón II, piso $1^{\circ}$, Ciudad Autónoma de Buenos Aires

Prof. Dr. Jean-François Gérard

Editor-in-Chief

New Journal of Chemistry

Dear Prof. Dr. Gérard

I am pleased to submit an original research article entitled "Simple dissymmetrical and asymmetrical Tröger's Bases: Photophysical and structural characterization" by Leandro Trupp, Andrea C. Bruttomesso and Beatriz C. Barja for consideration for publication in New Journal of Chemistry.

In this paper we present a comprehensive study involving the synthesis and photophysical characterization of new Tröger's bases (TBs) containing nitrogen-based substituents. We consider that this manuscript is a starting point in the photophysical studies of the TBs, compounds with a rich history and current and potential applications. The fixed configuration of TBs makes these molecules chiral and fluorescent possessing an hydrophobic cavity, rendering them useful in areas such as molecular recognition, drug development, bioorganic and supramolecular chemistry and also promising scaffolds for the construction of luminescent materials. Unexpectedly, scarce information regarding their experimental photophysical properties has been published, making this manuscript a key analysis in this line of study.

We synthetized a new asymmetrical TB with one amino and one isocyano group together with three dissymmetrical TBs: diamino, diisocyano and diformamido. Their photophysical studies are presented including the solvatochromic effects. An intramolecular charge transfer state (ICT) was found for the isocyano containing derivatives being associated to the interactions of the isocyano acceptor group with the nitrogen donor atom in the central diazocinic core. The ${ }^{13} \mathrm{C}$ NMR, ${ }^{1} \mathrm{H}$ NMR and ATR-FT IR spectroscopy were also analyzed. In a similar way to what we had previously observed in the diformamido-TB, we found communication between both ends of the TBs, a phenomenon only observed a few times.

The authors consider this manuscript appropriate for publication in the New Journal of Chemistry in view of the scope and expectations of the journal. In addition, the only study regarding the photophysical properties of TBs was published in the New J. Chem. in 2015, making this work a continuation of such publication but regarding the analysis of more complex molecules and including a thorough NMR and IR interpretation. We declare that this manuscript has not been published and is not under consideration for publication elsewhere. We have no conflicts of interest to disclose.

Thank you for your consideration

Sincerely,

Dr. Beatriz C Barja

Scientific Independent Researcher -CONICET- INQUIMAE

Facultad de Ciencias Exactas y Naturales

Universidad de Buenos Aires 
Received 00th January 20xx, Accepted 00th January 20xx

DOI: $10.1039 / \times 0 \times x 00000 x$

\title{
Simple dissymmetrical and asymmetrical Tröger's Bases: Photophysical and structural characterization
}

\author{
Leandro Trupp, ${ }^{\text {abcd }}$ Andrea C. Bruttomesso ${ }^{\text {tcd }}$ and Beatriz C. Barja*ab
}

Despite their continuously growing preparation and applications in the last decades, the photophysical properties of Tröger's bases (TBs) with small substituents have not been analyzed. We synthetized three dissymmetrical TBs with amino, isocyano and formamido groups and a new asymmetrical TB with one amino and one isocyano group and studied their absorption and emission properties and solvatochromic effects. An intramolecular charge transfer (ICT) state was found for the isocyano containing derivatives, associated to the isocyano acceptor group and the nitrogen donor atom in the central diazocinic core. NMR and IR spectroscopy were also analyzed, demonstrating the communication between both ends of the TBs.

\section{Introduction}

Control over the three-dimensional disposition of different substituents is desired in synthetic organic design, and thus building blocks with well-defined rigid structures are particularly convenient. One compound of this kind is Tröger's base (2,8-dimethyl-6H,12H-5,11-methanodibenzo[ $b, f][1,5]$ diazocine, 1a), which consists of two aromatic rings fused by a bicyclic aliphatic methanodiazocine unit. The methylene bridge prevents pyramidal inversion of the two nitrogen atoms and thus the molecule adopts a rigid $\mathrm{V}$-shaped geometry with the aromatic rings almost perpendicular to each other and with a $C_{2}$ axis of symmetry (Figure 1 ). The angle has been predicted for a wide array of derivatives between $84^{\circ}$ and $105^{\circ}$, with a mean value of $95^{\circ} .1$

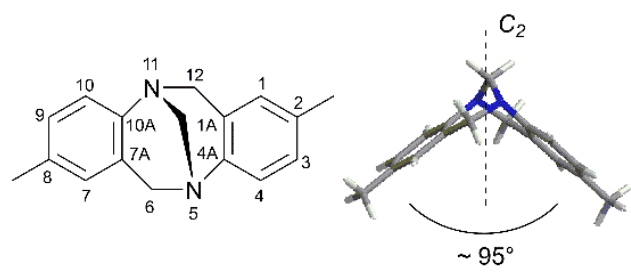

Figure 1. Structure of $(S, S)-1 a$ and three-dimensional structure obtained by molecular mechanics using ChemDraw3D.

a. Departamento de Química Inorgánica, Analítica y Química Física, Facultad de Ciencias Exactas y Naturales, Universidad de Buenos Aires, Int. Güiraldes 2160, Ciudad Universitaria, Buenos Aires, 1428, Argentina

b. Instituto de Química Física de los Materiales, Medio Ambiente y Energía (INQUIMAE), CONICET - Universidad de Buenos Aires, Int. Güiraldes 2160, Ciudad Universitaria, Buenos Aires, 1428, Argentina

Departamento de Química Orgánica, Facultad de Ciencias Exactas y Naturales, Universidad de Buenos Aires, Int. Güiraldes 2160, Ciudad Universitaria, Buenos Aires, 1428, Argentina

d. Unidad de Microanálisis y Métodos Físicos Aplicados a Química Orgánica (UMYMFOR), CONICET - Universidad de Buenos Aires, Int. Güiraldes 2160, Ciudad Universitaria, Buenos Aires, 1428, Argentina

† Deceased, 25th august 2018.

Electronic Supplementary Information (ESI) available: Full experimental details and characterization and spectral data such as $1 \mathrm{D}$ and 2D NMR, IR assignments, lifetime measurements and Lippert-Mataga plots. See DOI: 10.1039/x0xx00000x
Compounds with this benzodiazocinic core, independently of the substituents of the aromatic rings, are usually called Tröger's base derivatives or analogues, or simply Tröger's bases (TBs). ${ }^{2}$ When the molecules are symmetrical with respect to a $180^{\circ}$ rotation around the $C_{2}$ axis, that is, when the substituents of both aromatic moieties are the same in each relative position, compounds are said to be dissymmetrical, and otherwise they are asymmetrical. ${ }^{3,4}$

The fixed configuration of TBs makes them chiral molecules with a hydrophobic cavity, and renders them useful in areas such as molecular recognition, drug development and bioorganic and supramolecular chemistry, among others. ${ }^{5-11}$ Moreover, a wide array of TBs can be synthesized, and they can be in turn modified in numerous positions in order to attain the desired structures. ${ }^{2,12-14}$

In addition, TBs are usually fluorescent molecules, and are promising scaffolds for the construction of luminescent materials. This property can be explained analyzing TBs' structure and its most important features: (1) the perpendicularity of the aromatic rings allows larger Stokes shifts and reduces self-absorption; (2) the high rigidity can restrict internal rotation and thus reduce non-radiative deactivation pathways; (3) the rigid V-shaped structure prevents intermolecular $\pi-\pi$ close stacking and dipole-dipole interaction. ${ }^{15}$

Nevertheless, and despite the interesting features of Tröger's bases and their description as one of the "fascinating molecules in organic chemistry"16, almost no study has been made regarding its photophysical properties. Pimentel et al. have characterized simple Tröger's base derivatives with different substituents at the 2,8 positions as $-\mathrm{Me}(\mathbf{1 a}),-\mathrm{H}(\mathbf{1 b})$, and -COOMe (1c). ${ }^{17}$ As expected, they found that TBs present absorption in the UV region, which could be ascribed to $\pi-\pi^{*}$ electronic transitions, and emit in the violet-blue regions with a time decay of approximately 1-2 ns. The Stokes shifts were of 52-71 nm for $\mathbf{1 a}$ and $\mathbf{1 b}$ and of 62-115 nm for $\mathbf{1 c}$, depending on the solvent, whereas the fluorescence quantum yields were of around $5-17 \%$ for $\mathbf{1 a}$ and $\mathbf{1 b}$ and smaller than $2 \%$ for $\mathbf{1 c}$. Moreover, 1c presented a large solvatochromic effect, which 
was consistent with a change in dipole moment upon light absorption of $14.8 \mathrm{D}$.

In order to deepen the knowledge of the photophysics of Tröger's base derivatives, we synthesized four simple nitrogenated compounds (Chart 1) and studied their photophysical properties. Initially, diamino-TB 2a and diisocyano-TB 2c were proposed due both to their intrinsic properties and to their potential as scaffolds for building more complex structures. In this sense, the amine group can be easily reacted by alkylations, amide couplings, $\mathrm{C}-\mathrm{N}$ cross couplings, etc., whereas isonitriles are uniquely capable of participating in multicomponent reactions (MCRs) such as Ugi and Passerini MCRs.<smiles>Cc1cc(N)cc2c1N1CCN(C2)c2cc(N)cc(C)c21</smiles>

2a<smiles>Cc1cc(C)cc(N=CNc2cc(C)c3c(c2)CN2CCN3Cc3cc(N=CO)cc(C)c32)c1</smiles><smiles>Cc1cc(N)cc2c1C1Cc3cc(N)cc(C)c3N(C2)N1</smiles>

2b
Chart 1. Structure of compounds $2 a-d$.

In addition, the isocyano group is particularly interesting due to its unusual structure, since it constitutes the only class of stable organic compound with a formally divalent carbon atom. Not only this generates the possibility of a unique synthetic chemistry, but also makes isonitriles compounds with $\pi$ backbonding properties, capacity to act as strong proton acceptors and ability to form stable complexes with transition metal ions. ${ }^{18-21}$ Only a few reports about the electronic properties of isonitriles have been presented, and thus the study of its photophysical properties results interesting..$^{20-24}$
Moreover, we envisioned the synthesis and characterization of a new TB, the asymmetrical compound $\mathbf{2} \mathbf{b}$ that lies between $2 \mathrm{a}$ and $\mathbf{2 c}$ with one amine and one isocyanide substituent. The preparation of $\mathbf{2} \mathbf{b}$ was also motivated by its synthetic challenge -only a few asymmetric TBs have been synthesized $3,25-30$ - and by its potential for solvatochromic properties. The incorporation of both an electron donor (amine) and acceptor (isocyanide) in the same scaffold is particularly promising in this regard, as shown by Keki's group in their study of 4-amino-4'isocyanobiphenyl and 1-amino-5-isocyanonaphthalene..$^{20,31}$

Finally, compound $\mathbf{2 d}$ was originally obtained as a synthetic intermediate in the path to obtain $\mathbf{2} \mathbf{c}$ from $\mathbf{2 a}$, and was included in this work in order to study a new TB with a different functional group and to compare the formamide with its related amine. $\mathbf{2 d}$ also presented an interesting NMR behavior due to long-range anisotropic effects that generate a connection between both ends of the compound. This unusual result was thoroughly studied by our group using NMR spectroscopy techniques as well as DFT calculations. ${ }^{32}$

In this work, we thus set out to characterize the spectroscopic properties of four simple Tröger's bases with different nitrogenated substituents, and to analyze them in terms of their structure. Three of these compounds are dissymmetrical, whereas the remaining one is asymmetrical and has not been prepared before. In particular, absorption and emission spectra will be obtained, complemented by NMR and IR spectroscopy.

\section{Results and discussion}

\section{Compound Synthesis}

Compounds $\mathbf{2 a - d}$ were prepared according to the synthetic pathways presented in Scheme 1. Compound 2a was obtained following the procedure described by Kiehne et al., starting from an acid-catalyzed condensation step of 2-methyl-4nitroaniline with paraformaldehyde and its ulterior reduction with yields of $87 \%$ and $99 \%$ respectively. ${ }^{32,33}$<smiles>CC#CCN1Cc2cc(N)cc(C)c2N2Cc3cc(N)cc(C)c3N1Cc1cc([N+](=O)[O-])cc(C)c1N2Cc1cc(N)cc([N+](=O)[O-])c1</smiles>

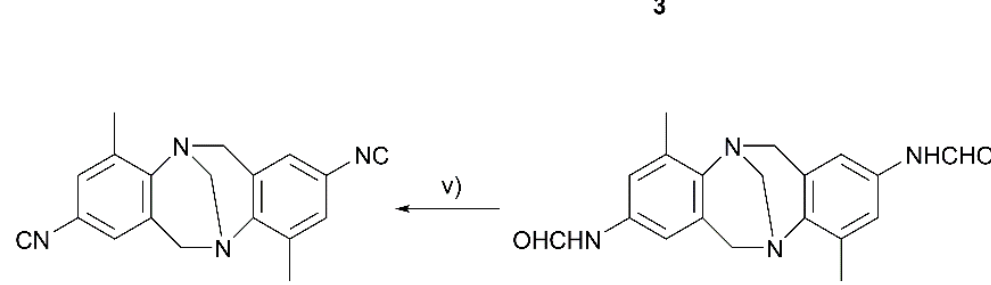

2c

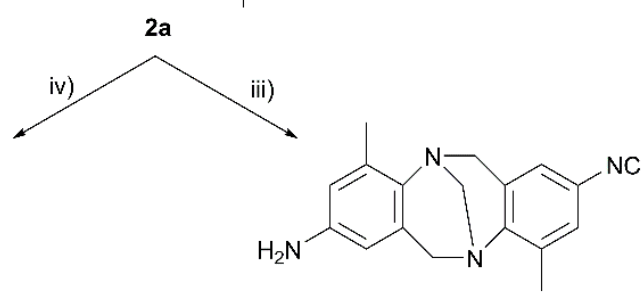

2b

Scheme 1. Synthetic routes used for the preparation of TBs 2a-d. i) $\left(\mathrm{CH}_{2} \mathrm{O}\right)$ n, TFA, 48 h, r.t., $87 \%$; ii) Fe, $\mathrm{HAcO}, \mathrm{EtOH}, 2 \mathrm{~h}, \Delta, 99 \%$; iii) $\mathrm{CHCl} / \mathrm{EtOH}, \mathrm{KOH}$ (aq.), $6 \mathrm{~h}, \Delta, 4 \%$; iv) $\mathrm{HCOOH} / \mathrm{Ac}_{2} \mathrm{O}, \mathrm{THF}, \mathrm{Et}_{3} \mathrm{~N}, 24$ h, r.t., $96 \%$; v) $\mathrm{POCl}_{3}, \mathrm{CH}_{2} \mathrm{Cl}_{2}, \mathrm{Et}_{3} \mathrm{~N}, 15 \mathrm{~min}, 0{ }^{\circ} \mathrm{C}, 100 \%$. 
Compound $\mathbf{2} \mathbf{b}$ was obtained in one step from $\mathbf{2} \mathbf{a}$ using the Hofmann isonitrile synthesis and following Heinze and Jacob experimental conditions for the reaction of only one amine moiety of a diamine. ${ }^{34}$ The desired compound was obtained in a very low yield (4\%) after purification by column chromatography on zinc oxide, due both to the lack of selectivity of the reaction and to the low stability of the product that partially decomposes throughout the chromatographic purification.

Compound $\mathbf{2 d}$ was prepared in $96 \%$ yield according to the procedure described previously by our group starting from $\mathbf{2 a}$, whereas $\mathbf{2 c}$ was obtained quantitatively by dehydration of $\mathbf{2 d}$. 32 Diisonitrile 2c had already been described by Jarzebski et al., but our synthetic methodology increased the yield from $20 \%$ to $96 \%$ considering the two steps from $2 a{ }^{35}$ The structure of the different compounds was confirmed by mass spectrometry (HR-ESI), 1D and 2D NMR spectroscopy and FTIR spectroscopy.

\section{NMR and IR structural characterization}

Tröger's bases are usually easily identified by ${ }^{1} \mathrm{H}$ NMR spectroscopy through the analysis of the $3.5-5.0 \mathrm{ppm}$ region. For dissymmetrical TBs three signals are observed, originated by the methylene units of the diazocinic core. The bridgehead methylene appears as a singlet, between the two doublets of the inequivalent exo and endo protons of the other methylene units. These hydrogens, that are located toward the interior (endo) or exterior (exo) of the cavity, are coupled by a geminal coupling constant ${ }^{2} \mathrm{~J}$ of ca. $17 \mathrm{~Hz}$, and are usually separated by 0.5-1.0 ppm with the exo protons being the less shielded ones. ${ }^{1,36}$ This is the case of the compounds $\mathbf{2 a}$ and $\mathbf{2} \mathbf{c}$, whereas in $\mathbf{2} \mathbf{d}$ presence of different conformers and the aforementioned long-range anisotropic effects give rise to more complex spectra. ${ }^{32}$

In addition, dissymmetrical compounds present simple spectra given that each nucleus is chemically and magnetically equivalent to another nucleus of the molecule, to which it is linked by a $180^{\circ}$ rotation around the $C_{2}$ symmetry axis. This is not the case of asymmetrical compounds, where each hydrogen presents a unique signal. In particular, the ${ }^{1} \mathrm{H}$ NMR spectrum of $\mathbf{2} \mathbf{b}$ is given by the superposition of the signals of the two halves of the TB, each of them practically identical to the spectrum of the correspondent dissymmetrical analog, either $\mathbf{2 a}$ or $\mathbf{2 c}$ (Figure 2).

In the diazocinic core region, given the asymmetry of the molecule, hydrogens 6 and 12 are no longer equivalent, and thus two pairs of doublets with ${ }^{2} \mathrm{~J}$ couplings of $16.5-17.0 \mathrm{~Hz}$ are observed, one for each methylene (Figure 3). The bridgehead protons are not equivalent either, since one is oriented toward the isocyanide moiety and the other toward the amine. This in turn generates a strong coupling between them, with a $2 \mathrm{~J}$ of 12.6 $\mathrm{Hz}$ and a roof effect deformation. In addition, these hydrogens are coupled with the endo protons with a $4 \mathrm{~J}$ constant of ca. $1.5 \mathrm{~Hz}$, due to the zig-zag or "W" disposition of the nuclei between both hydrogens. ${ }^{4,36-38}$ These long-distance coupling,

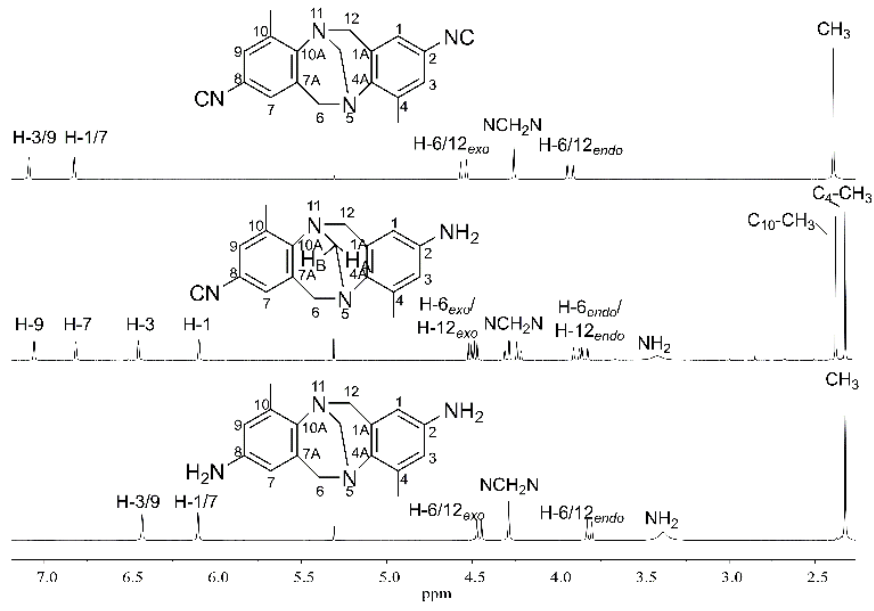

Figure 2. ${ }^{1} \mathrm{H}$ NMR spectra of $\mathbf{2 a}$ (bottom), $\mathbf{2 b}$ (middle) and $\mathbf{2 c}$ (top) in $\mathrm{CDCl}_{3}(500 \mathrm{MHz}$ ).

which is also observed in the 2D COSY spectrum, is only seldom visualized in ${ }^{1} \mathrm{H}$ spectra.

${ }^{13} \mathrm{C}$ NMR spectrum of $\mathbf{2} \mathbf{b}$ also presents separated signals for the nuclei of each side of the molecule, and its complete assignment could be performed from bidimensional HSQC and HMBC spectra (Figures S1-S5, ESI). The differences between the signals observed in the asymmetrical compound and the correspondent dissymmetrical analogs are shown in Table S1 (ESI). Even though the differences are very small, a nonnegligible degree of communication between both ends of the TB is observed, as was the case for $\mathbf{2} \mathbf{d} .^{32}$ This communication is probably due to the rigid geometry of the diazocinic core, which makes the nitrogen atoms face each other and allows the lone pairs to enter the non-conjugated bridge and overlap with the arylamine $\pi$-system, providing an important electronic connecting role to the endomethylene group. ${ }^{39}$

The communication is most notably observed in the nuclei that are farther away from the 2,8 positions. Substitution of one $-\mathrm{NH}_{2}$ group of $\mathbf{2 a}$ for a $-\mathrm{NC}$ group in position 8 to give $\mathbf{2 b}$ produces a $0.3 \mathrm{ppm}$ shift in $\mathrm{C}-2$ and a $0.04 \mathrm{ppm}$ variation in $\mathrm{H}-$ 3 , both at a 9-bond distance and in non-conjugated aromatic rings. The same phenomenon is observed when substituting the remaining $-\mathrm{NH}_{2}$ group of $\mathbf{2 b}$ for $-\mathrm{NC}$ in position 2 to give $\mathbf{2 c}$, which produces a $0.5 \mathrm{ppm}$ shift in $\mathrm{C}-8$ and a $0.03 \mathrm{ppm}$ variation in $\mathrm{H}-9$.

The FTIR spectra of the compounds were measured in solid state in ATR mode and are shown in Figure 4. The $\mathrm{NH}_{2}$ and $\mathrm{NH}$ stretchings of the primary amines in $\mathbf{2 a}$ and secondary amides in $\mathbf{2 d}$ are in the $3400-3200 \mathrm{~cm}^{-1}$ range. The characteristic band at $(2124 \pm 1) \mathrm{cm}^{-1}$, free from spectral interferences, unambiguously indicates the presence of the isocyanide group in $\mathbf{2} \mathbf{b}$ and $\mathbf{2 c}$, with approximately half the intensity in the asymmetric compound. ${ }^{20,40}$ The strong band at $1660 \mathrm{~cm}^{-1}$ in $\mathbf{2 d}$ corresponds to the typical stretching of the carbonyl group of the formanilide. The detailed assignment of the bands is summarized in Table S2 (ESI). ${ }^{41-44}$ 

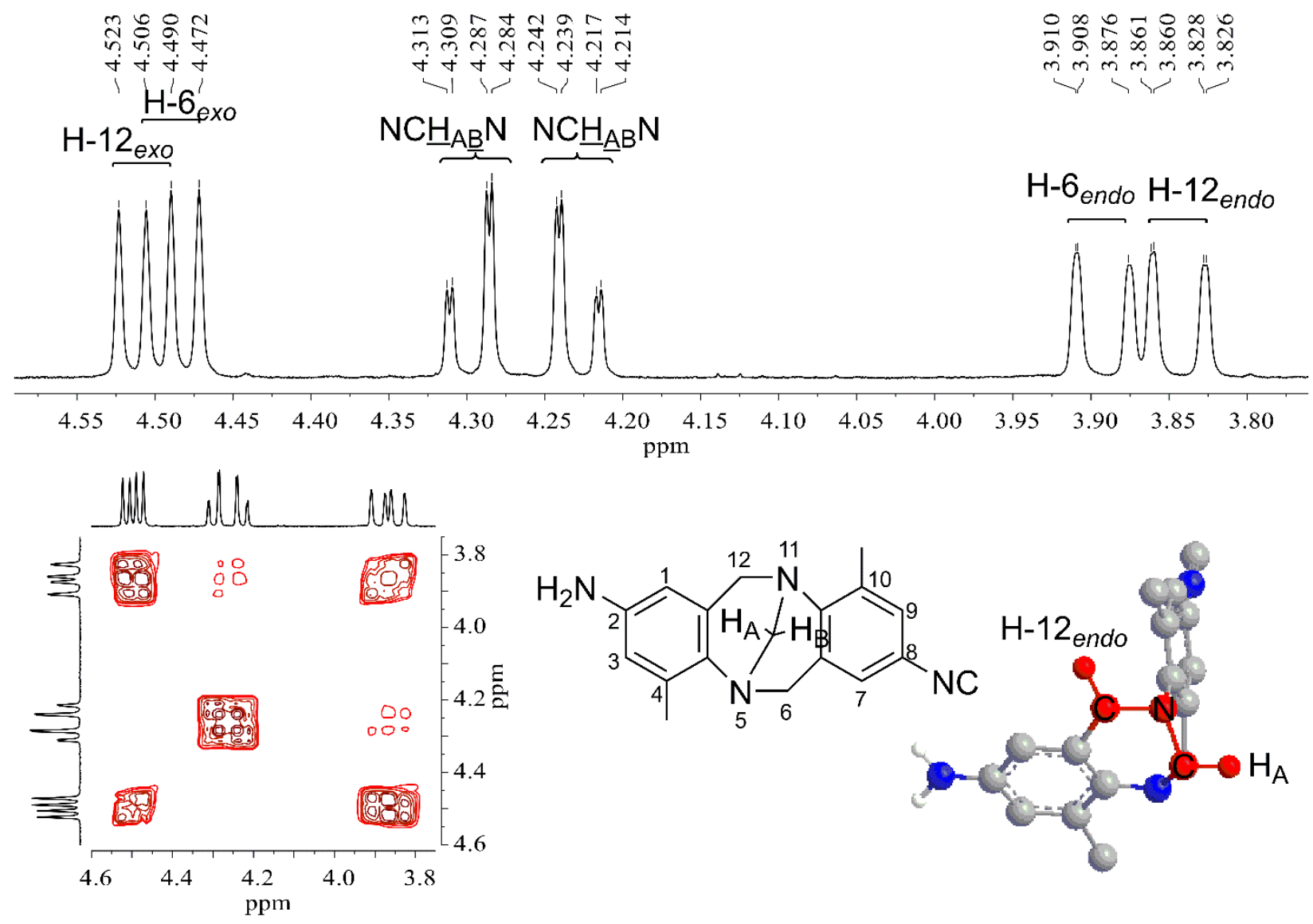

Figure 3. Section of the ${ }^{1} \mathrm{H} N M R$ (top) and COSY (bottom, left) spectra of $\mathbf{2} \mathbf{c}$ in $\mathrm{CDCl}_{3}(500 \mathrm{MHz}$ ) and three-dimensional structure obtained by molecular mechanics using ChemDraw3D (bottom, right).

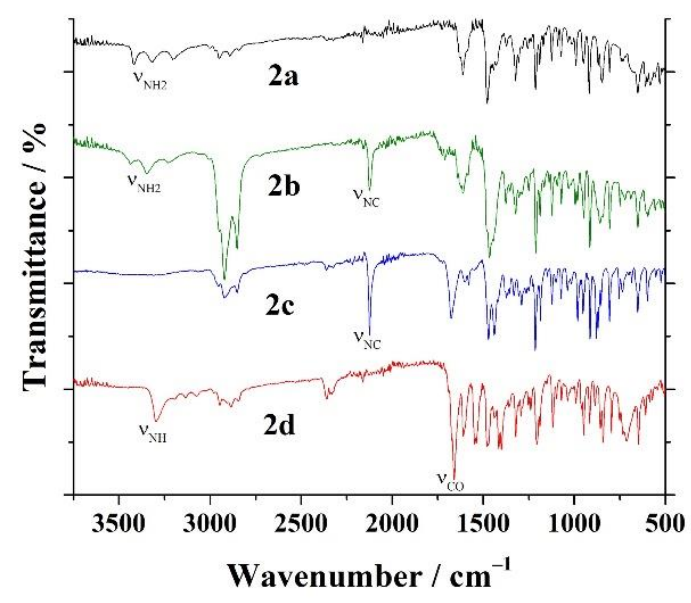

Figure 4. IR spectra of $\mathbf{2 a - d}$ (neat, ATR mode).

When inspecting the IR spectra of the compounds, it is clear that the superposition of the bands of $\mathbf{2 a}$ and $\mathbf{2 c}$ does not reproduce exactly the frequencies and profiles of the asymmetrical $\mathbf{2} \mathbf{b}$ compound, indicating again that an interaction between both ends of the molecule is taking place. This interaction is evidenced in $\mathbf{2} \mathbf{b}$ by the shifts of $+21 \mathrm{~cm}^{-1}$ and +30 $\mathrm{cm}^{-1}$ in the symmetric and asymmetric amine $\mathrm{v}_{\mathrm{N}-\mathrm{H}}$ stretching modes, respectively, with respect to 2 a. These shifts strongly suggest that the aromatic delocalization of the two amino groups in $2 \mathbf{a}$ was partly suppressed by the inclusion of the isocyanide group. The $v_{N C}$ stretching frequency peak of the isocyano group is originated by the $\mathrm{CN}$ bond character, which can be represented as a mixture of a double-bonded neutral carbene-type and a triple-bonded zwitterionic resonant structures. ${ }^{21,45-48}$ This could affect the conjugation of the amino group with the benzene ring in $\mathbf{2} \mathbf{b}$.

Discarding $\mathrm{CO}$ and $\mathrm{NH}$ groups, the strong broad band located at $1676 \mathrm{~cm}^{-1}$ in $2 \mathrm{c}$ falls in the range of the olefinic alkyl

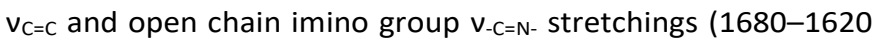
$\mathrm{cm}^{-1}$ and $1690-1640 \mathrm{~cm}^{-1}$ respectively), and therefore could be associated with a double bond character present in the molecule. Nevertheless, an unambiguous assignment is not possible.

Another interesting feature is the very strong change in the intensity of the bands associated with the stretchings of the aliphatic methylene and methyl groups $(\mathrm{CH}$ stretching below $3000 \mathrm{~cm}^{-1}$ range). Such enhancements occur when a large variation of the dipole moment of the bond is taking place and it is observed when going from $\mathbf{2 a}$ or $\mathbf{2} \mathbf{c}$ to $\mathbf{2} \mathbf{b}$.

The diamide compound $\mathbf{2 d}$ exhibits two bands known as amide $\mathrm{I}$ and amide II. Amide $\mathrm{I}$ is assigned to the $\mathrm{C}=\mathrm{O}$ stretching vibration (1660 $\mathrm{cm}^{-1}$, strong), while amide II is located at 1547 $\mathrm{cm}^{-1}$ and corresponds to the coupling of the in plane deformation of the $\mathrm{NH}$ moiety with the $\mathrm{CN}$ stretching $\left(\mathrm{v}_{\mathrm{NH}} / \mathrm{v}_{\mathrm{CN}}\right.$ 
(II)). The possibility of intermolecular hydrogen bonding among $-\mathrm{C}=\mathrm{O} \cdots \mathrm{H}-\mathrm{N}-$ in $\mathbf{2} \mathbf{d}$ in solid state samples lowers and broadens the $\mathrm{N}-\mathrm{H}$ stretching frequency of the amino group, as observed in the spectrum of $\mathbf{2 d}$ at $3298 \mathrm{~cm}^{-1}$. The stronger the hydrogen bond the longer the $-\mathrm{C}=\mathrm{O}$ bond will be, resulting in a lower vibrational frequency and a broader and more intense absorption band, as it is observed for the band at $1660 \mathrm{~cm}^{-1}$. It is worth mentioning that the very weak bands located at 3194 , 3134 and $3072 \mathrm{~cm}^{-1}$ are overtone signals as usually observed in amides.

In addition, the four compounds show a great number of signals in the $800-1500 \mathrm{~cm}^{-1}$ region, which belong to the Tröger's base skeleton and are in many cases common with the signals of the other molecules presented herein and of other TBs. ${ }^{17,49-51}$

\section{Photophysical measurements Figure 5. Absorption and emission} spectra of compounds $2 a-d$ in different solvents.

The absorption and emission spectra of compounds $\mathbf{2} \mathbf{a}-\mathbf{d}$ were obtained in different solvents covering a wide range of polarities, such as hexane $\left(\varepsilon_{r}=1.89\right)$, dichloromethane $\left(\varepsilon_{r}=\right.$
8.93) and acetonitrile $\left(\varepsilon_{r}=37.5\right)$, and a protic solvent like methanol. Normalized spectra are shown in Figure 5.

The absorption spectra present in most cases two bands, or a main band and a red-shifted shoulder. The main parameters associated to these spectra are shown in Table S3 (ESI). The four compounds studied have an intense absorption band around $250 \mathrm{~nm}$ with molar absorption coefficients of ca. $1.5 \times 10^{4} \mathrm{M}^{-}$ ${ }^{1} \mathrm{~cm}^{-1}$, which are ascribed to spin and symmetry allowed ${ }^{1} \pi \pi^{*}$ transitions associated with the framework of the TB. ${ }^{17}$ These bands do not depend strongly either on the solvent or the nature of the substituents.

Replacement of an amino group in $\mathbf{2 a}$ for an isocyanide to obtain $\mathbf{2 b}$ produces the blue-shift of the lower energy absorption band, which moves from 305-310 nm to 285-300 $\mathrm{nm}$ (shoulder analyzed by spectral deconvolution), and in turn increases its intensity. Similar shifts were observed in naphthalimide Tröger's base derivatives. ${ }^{53}$ A second replacement of the amino group ( $\mathbf{2}$ b to $\mathbf{2} \mathbf{c}$ ) generates a new hyper and hypsochromic effect on this band, whose maximum absorption wavelength shifts to $270 \mathrm{~nm}$.
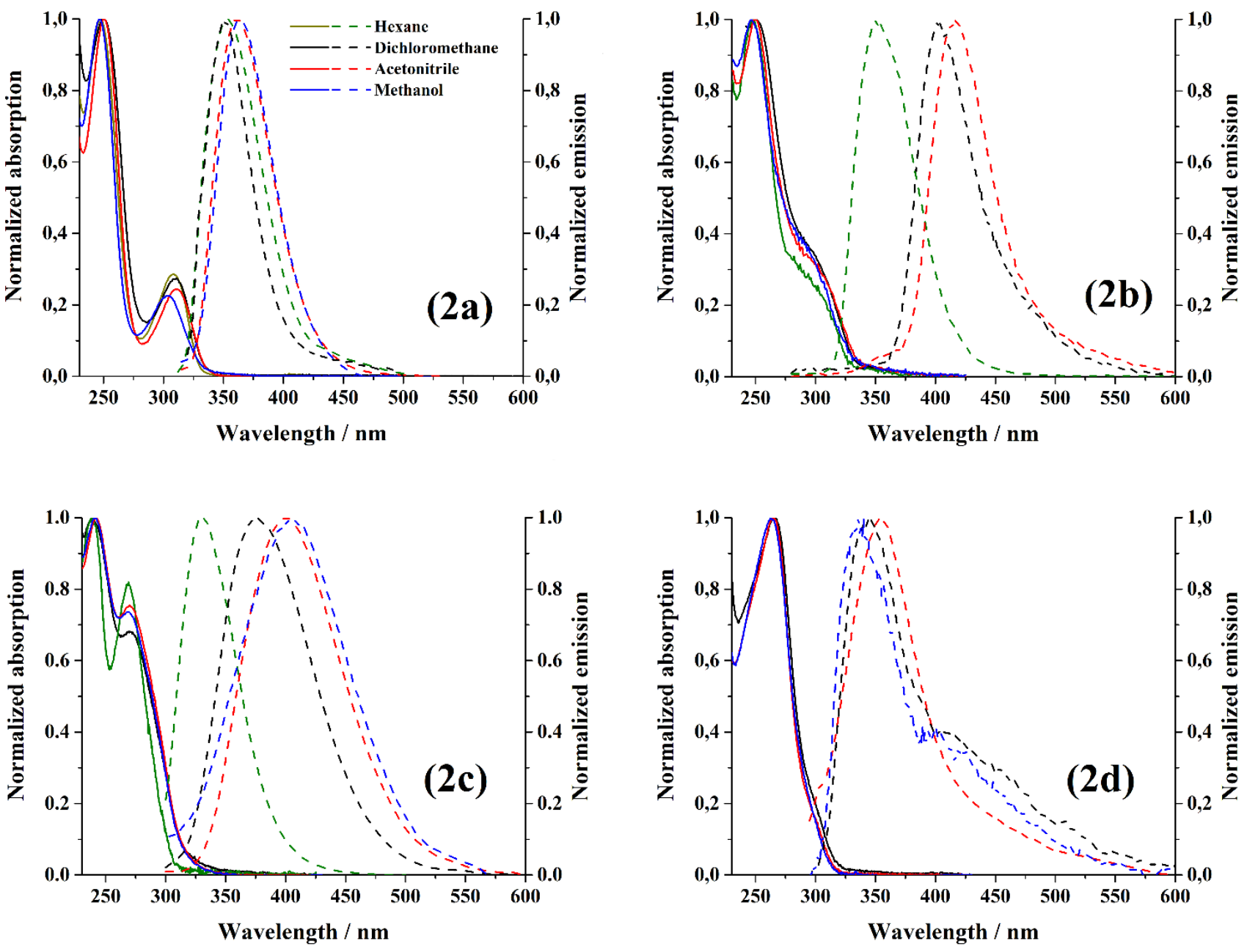

Figure 5. Absorption and emission spectra of compounds $\mathbf{2 a - d}$ in different solvents. 
The bathochromic effect produced in the absorption spectra by the replacement of an isocyano for an amino group is explained considering the mesomeric effect of the $-\mathrm{NH}_{2}$ group, whose electron pair participates in the conjugated aromatic system reducing the HOMO-LUMO energy difference and redshifting the ${ }^{1} \pi \pi^{*}$ transition. ${ }^{52,54}$ This effect could be lost in the isocyano groups, given their zwitterionic character with a positive charge density on the nitrogen atom which would restrict the conjugation with the aromatic system. The same explanation holds for $\mathbf{2 d}$, where the formamide groups do not conjugate with the aromatic rings.

The solvent effects are evident in the emission spectra, which were presented in Figure 5 and whose main features are shown in Table 1 . In the case of $\mathbf{2 a}$ and $\mathbf{2 d}$, the fluorescence maxima are located in the near UV region for every solvent, with widths at half maximum (FWHM) of 45-55 nm. For compounds $\mathbf{2 b}$ and $\mathbf{2 c}$, these wavelengths suffer a significant red-shift when the solvent polarity is increased.

Table 1. Relevant photophysical data of the fluorescence emission spectra of TBs $\mathbf{2 a - d}$ in different solvents. $\lambda_{F}$ is the emission maxima $(n m), \Delta \lambda_{S T}$ is the Stokes shift (calculated with respect to $\lambda_{\max }$ ) and $\Phi_{\mathrm{F}}$ is the fluorescence quantum yield.

\begin{tabular}{|c|c|c|c|c|c|}
\hline TB & Solvent & $\lambda_{\mathrm{F}}$ & $\Delta \lambda_{\mathrm{ST}} / \mathrm{nm}$ & $\Delta \lambda_{\mathrm{ST}} / \mathrm{cm}^{-1}$ & $\Phi_{\mathrm{F}} / \%^{[\mathrm{a}]}$ \\
\hline \multirow{4}{*}{$2 a$} & Hexane & 351 & 43 & 3978 & 4.3 \\
\hline & Dichloromethane & 350 & 40 & 3687 & 0.9 \\
\hline & Acetonitrile & 362 & 52 & 4634 & 5.3 \\
\hline & Methanol & 364 & 60 & 5422 & 1.7 \\
\hline \multirow{4}{*}{$2 b$} & Hexane & 351 & $59^{[b]}$ & $5757^{[b]}$ & 3.9 \\
\hline & Dichloromethane & 403 & $104^{[b]}$ & $8631^{[b]}$ & 2.1 \\
\hline & Acetonitrile & 416 & $121^{[b]}$ & $9860^{[b]}$ & 2.5 \\
\hline & Methanol & [c] & [c] & [c] & [c] \\
\hline \multirow{4}{*}{$2 c$} & Hexane & 330 & 61 & 6872 & 3.0 \\
\hline & Dichloromethane & 375 & 103 & 10098 & 8.0 \\
\hline & Acetonitrile & 400 & 130 & 12037 & 5.7 \\
\hline & Methanol & 403 & 134 & 12361 & 0.8 \\
\hline \multirow{4}{*}{$2 d$} & Hexane & [d] & [d] & [d] & [d] \\
\hline & Dichloromethane & 344 & $78^{[e]}$ & 7654 [e] & 0.1 \\
\hline & Acetonitrile & 354 & $89[\mathrm{e}]$ & 9246 [e] & 0.1 \\
\hline & Methanol & 336 & $73^{[e]}$ & $8261^{[\mathrm{e}]}$ & $<0.1$ \\
\hline
\end{tabular}

[a] $10 \%$ error is estimated. [b] Calculated from spectral deconvolution of $\lambda_{\max 2 .}$ [c] Negligible emission. [d] Not obtained due to low solubility. [e] Calculated with respect to $\lambda_{\max 1}$.

The replacement of an amino for an isocyano group (2a to 2b) produces a bathochromic shift of the emission maxima of ca. $4000 \mathrm{~cm}^{-1}(60 \mathrm{~nm})$ when polarity is increased from hexane to acetonitrile, generating thus a notorious rise in the Stokes shift (ca. $120 \mathrm{~nm}$ in the latter solvent). Diisocyano-TB 2c shows an even higher Stokes shift increase, obtaining a difference of over $5000 \mathrm{~cm}^{-1}(70 \mathrm{~nm})$ between hexane and acetonitrile simultaneously with a large broadening of the emission bands. FWHM values for $\mathbf{2 c}$ are around $100 \mathrm{~nm}$ in every solvent except in hexane.

Diformamide 2d presents fluorescence maxima ca. $350 \mathrm{~nm}$, but a variation of the emission spectra with successive irradiation was observed in dichloromethane and methanol. This would indicate a photochemical decomposition of $\mathbf{2} \mathbf{d}$ and was not studied further. The spectra in Figure 4 were obtained by a single measurement of fresh solutions, and they still show the presence of red-shifted fluorescence bands.

Fluorescence quantum yields are shown in Table 1 . The results obtained for compounds $\mathbf{2 a}-\mathbf{c}$ are similar to the TBs $\mathbf{1 a}-$ c, with substituents $-\mathrm{H},-\mathrm{Me}$ and $-\mathrm{COOMe}$ respectively, and present values generally between $1 \%$ and $8 \%$ and dependent both on the substituents and the solvent. ${ }^{17} \mathbf{2 c}$ presents the larger fluorescence quantum yields, and the protic solvent (methanol) produces in general lower emission. In the case of 2d, quantum yields were smaller than $0.1 \%$, showing that the presence of formamide units, with increased structural flexibility, favors non-radiative deactivations.

Table 2 shows the fluorescence lifetimes measured for $\mathbf{2 a - c}$ in acetonitrile (Figures S7-S9, ESI), as well as the calculated values of radiative and non-radiative decay constants, determined from experimental lifetimes and quantum yields. Non-radiative decays are of the same order of magnitude, whereas the radiative decay constant of $\mathbf{2} \mathbf{b}$ is significantly smaller and produces a poorer quantum yield. In the remaining solvents, reliable lifetimes could not be obtained due to the lack of sufficient emission counts.

Table 2. Fluorescence lifetimes $\tau$ and radiative $k_{r}$ and non-radiative $k_{n r}$ decay constants of $2 a-c$ in acetonitrile.

\begin{tabular}{cccc}
\hline TB & $\tau / \mathrm{ns}^{[a]}$ & $\mathrm{k}_{\mathrm{r}} / \mathrm{s}^{-1}$ & $\mathrm{k}_{\mathrm{nr}} / \mathrm{s}^{-1}$ \\
\hline 2a & 1.5 & $3.6 \times 10^{7}$ & $6.4 \times 10^{8}$ \\
2b & 5.7 & $4.4 \times 10^{6}$ & $1.7 \times 10^{8}$ \\
2c & 2.8 & $2.0 \times 10^{7}$ & $3.4 \times 10^{8}$ \\
\hline
\end{tabular}

[a] $10 \%$ error is estimated.

The bathochromic effect on the emission spectra of $\mathbf{2 a - c}$ with the solvent polarity indicates that the dipolar moments of the molecules in the excited state are larger than in the ground state. ${ }^{55,56}$ The existence of polar excited states, associated to ${ }^{1} \pi \pi^{*}$ transitions, can either be linked to specific fluorophoresolvent interactions or to non-specific reasons. 52,55

Solvatochromism increases in the order $\mathbf{2} \mathbf{a} \rightarrow \mathbf{2} \mathbf{b} \rightarrow \mathbf{2} \mathbf{c}$, showing that the origin of the rise in polarity in the excited state would be given by the mere presence of amino and isocyano groups, being more pronounced in the isocyanides. From these results, it is possible to conclude that in $\mathbf{2} \mathbf{b}$ these groups act independently in the generation of solvatochromic effects. Therefore, there would not be charge transfer effects from the terminal amino donor group to the isocyano acceptor on the opposite end of the molecule, as occurred in Keki's compounds, 
because this would imply a higher solvatochromic effect in 2b. ${ }^{20,31}$

Nevertheless, the particular band broadening together with the large Stokes shifts and solvatochromic effects observed preferentially in $\mathbf{2 c}$ suggest the possible presence of an intramolecular charge transfer excited state (ICT). ${ }^{52,57}$ This nonspecific phenomenon generates solvatochromism due to the charge separation produced after excitation, which gives rise to an electronic state that is more strongly stabilized in polar solvents. In the cases of $\mathbf{2} \mathbf{b}$ and $\mathbf{2} \mathbf{c}$ it can be proposed that the charge transfer is produced between an electron donor group as the central nitrogen atoms of the diazocinic core and an acceptor group as the terminal isocyanide, which are in para relative positions.

The solvatochromic effect was analyzed for $\mathbf{2 a} \mathbf{a}-\mathbf{d}$ in terms of the Lippert-Mataga model, which relates the Stokes shift $\left(\Delta \bar{v}_{S T}\right)$ increase with solvent polarity with the difference in the dipole moment between the excited and ground states $\left(\Delta \mu=\mu_{\mathrm{e}}-\right.$ $\left.\mu_{\mathrm{g}}\right): 55,56$
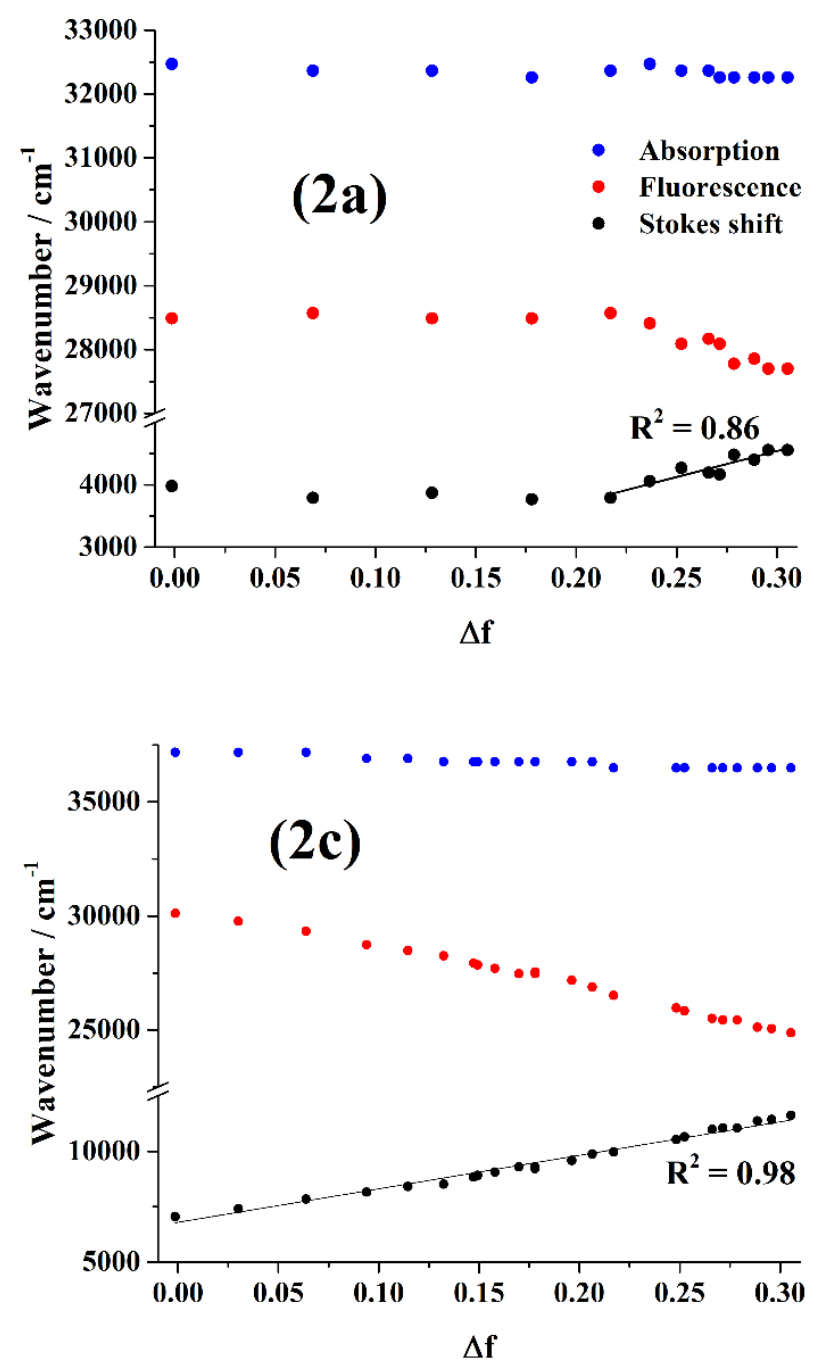

Figure 6. Lippert-Mataga plots of compounds 2a-d.

$$
\Delta \bar{v}_{\text {ST }}=\frac{2(\Delta \mu)^{2}}{h_{c a^{3}}} \Delta f+\Delta \bar{v}_{0}
$$

where $h$ is the Planck's constant, $c$ is the speed of light, $a$ is the Onsager cavity radius of the solute and $\Delta f$ is the orientation polarization function. This function is defined as follows:

$$
\Delta f=\frac{\epsilon-1}{2 \epsilon+1}-\frac{n^{2}-1}{2 n^{2}+1}
$$

where the dielectric constant $\epsilon$ and the refraction index $n$ for a mixture of solvents depend on the volumetric fractions of both solvents $f_{A}$ and $f_{B}$ and are obtained as

$$
\begin{aligned}
& \epsilon=f_{A} \epsilon_{A}+f_{B} \epsilon_{B} \\
& n^{2}=f_{A} n_{A}^{2}+f_{B} n_{B}^{2}
\end{aligned}
$$

The absorption and fluorescence maxima and the Stokes shift were plotted against $\Delta f$ for compounds $\mathbf{2 a - d}$, as is shown in Figure 6. Acetonitrile-dichloromethane mixtures $(\Delta f>0.21)$ where used for every compound, whereas hexanedichloromethane mixtures $(\Delta f<0.21)$ were also analyzed for $\mathbf{2 a}-\mathbf{c}$. For compounds $\mathbf{2} \mathbf{a}$ and $\mathbf{2} \mathbf{c}$ the red-shifted absorption maxima was considered, whereas for compounds $\mathbf{2} \mathbf{b}$ and $\mathbf{2} \mathbf{d}$ the main absorption band was taken into account.
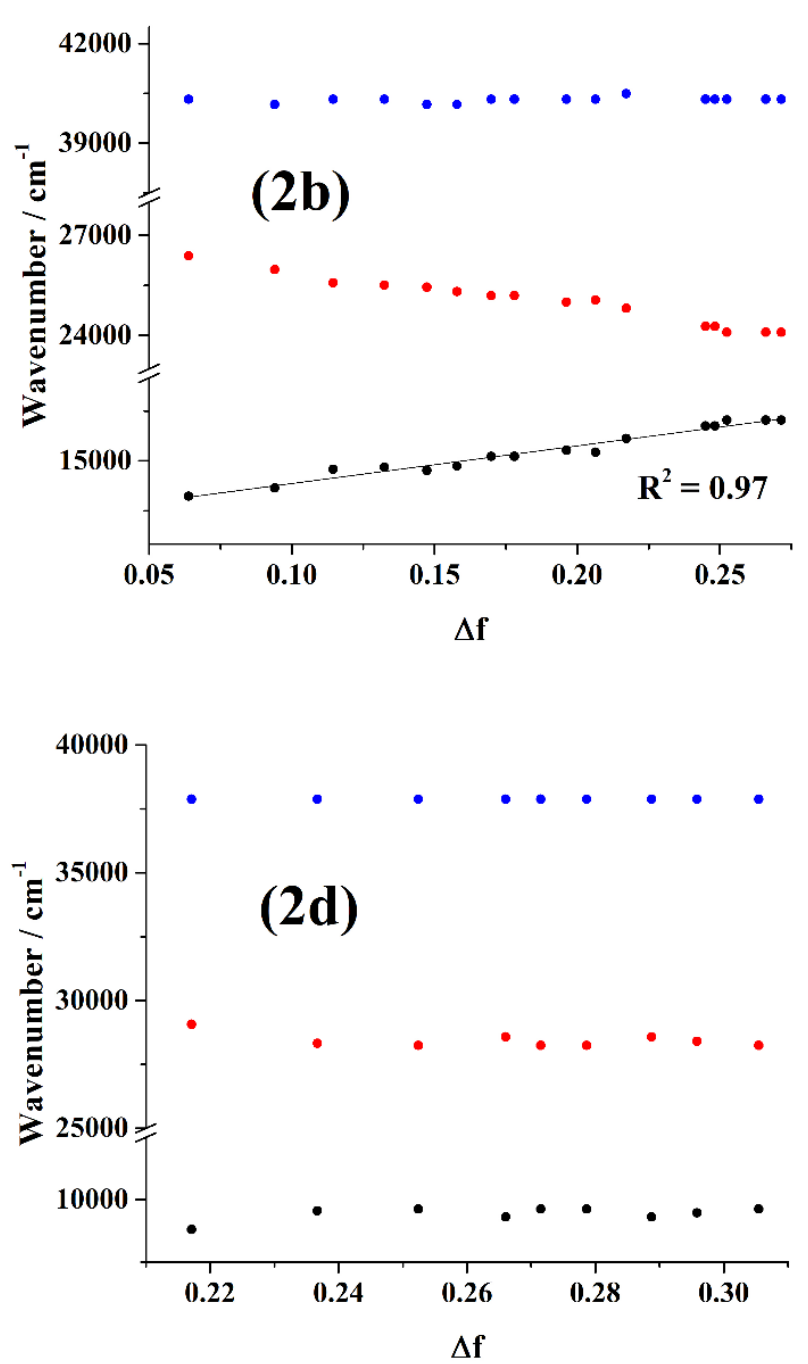
In the case of $\mathbf{2 a}$, hexane-dichloromethane mixtures do not present significant variations in the positions of the absorption and fluorescence maxima, but this effect is indeed observed in dichloromethane-acetonitrile mixtures. This dual solvatochromic behavior, of inexistent solvatochromism in low polar solvents but evident in more polar mixtures, could be originated by the formation of excited states of different nature in each regime. This is the case of some fluorophores like Neutral Red and PRODAN, that in low polarity media are associated to locally excited (LE) states whose dipolar moment does not vary significantly with respect to the ground state whereas high polarity solvents give rise to lower energy ICT states. ${ }^{58,59}$

Linear plots were obtained for the second regime of $2 a\left(R^{2}\right.$ $=0.86)$, for $\mathbf{2 b}\left(R^{2}=0.97\right)$ and $\mathbf{2 c}\left(R^{2}=0.98\right)$, demonstrating that the Lippert-Mataga model accurately describes the behavior of these systems and that no specific solvent effects are apparently present in aprotic solvents. On the contrary, $\mathbf{2} \mathbf{d}$ does not present any significant solvatochromic effect, as was already expected from the initial emission spectra in dichloromethane and acetonitrile.

The changes in dipole moments $\Delta \mu$ were calculated as 10.8 D for $\mathbf{2 a}, 12.6 \mathrm{D}$ for $\mathbf{2 b}$ and 14,5 D for $\mathbf{2 c}$, with errors estimated in around $10 \%$ considering both the standard deviations of Lippert plots and the approximation in Onsager radius. The radii were obtained as the average value between the ones calculated for compounds $\mathbf{1 b}$ and $\mathbf{1 c}(5,2 \AA \pm 0,3 \AA) \cdot{ }^{17}$ The dipole moments are similar to the one obtained for compound $\mathbf{1 c}$ and significantly larger than those of compounds $\mathbf{1 a}$ and $\mathbf{1} \mathbf{b}$, and show an increase of ca. $2 \mathrm{D}$ with each replacement of an amino group for an isocyanide.

\section{Conclusions}

The photophysical properties of four simple nitrogenated Tröger's bases were studied, including three dissymmetrical compounds $\mathbf{2 a}, \mathbf{2} \mathbf{c}$ and $\mathbf{2} \mathbf{d}$ and a new asymmetrical derivative $\mathbf{2 b}$ with amino and isocyano substituents. The NMR and IR spectra of this compound showed that spectroscopic properties result mainly as the superposition of those of the dissymmetrical analogues, but with a certain degree of communication between both ends of the TB scaffold, as was already observed by our group for diformamide $\mathbf{2 d}$. $^{32}$

This communication was not so evident regarding the optical properties of the TBs, which indicate the absence of intramolecular charge transfer between the amino donor group and the isocyano acceptor group in the extremes of $\mathbf{2 b}$. Instead, an ICT state can be proposed between the isocyano group and a central nitrogen of the diazocinic core both in $\mathbf{2} \mathbf{b}$ and $\mathbf{2 c}$, as suggested by the observed solvatochromic effect, band broadening and large Stokes shifts.

A spin and symmetry allowed ${ }^{1} \pi \pi^{*}$ transition ascribed to the TB skeleton is responsible for the main absorption band in the UV region, but a red-shifted band and the emission spectrum are substantially dependent on the substituents. In addition, the fluorescence quantum yields of the TBs studied presented non negligible values, consistent with those of the previously reported analogues.

The results presented herein constitute one of the first approaches to the investigation of the photophysical and structural properties of simple Tröger's bases. This knowledge is of paramount importance in order to fully understand and design more complex systems that profit of the unique geometry and features of TBs, which are taken advantage of in numerous fields such as supramolecular chemistry and molecular recognition among others. In fact, in our group we are working in the development of TB-based ligands for the preparation of luminescent lanthanide complexes, where the TB acts not only as a geometrical scaffold but also in some cases as the antenna, with very promising results.

\section{Conflicts of interest}

There are no conflicts to declare.

\section{Acknowledgements}

This work was supported by Agencia Nacional de Promoción Científica y Tecnológica (PICT 2013-2331 to J.A.R.) and Universidad de Buenos Aires (UBACyT 20020130100826BA to J.A.R.).

\section{References}

1 C. Pardo, I. Alkorta and J. Elguero, Tetrahedron Asymmetry, 2006, 17, 191-198. S. Sergeyev, Helv. Chim. Acta, 2009, 92, 415-444.

3 J. Artacho and K. Wärnmark, Synthesis (Stuttg)., 2009, 3120-3126.

C. Pardo, M. Ramos, A. Fruchier and J. Elguero, Magn. Reson. Chem., 1996, 34, 708-710.

5 L. Mosca, J. Čejka, B. Dolenský, M. Havlík, M. Jakubek, R. Kaplánek, V. Král and P. Anzenbacher, Chem. Commun., 2016, 52, 10664-10667.

L. Xu, X. Yan and C. Yuan, RSC Adv., 2018, 8, 35289-35293.

C. Yuan, Y. Zhang, H. Xi and X. Tao, RSC Adv., 2017, 7, 55577-55581.

8 B. R. Manda, M. Alla, R. J. Ganji and A. Addlagatta, Eur. J. Med. Chem., 2014, 86, 39-47. S. Shanmugaraju, C. Dabadie, K. Byrne, A. J. Savyasachi, D. Umadevi, W. Schmitt, J. A. Kitchen and T. Gunnlaugsson, Chem. Sci., 2017, 8, 1535-1546. I. Neogi, S. Jhulki, A. Ghosh, T. J. Chow and J. N. Moorthy, Org. Electron. physics, Mater. Appl., 2014, 15, 3766-3772. C. Yuan, J. Li, H. Xi and Y. Li, Mater. Lett., 2019, 236, 9-12.

12 B. Dolenský, J. Elguero, V. Král, C. Pardo and M. Valík, Adv. Heterocycl. Chem., 2007, 93, 1-56.

13 Ö. V. Rúnarsson, J. Artacho and K. Wärnmark, European J. Org. Chem., 2012, 7015-7041.

14 M. Valík, R. M. Strongin and V. Král, Supramol. Chem., 2005, 17, 347-367. 
Zhang, J. juan Liu and H. Wu, Tetrahedron, 2016, 72, 40814084.

F. Vögtle, Reizvolle Moleküle der Organischen Chemie, B. G. Teubner, 1989.

17 D. M. P. Aroche, J. M. Toldo, R. R. Descalzo, P. F. B. Gonçalves and F. S. Rodembusch, New J. Chem., 2015, 39, 6987-6996.

18 A. Dömling, Chem. Rev., 2006, 106, 17-89.

19 M. L. Bode, D. Gravestock and A. L. Rousseau, Org. Prep. Proced. Int., 2016, 48, 89-221.

20 D. Rácz, M. Nagy, A. Mándi, M. Zsuga and S. Kéki, J. Photochem. Photobiol. A Chem., 2013, 270, 19-37.

21 R. Ramozzi, N. Chéron, B. Braïda, P. C. Hiberty and P. Fleurat-Lessard, New J. Chem., 2012, 36, 1137-1140. D. N. Mehta-Hurt, J. A. Korn, A. K. Gutberlet and T. S. Zwier, J. Phys. Chem. A, 2015, 119, 2863-2877. Chem. Phys., 1972, 56, 4385-4393.

W. Wang, X. Sun, J. Qu, X. Xie, Z. H. Qi, D. Hong, S. Jing, D. Zheng, Y. Tian, H. Ma, S. Yu and J. Ma, Phys. Chem. Chem. Phys., 2017, 19, 31443-31451. 365.

C. Pardo, E. Sesmilo, E. Gutiérrez-Puebla, A. Monge, J. Elguero and A. Fruchier, J. Org. Chem., 2001, 66, 16071611.

B. Dolenský, M. Valík, D. Sýkora and V. Král, Org. Lett., 2005, 7, 67-70.

J. Jensen, J. Tejler and K. Wärnmark, J. Org. Chem., 2002, 67, 6008-6014.

M. Havlík, B. Dolenský, M. Jakubek and V. Král, European J. Org. Chem., 2014, 2798-2805.

P. A. Lanza, D. Dusso, C. L. Ramirez, A. R. Parise, C. A. Chesta, E. L. Moyano and D. M. A. Vera, European J. Org. Chem., 2019, 2019, 7644-7655.

M. Nagy, D. Rácz, S. L. Kovács, L. Lázár, P. P. Fehér, M. Purgel, M. Zsuga and S. Kéki, J. Photochem. Photobiol. A Chem., 2016, 318, 124-134.

L. Trupp, S. L. Laurella, M. C. Tettamanzi, B. C. Barja and A. C. Bruttomesso, J. Mol. Struct., 2018, 1157, 434-443. 1283-1286.

K. Heinze and V. Jacob, Eur. J. Inorg. Chem., 2003, 39183923.

A. Jarzebski, C. Bannwarth, C. Tenten, C. Benkhäuser, G. Schnakenburg, S. Grimme and A. Lützen, Synthesis (Stuttg)., 2015, 47, 3118-3132.

M. D. Cowart, I. Sucholeiki, R. R. Bukownik and C. S. Wilcox, J. Am. Chem. Soc., 1988, 110, 6204-6210.

J. Elguero, A. Fruchier, T. Mas and C. Pardo, Magn. Reson. Chem., 2005, 43, 665-669. Chem., 1999, 37, 73-76. C. L. Ramírez, C. Pegoraro, L. Trupp, A. Bruttomesso, V. Amorebieta, D. M. A. Vera and A. R. Parise, Phys. Chem. Chem. Phys., 2011, 13, 20076-20080. J. G. Polisar, L. Li and J. R. Norton, Tetrahedron Lett., 2011,

52, 2933-2934.

B. Stuart, Infrared Spectroscopy: Fundamentals and Applications, Wiley, 2004.

J. Coates, Interpretation of Infrared Spectra, A Practical Approach, Encyclopedia of Analytical Chemistry, Wiley, 2006.

J. A. Dean, Lange's Handbook of Chemistry, McGraw-Hill, 15th edn., 1999.

Roeges and N. G., A Guide to the Complete Interpretation of Infrared Spectra of Organic Structures, Wiley, New York, NY, 1994.

H. Lindemann and L. Wiegrebe, Ber. Dtsch. Chem. Ges., 1930, 63, 1650.

N. V. Sidgwick, Chem. Rev.

J. U. Nef, Justus Liebigs Ann. Chem., 1892, 270, 267-335.

J. U. Nef, Justus Liebigs Ann. Chem., 1899, 309, 126.

F. Hof, M. Schär, D. M. Scofield, F. Fischer, F. Diederich and S. Sergeyev, Helv. Chim. Acta, 2005, 88, 2333-2344.

S. Sergeyev, M. Schär, P. Seiler, O. Lukoyanova, L. Echegoyen and F. Diederich, Chem. - A Eur. J., 2005, 11, 2284-2294.

Z. Li, X. Xu, Y. Peng, Z. Jiang, C. Ding and X. Qian, Synthesis (Stuttg)., 2005, 1228-1230.

M. Klessinger and J. Michl, Excited States and Photochemistry of Organic Molecules, VCH, 1995. N. R. Deprez, K. A. McNitt, M. E. Petersen, R. G. Brown and D. E. Lewis, Tetrahedron Lett., 2005, 46, 2149-2153. $\mathrm{H}$. Suzuki, Electronic Absorption Spectra and Geometry of Organic Molecules, Academic Press, 1967.

\section{Joseph R. Lakowicz, Principles of Fluorescence} Spectroscopy, Springer International Publishing, 3ra edn., 2006.

C. Reichardt and T. Welton, Solvents and Solvent Effects in Organic Chemistry, Wiley-VCH, 4ta edn., 2011.

7 Y. Zhao, K. Chen, E. A. Yildiz, S. Li, Y. Hou, X. Zhang, Z. Wang, J. Zhao, A. Barbon, H. G. Yaglioglu and H. Wu, Chem. - A Eur. J., 2020, 1-10.

G. Weber and F. J. Farris, Biochemistry, 1979, 18, 30753078.

M. K. Singh, H. Pal, A. C. Bhasikuttan and A. V. Sapre, Photochem. Photobiol., 1998, 68, 32-38. 


\title{
Simple dissymmetrical and asymmetrical Tröger's Bases: Photophysical and structural characterization
}

Received 00th January 20xx, Accepted 00th January 20xx

DOI: $10.1039 / \times 0 \times x 00000 x$

\author{
Leandro Trupp, ${ }^{\text {abcd }}$ Andrea C. Bruttomesso ${ }^{\text {tcd }}$ and Beatriz C. Barja*ab
}

Despite their continuously growing preparation and applications in the last decades, the photophysical properties of Tröger's bases (TBs) with small substituents have not been analyzed. We synthetized three dissymmetrical TBs with amino, isocyano and formamido groups and a new asymmetrical TB with one amino and one isocyano group and studied their absorption and emission properties and solvatochromic effects. An intramolecular charge transfer (ICT) state was found for the isocyano containing derivatives, associated to the isocyano acceptor group and the nitrogen donor atom in the central diazocinic core. NMR and IR spectroscopy were also analyzed, demonstrating the communication between both ends of the TBs.

\section{Introduction}

Control over the three-dimensional disposition of different substituents is desired in synthetic organic design, and thus building blocks with well-defined rigid structures are particularly convenient. One compound of this kind is Tröger's base (2,8-dimethyl-6H,12H-5,11-methanodibenzo $[b, f][1,5]$ diazocine, 1a), which consists of two aromatic rings fused by a bicyclic aliphatic methanodiazocine unit. The methylene bridge prevents pyramidal inversion of the two nitrogen atoms and thus the molecule adopts a rigid $\mathrm{V}$-shaped geometry with the aromatic rings almost perpendicular to each other and with a $C_{2}$ axis of symmetry (Figure 1). The angle has been predicted for a wide array of derivatives between $84^{\circ}$ and $105^{\circ}$, with a mean value of $95^{\circ} .^{1}$

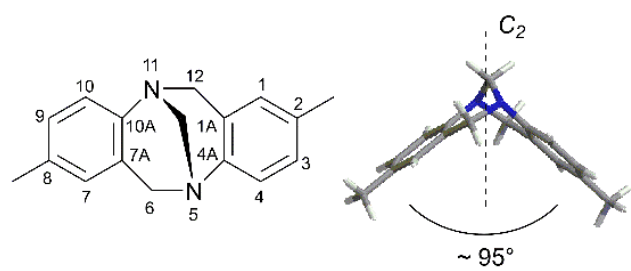

Figure 1. Structure of $(\mathrm{S}, \mathrm{S})-\mathbf{1 a}$ and three-dimensional structure obtained by molecular mechanics using ChemDraw3D.

\footnotetext{
a. Departamento de Química Inorgánica, Analítica y Química Física, Facultad de Ciencias Exactas y Naturales, Universidad de Buenos Aires, Int. Güiraldes 2160, Ciudad Universitaria, Buenos Aires, 1428, Argentina

b. Instituto de Química Física de los Materiales, Medio Ambiente y Energía (INQUIMAE), CONICET - Universidad de Buenos Aires, Int. Güiraldes 2160, Ciudad Universitaria, Buenos Aires, 1428, Argentina

Departamento de Química Orgánica, Facultad de Ciencias Exactas y Naturales, Universidad de Buenos Aires, Int. Güiraldes 2160, Ciudad Universitaria, Buenos Aires, 1428, Argentina

d. Unidad de Microanálisis y Métodos Físicos Aplicados a Química Orgánica (UMYMFOR), CONICET - Universidad de Buenos Aires, Int. Güiraldes 2160, Ciudad Universitaria, Buenos Aires, 1428, Argentina

† Deceased, 25th august 2018.

Electronic Supplementary Information (ESI) available: Full experimental details and characterization and spectral data such as $1 \mathrm{D}$ and 2D NMR, IR assignments, lifetime measurements and Lippert-Mataga plots. See DOI: 10.1039/x0xx00000x
}

Compounds with this benzodiazocinic core, independently of the substituents of the aromatic rings, are usually called Tröger's base derivatives or analogues, or simply Tröger's bases (TBs). ${ }^{2}$ When the molecules are symmetrical with respect to a $180^{\circ}$ rotation around the $C_{2}$ axis, that is, when the substituents of both aromatic moieties are the same in each relative position, compounds are said to be dissymmetrical, and otherwise they are asymmetrical. . $^{3,4}$

The fixed configuration of TBs makes them chiral molecules with a hydrophobic cavity, and renders them useful in areas such as molecular recognition, drug development and bioorganic and supramolecular chemistry, among others. ${ }^{5-11}$ Moreover, a wide array of TBs can be synthesized, and they can be in turn modified in numerous positions in order to attain the desired structures. ${ }^{2,12-14}$

In addition, TBs are usually fluorescent molecules, and are promising scaffolds for the construction of luminescent materials. This property can be explained analyzing TBs' structure and its most important features: (1) the perpendicularity of the aromatic rings allows larger Stokes shifts and reduces self-absorption; (2) the high rigidity can restrict internal rotation and thus reduce non-radiative deactivation pathways; (3) the rigid V-shaped structure prevents intermolecular $\pi-\pi$ close stacking and dipole-dipole interaction. ${ }^{15}$

Nevertheless, and despite the interesting features of Tröger's bases and their description as one of the "fascinating molecules in organic chemistry"16, almost no study has been made regarding its photophysical properties. Pimentel et al. have characterized simple Tröger's base derivatives with different substituents at the 2,8 positions as $-\mathrm{Me}(\mathbf{1 a}),-\mathrm{H}(\mathbf{1 b})$, and -COOMe (1c). ${ }^{17}$ As expected, they found that TBs present absorption in the UV region, which could be ascribed to $\pi-\pi^{*}$ electronic transitions, and emit in the violet-blue regions with a time decay of approximately 1-2 ns. The Stokes shifts were of 52-71 nm for $\mathbf{1 a}$ and $\mathbf{1 b}$ and of 62-115 nm for $\mathbf{1 c}$, depending on the solvent, whereas the fluorescence quantum yields were of around $5-17 \%$ for $\mathbf{1 a}$ and $\mathbf{1 b}$ and smaller than $2 \%$ for $\mathbf{1 c}$. Moreover, 1c presented a large solvatochromic effect, which 
was consistent with a change in dipole moment upon light absorption of $14.8 \mathrm{D}$.

In order to deepen the knowledge of the photophysics of Tröger's base derivatives, we synthesized four simple nitrogenated compounds (Chart 1) and studied their photophysical properties. Initially, diamino-TB $\mathbf{2 a}$ and diisocyano-TB 2c were proposed due both to their intrinsic properties and to their potential as scaffolds for building more complex structures. In this sense, the amine group can be easily reacted by alkylations, amide couplings, $\mathrm{C}-\mathrm{N}$ cross couplings, etc., whereas isonitriles are uniquely capable of participating in multicomponent reactions (MCRs) such as Ugi and Passerini MCRs.<smiles>Cc1cc(N)cc2c1N1CCN(C2)c2cc(N)cc(C)c21</smiles>

2a<smiles>Cc1cc(N=C=O)cc2c1N1Cc3cc(N=C=O)cc(C)c3N(C2)c2c(C)cc(N=C=O)cc2C1</smiles><smiles>Cc1cc([N+](=O)[O-])cc2c1N1CCN(C2)c2cc(N)cc(C)c21</smiles>

2b
Chart 1. Structure of compounds $2 \mathbf{a}-\mathbf{d}$.

In addition, the isocyano group is particularly interesting due to its unusual structure, since it constitutes the only class of stable organic compound with a formally divalent carbon atom. Not only this generates the possibility of a unique synthetic chemistry, but also makes isonitriles compounds with $\pi$ backbonding properties, capacity to act as strong proton acceptors and ability to form stable complexes with transition metal ions. ${ }^{18-21}$ Only a few reports about the electronic properties of isonitriles have been presented, and thus the study of its photophysical properties results interesting. ${ }^{20-24}$
Moreover, we envisioned the synthesis and characterization of a new TB, the asymmetrical compound $\mathbf{2} \mathbf{b}$ that lies between $2 a$ and $\mathbf{2 c}$ with one amine and one isocyanide substituent. The preparation of $\mathbf{2} \mathbf{b}$ was also motivated by its synthetic challenge -only a few asymmetric TBs have been synthesized $3,25-30$ - and by its potential for solvatochromic properties. The incorporation of both an electron donor (amine) and acceptor (isocyanide) in the same scaffold is particularly promising in this regard, as shown by Keki's group in their study of 4-amino-4'isocyanobiphenyl and 1-amino-5-isocyanonaphthalene. ${ }^{20,31}$

Finally, compound $\mathbf{2 d}$ was originally obtained as a synthetic intermediate in the path to obtain $\mathbf{2} \mathbf{c}$ from $\mathbf{2 a}$, and was included in this work in order to study a new TB with a different functional group and to compare the formamide with its related amine. $\mathbf{2 d}$ also presented an interesting NMR behavior due to long-range anisotropic effects that generate a connection between both ends of the compound. This unusual result was thoroughly studied by our group using NMR spectroscopy techniques as well as DFT calculations. ${ }^{32}$

In this work, we thus set out to characterize the spectroscopic properties of four simple Tröger's bases with different nitrogenated substituents, and to analyze them in terms of their structure. Three of these compounds are dissymmetrical, whereas the remaining one is asymmetrical and has not been prepared before. In particular, absorption and emission spectra will be obtained, complemented by NMR and IR spectroscopy.

\section{Results and discussion}

\section{Compound Synthesis}

Compounds $\mathbf{2 a - d}$ were prepared according to the synthetic pathways presented in Scheme 1. Compound 2a was obtained following the procedure described by Kiehne et al., starting from an acid-catalyzed condensation step of 2-methyl-4nitroaniline with paraformaldehyde and its ulterior reduction with yields of $87 \%$ and $99 \%$ respectively. 32,33<smiles>CC#CCN1Cc2cc(N)cc(C)c2N2Cc3cc(N)cc(C)c3N1Cc1cc([N+](=O)[O-])cc(C)c1N2C</smiles>

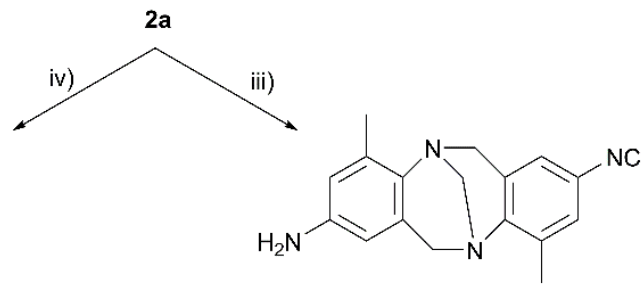

2b

Scheme 1. Synthetic routes used for the preparation of TBs 2a-d. i) $\left(\mathrm{CH}_{2} \mathrm{O}\right)$ n, TFA, 48 h, r.t., $87 \%$; ii) Fe, $\mathrm{HAcO}, \mathrm{EtOH}, 2 \mathrm{~h}, \Delta, 99 \%$; iii) $\mathrm{CHCl} / \mathrm{EtOH}, \mathrm{KOH}$ (aq.), $6 \mathrm{~h}, \Delta, 4 \%$; iv) $\mathrm{HCOOH} / \mathrm{Ac}_{2} \mathrm{O}, \mathrm{THF}, \mathrm{Et}_{3} \mathrm{~N}, 24$ h, r.t., $96 \%$; v) $\mathrm{POCl}_{3}, \mathrm{CH}_{2} \mathrm{Cl}_{2}, \mathrm{Et}_{3} \mathrm{~N}, 15 \mathrm{~min}, 0^{\circ} \mathrm{C}, 100 \%$. 
Compound $\mathbf{2} \mathbf{b}$ was obtained in one step from $\mathbf{2} \mathbf{a}$ using the Hofmann isonitrile synthesis and following Heinze and Jacob experimental conditions for the reaction of only one amine moiety of a diamine. ${ }^{34}$ The desired compound was obtained in a very low yield (4\%) after purification by column chromatography on zinc oxide, due both to the lack of selectivity of the reaction and to the low stability of the product that partially decomposes throughout the chromatographic purification.

Compound $\mathbf{2 d}$ was prepared in $96 \%$ yield according to the procedure described previously by our group starting from $\mathbf{2 a}$, whereas $\mathbf{2 c}$ was obtained quantitatively by dehydration of $\mathbf{2 d}$. 32 Diisonitrile $\mathbf{2 c}$ had already been described by Jarzebski et al., but our synthetic methodology increased the yield from $20 \%$ to $96 \%$ considering the two steps from $2 \mathrm{a} .{ }^{35}$ The structure of the different compounds was confirmed by mass spectrometry (HR-ESI), 1D and 2D NMR spectroscopy and FTIR spectroscopy.

\section{NMR and IR structural characterization}

Tröger's bases are usually easily identified by ${ }^{1} \mathrm{H}$ NMR spectroscopy through the analysis of the 3.5-5.0 ppm region. For dissymmetrical TBs three signals are observed, originated by the methylene units of the diazocinic core. The bridgehead methylene appears as a singlet, between the two doublets of the inequivalent exo and endo protons of the other methylene units. These hydrogens, that are located toward the interior (endo) or exterior (exo) of the cavity, are coupled by a geminal coupling constant ${ }^{2} \mathrm{~J}$ of ca. $17 \mathrm{~Hz}$, and are usually separated by 0.5-1.0 ppm with the exo protons being the less shielded ones. ${ }^{1,36}$ This is the case of the compounds $\mathbf{2} \mathbf{a}$ and $\mathbf{2} \mathbf{c}$, whereas in $\mathbf{2} \mathbf{d}$ presence of different conformers and the aforementioned long-range anisotropic effects give rise to more complex spectra. ${ }^{32}$

In addition, dissymmetrical compounds present simple spectra given that each nucleus is chemically and magnetically equivalent to another nucleus of the molecule, to which it is linked by a $180^{\circ}$ rotation around the $C_{2}$ symmetry axis. This is not the case of asymmetrical compounds, where each hydrogen presents a unique signal. In particular, the ${ }^{1} \mathrm{H}$ NMR spectrum of $\mathbf{2} \mathbf{b}$ is given by the superposition of the signals of the two halves of the TB, each of them practically identical to the spectrum of the correspondent dissymmetrical analog, either $\mathbf{2 a}$ or $\mathbf{2 c}$ (Figure 2).

In the diazocinic core region, given the asymmetry of the molecule, hydrogens 6 and 12 are no longer equivalent, and thus two pairs of doublets with ${ }^{2} \mathrm{~J}$ couplings of $16.5-17.0 \mathrm{~Hz}$ are observed, one for each methylene (Figure 3). The bridgehead protons are not equivalent either, since one is oriented toward the isocyanide moiety and the other toward the amine. This in turn generates a strong coupling between them, with a ${ }^{2} \mathrm{~J}$ of 12.6 $\mathrm{Hz}$ and a roof effect deformation. In addition, these hydrogens are coupled with the endo protons with a ${ }^{4} \mathrm{~J}$ constant of ca. $1.5 \mathrm{~Hz}$, due to the zig-zag or "W" disposition of the nuclei between both hydrogens. ${ }^{4,36-38}$ These long-distance coupling,

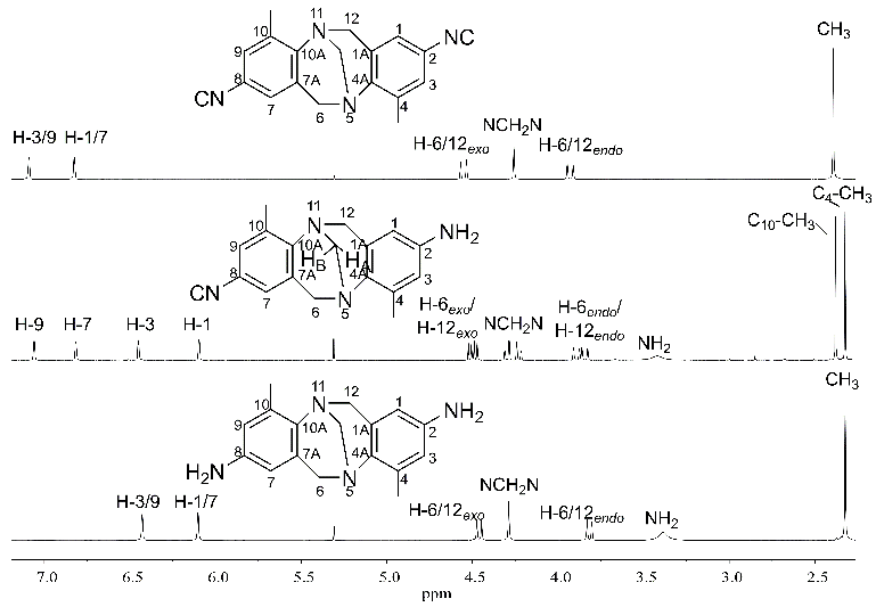

Figure 2. ${ }^{1} \mathrm{H}$ NMR spectra of $\mathbf{2} \mathbf{a}$ (bottom), $\mathbf{2} \mathbf{b}$ (middle) and $\mathbf{2} \mathbf{c}$ (top) in $\mathrm{CDCl}_{3}(500 \mathrm{MHz}$ )..

which is also observed in the 2D COSY spectrum, is only seldom visualized in ${ }^{1} \mathrm{H}$ spectra.

${ }^{13} \mathrm{C}$ NMR spectrum of $\mathbf{2} \mathbf{b}$ also presents separated signals for the nuclei of each side of the molecule, and its complete assignment could be performed from bidimensional HSQC and HMBC spectra (Figures S1-S5, ESI). The differences between the signals observed in the asymmetrical compound and the correspondent dissymmetrical analogs are shown in Table S1 (ESI). Even though the differences are very small, a nonnegligible degree of communication between both ends of the TB is observed, as was the case for $\mathbf{2} \mathbf{d} .^{32}$ This communication is probably due to the rigid geometry of the diazocinic core, which makes the nitrogen atoms face each other and allows the lone pairs to enter the non-conjugated bridge and overlap with the arylamine $\pi$-system, providing an important electronic connecting role to the endomethylene group. ${ }^{39}$

The communication is most notably observed in the nuclei that are farther away from the 2,8 positions. Substitution of one $-\mathrm{NH}_{2}$ group of $\mathbf{2 a}$ for a $-\mathrm{NC}$ group in position 8 to give $\mathbf{2 b}$ produces a $0.3 \mathrm{ppm}$ shift in $\mathrm{C}-2$ and a $0.04 \mathrm{ppm}$ variation in $\mathrm{H}-$ 3 , both at a 9-bond distance and in non-conjugated aromatic rings. The same phenomenon is observed when substituting the remaining $-\mathrm{NH}_{2}$ group of $\mathbf{2} \mathbf{b}$ for $-\mathrm{NC}$ in position 2 to give $\mathbf{2 c}$, which produces a $0.5 \mathrm{ppm}$ shift in $\mathrm{C}-8$ and a $0.03 \mathrm{ppm}$ variation in $\mathrm{H}-9$.

The FTIR spectra of the compounds were measured in solid state in ATR mode and are shown in Figure 4. The $\mathrm{NH}_{2}$ and $\mathrm{NH}$ stretchings of the primary amines in $\mathbf{2 a}$ and secondary amides in $\mathbf{2 d}$ are in the $3400-3200 \mathrm{~cm}^{-1}$ range. The characteristic band at $(2124 \pm 1) \mathrm{cm}^{-1}$, free from spectral interferences, unambiguously indicates the presence of the isocyanide group in $\mathbf{2} \mathbf{b}$ and $\mathbf{2 c}$, with approximately half the intensity in the asymmetric compound. ${ }^{20,40}$ The strong band at $1660 \mathrm{~cm}^{-1}$ in $\mathbf{2 d}$ corresponds to the typical stretching of the carbonyl group of the formanilide. The detailed assignment of the bands is summarized in Table S2 (ESI). ${ }^{41-44}$ 

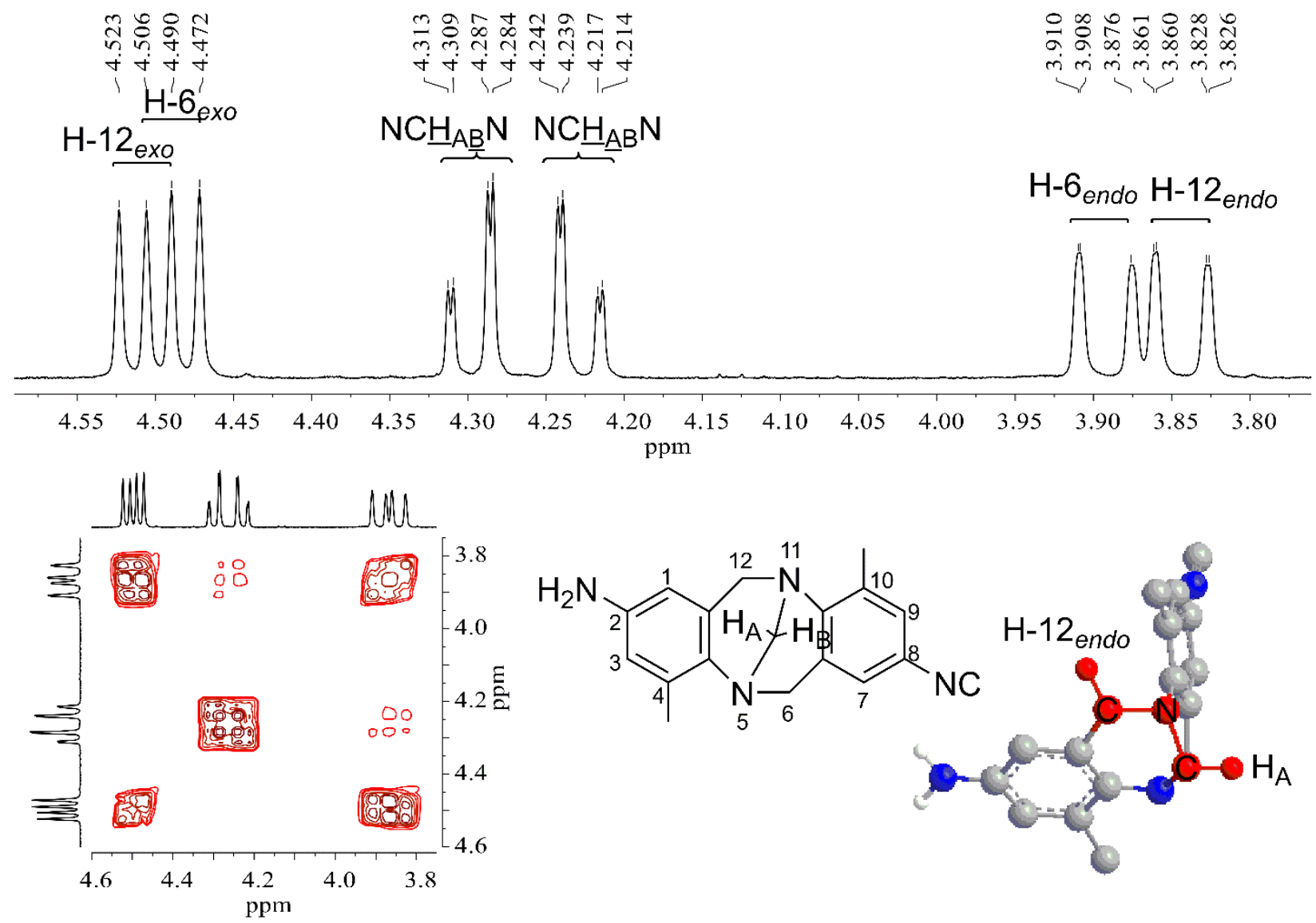

Figure 3. Section of the ${ }^{1} \mathrm{H}$ NMR (top) and COSY (bottom, left) spectra of $\mathbf{2} \mathbf{c}$ in $\mathrm{CDCl}_{3}(500 \mathrm{MHz}$ ) and three-dimensional structure obtained by molecular mechanics using ChemDraw3D (bottom, right).

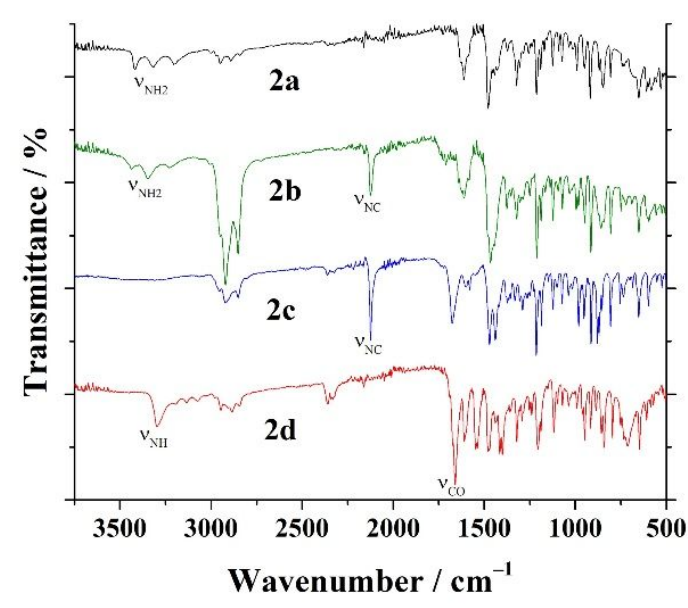

Figure 4. IR spectra of $\mathbf{2 a - d}$ (neat, ATR mode).

When inspecting the IR spectra of the compounds, it is clear that the superposition of the bands of $\mathbf{2 a}$ and $\mathbf{2 c}$ does not reproduce exactly the frequencies and profiles of the asymmetrical $\mathbf{2} \mathbf{b}$ compound, indicating again that an interaction between both ends of the molecule is taking place. This interaction is evidenced in $\mathbf{2} \mathbf{b}$ by the shifts of $+21 \mathrm{~cm}^{-1}$ and +30 $\mathrm{cm}^{-1}$ in the symmetric and asymmetric amine $\mathrm{v}_{\mathrm{N}-\mathrm{H}}$ stretching modes, respectively, with respect to 2 a. These shifts strongly suggest that the aromatic delocalization of the two amino groups in 2a was partly suppressed by the inclusion of the isocyanide group. The $\mathrm{V}_{\mathrm{NC}}$ stretching frequency peak of the isocyano group is originated by the $\mathrm{CN}$ bond character, which can be represented as a mixture of a double-bonded neutral carbene-type and a triple-bonded zwitterionic resonant structures. ${ }^{21,45-48}$ This could affect the conjugation of the amino group with the benzene ring in $\mathbf{2} \mathbf{b}$.

Discarding $\mathrm{CO}$ and $\mathrm{NH}$ groups, the strong broad band located at $1676 \mathrm{~cm}^{-1}$ in $2 \mathrm{c}$ falls in the range of the olefinic alkyl

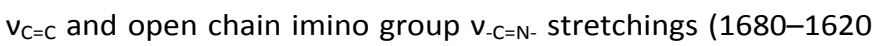
$\mathrm{cm}^{-1}$ and $1690-1640 \mathrm{~cm}^{-1}$ respectively), and therefore could be associated with a double bond character present in the molecule. Nevertheless, an unambiguous assignment is not possible.

Another interesting feature is the very strong change in the intensity of the bands associated with the stretchings of the aliphatic methylene and methyl groups ( $\mathrm{CH}$ stretching below $3000 \mathrm{~cm}^{-1}$ range). Such enhancements occur when a large variation of the dipole moment of the bond is taking place and it is observed when going from $\mathbf{2 a}$ or $\mathbf{2} \mathbf{c}$ to $\mathbf{2 b}$.

The diamide compound $\mathbf{2 d}$ exhibits two bands known as amide $\mathrm{I}$ and amide II. Amide $\mathrm{I}$ is assigned to the $\mathrm{C}=\mathrm{O}$ stretching vibration (1660 $\mathrm{cm}^{-1}$, strong), while amide II is located at 1547 $\mathrm{cm}^{-1}$ and corresponds to the coupling of the in plane deformation of the $\mathrm{NH}$ moiety with the $\mathrm{CN}$ stretching $\left(\mathrm{v}_{\mathrm{NH}} / \mathrm{v}_{\mathrm{CN}}\right.$ 
(II)). The possibility of intermolecular hydrogen bonding among $-\mathrm{C}=\mathrm{O} \cdots \mathrm{H}-\mathrm{N}-$ in $\mathbf{2 d}$ in solid state samples lowers and broadens the $\mathrm{N}-\mathrm{H}$ stretching frequency of the amino group, as observed in the spectrum of $\mathbf{2} \mathbf{d}$ at $3298 \mathrm{~cm}^{-1}$. The stronger the hydrogen bond the longer the $-\mathrm{C}=\mathrm{O}$ bond will be, resulting in a lower vibrational frequency and a broader and more intense absorption band, as it is observed for the band at $1660 \mathrm{~cm}^{-1}$. It is worth mentioning that the very weak bands located at 3194 , 3134 and $3072 \mathrm{~cm}^{-1}$ are overtone signals as usually observed in amides.

In addition, the four compounds show a great number of signals in the $800-1500 \mathrm{~cm}^{-1}$ region, which belong to the Tröger's base skeleton and are in many cases common with the signals of the other molecules presented herein and of other TBs. ${ }^{17,49-51}$

\section{Photophysical measurements Figure 5. Absorption and emission spectra of compounds $2 a-d$ in different solvents.}

The absorption and emission spectra of compounds $\mathbf{2 a}-\mathbf{d}$ were obtained in different solvents covering a wide range of polarities, such as hexane $\left(\varepsilon_{\mathrm{r}}=1.89\right)$, dichloromethane $\left(\varepsilon_{\mathrm{r}}=\right.$
8.93) and acetonitrile $\left(\varepsilon_{r}=37.5\right)$, and a protic solvent like methanol. Normalized spectra are shown in Figure 5.

The absorption spectra present in most cases two bands, or a main band and a red-shifted shoulder. The main parameters associated to these spectra are shown in Table S3 (ESI). The four compounds studied have an intense absorption band around $250 \mathrm{~nm}$ with molar absorption coefficients of ca. $1.5 \times 10^{4} \mathrm{M}^{-}$ ${ }^{1} \mathrm{~cm}^{-1}$, which are ascribed to spin and symmetry allowed ${ }^{1} \pi \pi^{*}$ transitions associated with the framework of the TB. ${ }^{17}$ These bands do not depend strongly either on the solvent or the nature of the substituents.

Replacement of an amino group in $\mathbf{2 a}$ for an isocyanide to obtain $\mathbf{2 b}$ produces the blue-shift of the lower energy absorption band, which moves from 305-310 nm to 285-300 $\mathrm{nm}$ (shoulder analyzed by spectral deconvolution), and in turn increases its intensity. Similar shifts were observed in naphthalimide Tröger's base derivatives. ${ }^{53}$ A second replacement of the amino group (2b to $\mathbf{2} \mathbf{c}$ ) generates a new hyper and hypsochromic effect on this band, whose maximum absorption wavelength shifts to $270 \mathrm{~nm}$.
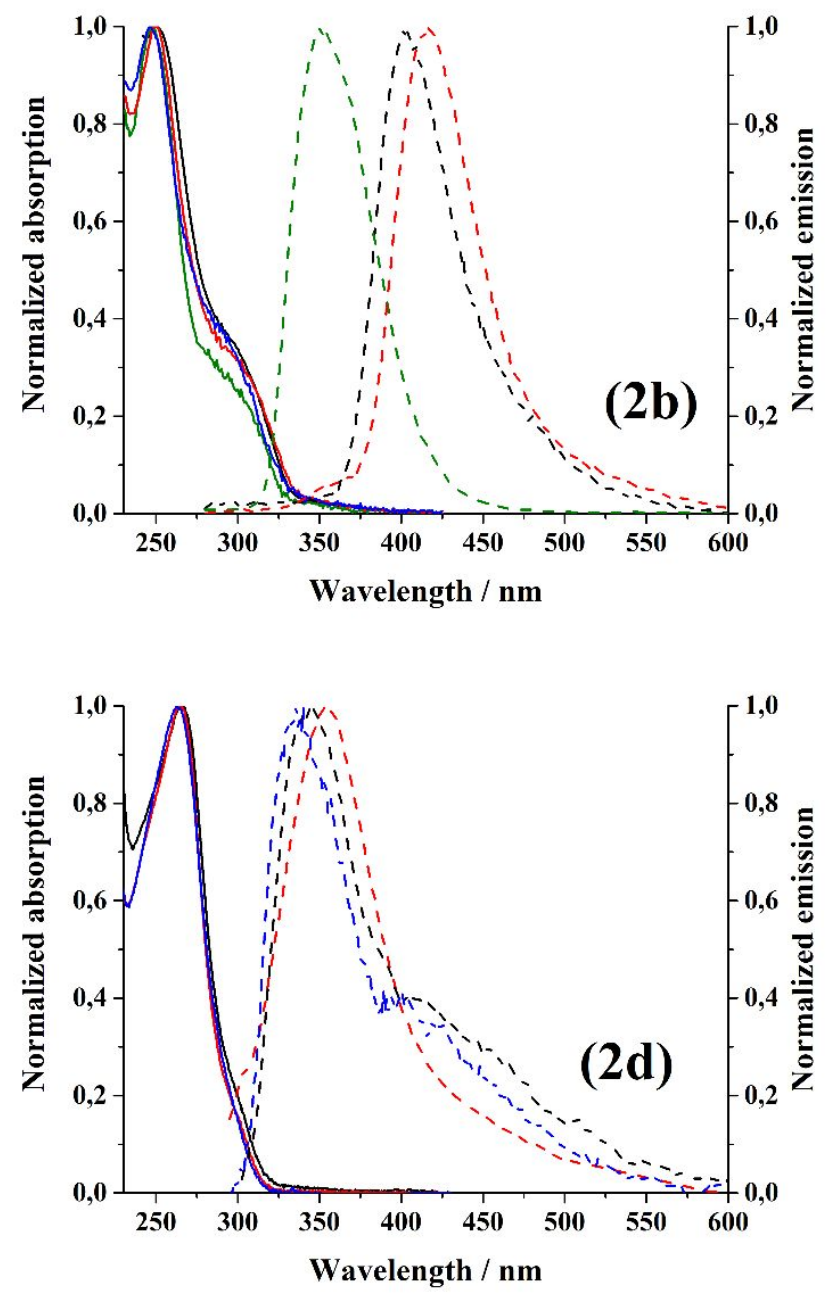

Figure 5. Absorption and emission spectra of compounds $\mathbf{2 a - d}$ in different solvents. 
The bathochromic effect produced in the absorption spectra by the replacement of an isocyano for an amino group is explained considering the mesomeric effect of the $-\mathrm{NH}_{2}$ group, whose electron pair participates in the conjugated aromatic system reducing the HOMO-LUMO energy difference and redshifting the ${ }^{1} \pi \pi^{*}$ transition. ${ }^{52,54}$ This effect could be lost in the isocyano groups, given their zwitterionic character with a positive charge density on the nitrogen atom which would restrict the conjugation with the aromatic system. The same explanation holds for $\mathbf{2 d}$, where the formamide groups do not conjugate with the aromatic rings.

The solvent effects are evident in the emission spectra, which were presented in Figure 5 and whose main features are shown in Table 1 . In the case of $\mathbf{2 a}$ and $\mathbf{2} \mathbf{d}$, the fluorescence maxima are located in the near UV region for every solvent, with widths at half maximum (FWHM) of 45-55 nm. For compounds $\mathbf{2 b}$ and $\mathbf{2 c}$, these wavelengths suffer a significant red-shift when the solvent polarity is increased.

Table 1. Relevant photophysical data of the fluorescence emission spectra of TBs $\mathbf{2 a - c}$ in different solvents. $\lambda_{F}$ is the emission maxima $(n m), \Delta \lambda_{S T}$ is the Stokes shift (calculated with respect to $\lambda_{\max }$ ) and $\Phi_{\mathrm{F}}$ is the fluorescence quantum yield.

\begin{tabular}{|c|c|c|c|c|c|}
\hline TB & Solvent & $\lambda_{\mathrm{F}}$ & $\Delta \lambda_{\mathrm{ST}} / \mathrm{nm}$ & $\Delta \lambda_{\mathrm{ST}} / \mathrm{cm}^{-1}$ & $\Phi_{\mathrm{F}} / \%^{[\mathrm{a}]}$ \\
\hline \multirow{4}{*}{$2 a$} & Hexane & 351 & 43 & 3978 & 4.3 \\
\hline & Dichloromethane & 350 & 40 & 3687 & 0.9 \\
\hline & Acetonitrile & 362 & 52 & 4634 & 5.3 \\
\hline & Methanol & 364 & 60 & 5422 & 1.7 \\
\hline \multirow{4}{*}{$2 b$} & Hexane & 351 & $59^{[b]}$ & $5757^{[b]}$ & 3.9 \\
\hline & Dichloromethane & 403 & $104^{[b]}$ & $8631^{[b]}$ & 2.1 \\
\hline & Acetonitrile & 416 & $121^{[b]}$ & $9860^{[b]}$ & 2.5 \\
\hline & Methanol & [c] & [c] & [c] & [c] \\
\hline \multirow{4}{*}{ 2c } & Hexane & 330 & 61 & 6872 & 3.0 \\
\hline & Dichloromethane & 375 & 103 & 10098 & 8.0 \\
\hline & Acetonitrile & 400 & 130 & 12037 & 5.7 \\
\hline & Methanol & 403 & 134 & 12361 & 0.8 \\
\hline \multirow{4}{*}{$2 d$} & Hexane & [d] & [d] & [d] & [d] \\
\hline & Dichloromethane & 344 & $78^{[\mathrm{e}]}$ & $7654^{[\mathrm{e}]}$ & 0.1 \\
\hline & Acetonitrile & 354 & $89[\mathrm{e}]$ & 9246 [e] & 0.1 \\
\hline & Methanol & 336 & $73^{[\mathrm{e}]}$ & $8261[\mathrm{e}]$ & $<0.1$ \\
\hline
\end{tabular}

[a] $10 \%$ error is estimated. [b] Calculated from spectral deconvolution of $\lambda_{\max 2 .}$ [c] Negligible emission. [d] Not obtained due to low solubility. [e] Calculated with respect to $\lambda_{\max 1}$.

The replacement of an amino for an isocyano group (2a to 2b) produces a bathochromic shift of the emission maxima of ca. $4000 \mathrm{~cm}^{-1}(60 \mathrm{~nm})$ when polarity is increased from hexane to acetonitrile, generating thus a notorious rise in the Stokes shift (ca. $120 \mathrm{~nm}$ in the latter solvent). Diisocyano-TB 2c shows an even higher Stokes shift increase, obtaining a difference of over $5000 \mathrm{~cm}^{-1}(70 \mathrm{~nm})$ between hexane and acetonitrile simultaneously with a large broadening of the emission bands. FWHM values for $\mathbf{2 c}$ are around $100 \mathrm{~nm}$ in every solvent except in hexane.

Diformamide $\mathbf{2 d}$ presents fluorescence maxima ca. $350 \mathrm{~nm}$, but a variation of the emission spectra with successive irradiation was observed in dichloromethane and methanol. This would indicate a photochemical decomposition of $\mathbf{2} \mathbf{d}$ and was not studied further. The spectra in Figure 4 were obtained by a single measurement of fresh solutions, and they still show the presence of red-shifted fluorescence bands.

Fluorescence quantum yields are shown in Table 1 . The results obtained for compounds $\mathbf{2 a}-\mathbf{c}$ are similar to the TBs $\mathbf{1 a}-$ c, with substituents $-\mathrm{H},-\mathrm{Me}$ and $-\mathrm{COOMe}$ respectively, and present values generally between $1 \%$ and $8 \%$ and dependent both on the substituents and the solvent. ${ }^{17} \mathbf{2 c}$ presents the larger fluorescence quantum yields, and the protic solvent (methanol) produces in general lower emission. In the case of $\mathbf{2 d}$, quantum yields were smaller than $0.1 \%$, showing that the presence of formamide units, with increased structural flexibility, favors non-radiative deactivations.

Table 2 shows the fluorescence lifetimes measured for $\mathbf{2 a - c}$ in acetonitrile (Figures S7-S9, ESI), as well as the calculated values of radiative and non-radiative decay constants, determined from experimental lifetimes and quantum yields. Non-radiative decays are of the same order of magnitude, whereas the radiative decay constant of $\mathbf{2} \mathbf{b}$ is significantly smaller and produces a poorer quantum yield. In the remaining solvents, reliable lifetimes could not be obtained due to the lack of sufficient emission counts.

Table 2. Fluorescence lifetimes $\tau$ and radiative $k_{r}$ and non-radiative $k_{n r}$ decay constants of $2 a-c$ in acetonitrile.

\begin{tabular}{cccc}
\hline TB & $\tau / \mathrm{ns}^{[a]}$ & $\mathrm{k}_{\mathrm{r}} / \mathrm{s}^{-1}$ & $\mathrm{k}_{\mathrm{nr}} / \mathrm{s}^{-1}$ \\
\hline 2a & 1.5 & $3.6 \times 10^{7}$ & $6.4 \times 10^{8}$ \\
$\mathbf{2 b}$ & 5.7 & $4.4 \times 10^{6}$ & $1.7 \times 10^{8}$ \\
2c & 2.8 & $2.0 \times 10^{7}$ & $3.4 \times 10^{8}$ \\
\hline
\end{tabular}

[a] $10 \%$ error is estimated.

The bathochromic effect on the emission spectra of $\mathbf{2 a - c}$ with the solvent polarity indicates that the dipolar moments of the molecules in the excited state are larger than in the ground state. ${ }^{55,56}$ The existence of polar excited states, associated to ${ }^{1} \pi \pi^{*}$ transitions, can either be linked to specific fluorophoresolvent interactions or to non-specific reasons. ${ }^{52,55}$

Solvatochromism increases in the order $\mathbf{2} \mathbf{a} \rightarrow \mathbf{2} \mathbf{b} \rightarrow \mathbf{2} \mathbf{c}$, showing that the origin of the rise in polarity in the excited state would be given by the mere presence of amino and isocyano groups, being more pronounced in the isocyanides. From these results, it is possible to conclude that in $\mathbf{2} \mathbf{b}$ these groups act independently in the generation of solvatochromic effects. Therefore, there would not be charge transfer effects from the terminal amino donor group to the isocyano acceptor on the opposite end of the molecule, as occurred in Keki's compounds, 
because this would imply a higher solvatochromic effect in 2b. ${ }^{20,31}$

Nevertheless, the particular band broadening together with the large Stokes shifts and solvatochromic effects observed preferentially in $\mathbf{2 c}$ suggest the possible presence of an intramolecular charge transfer excited state (ICT). ${ }^{52,57}$ This nonspecific phenomenon generates solvatochromism due to the charge separation produced after excitation, which gives rise to an electronic state that is more strongly stabilized in polar solvents. In the cases of $\mathbf{2} \mathbf{b}$ and $\mathbf{2} \mathbf{c}$ it can be proposed that the charge transfer is produced between an electron donor group as the central nitrogen atoms of the diazocinic core and an acceptor group as the terminal isocyanide, which are in para relative positions.

The solvatochromic effect was analyzed for $\mathbf{2 a - d}$ in terms of the Lippert-Mataga model, which relates the Stokes shift ( $\left.\Delta \bar{v}_{S T}\right)$ increase with solvent polarity with the difference in the dipole moment between the excited and ground states $\left(\Delta \mu=\mu_{e}-\right.$ $\left.\mu_{\mathrm{g}}\right): 55,56$

\section{ARTICLE}

$$
\Delta \bar{v}_{S T}=\frac{2(\Delta \mu)^{2}}{\mathrm{hca}^{3}} \Delta \mathrm{f}+\Delta \overline{\mathrm{v}}_{0}
$$

where $h$ is the Planck's constant, $c$ is the speed of light, $a$ is the Onsager cavity radius of the solute and $\Delta f$ is the orientation polarization function. This function is defined as follows:

$$
\Delta f=\frac{\epsilon-1}{2 \epsilon+1}-\frac{n^{2}-1}{2 n^{2}+1}
$$

where the dielectric constant $\epsilon$ and the refraction index $n$ for a mixture of solvents depend on the volumetric fractions of both solvents $f_{A}$ and $f_{B}$ and are obtained as

$$
\begin{array}{r}
\epsilon=\mathrm{f}_{A} \epsilon_{A}+\mathrm{f}_{B} \epsilon_{B} \\
\mathrm{n}^{2}=\mathrm{f}_{A} n_{A}^{2}+\mathrm{f}_{B} n_{B}^{2}
\end{array}
$$

The absorption and fluorescence maxima and the Stokes shift were plotted against $\Delta f$ for compounds $\mathbf{2 a}-\mathbf{d}$, as is shown in Figure 6. Acetonitrile-dichloromethane mixtures $(\Delta f>0.21)$ where used for every compound, whereas hexanedichloromethane mixtures $(\Delta f<0.21)$ were also analyzed for $\mathbf{2 a}-\mathbf{c}$. For compounds $\mathbf{2 a}$ and $\mathbf{2} \mathbf{c}$ the red-shifted absorption maxima was considered, whereas for compounds $\mathbf{2} \mathbf{b}$ and $\mathbf{2} \mathbf{d}$ the main absorption band was taken into account. 

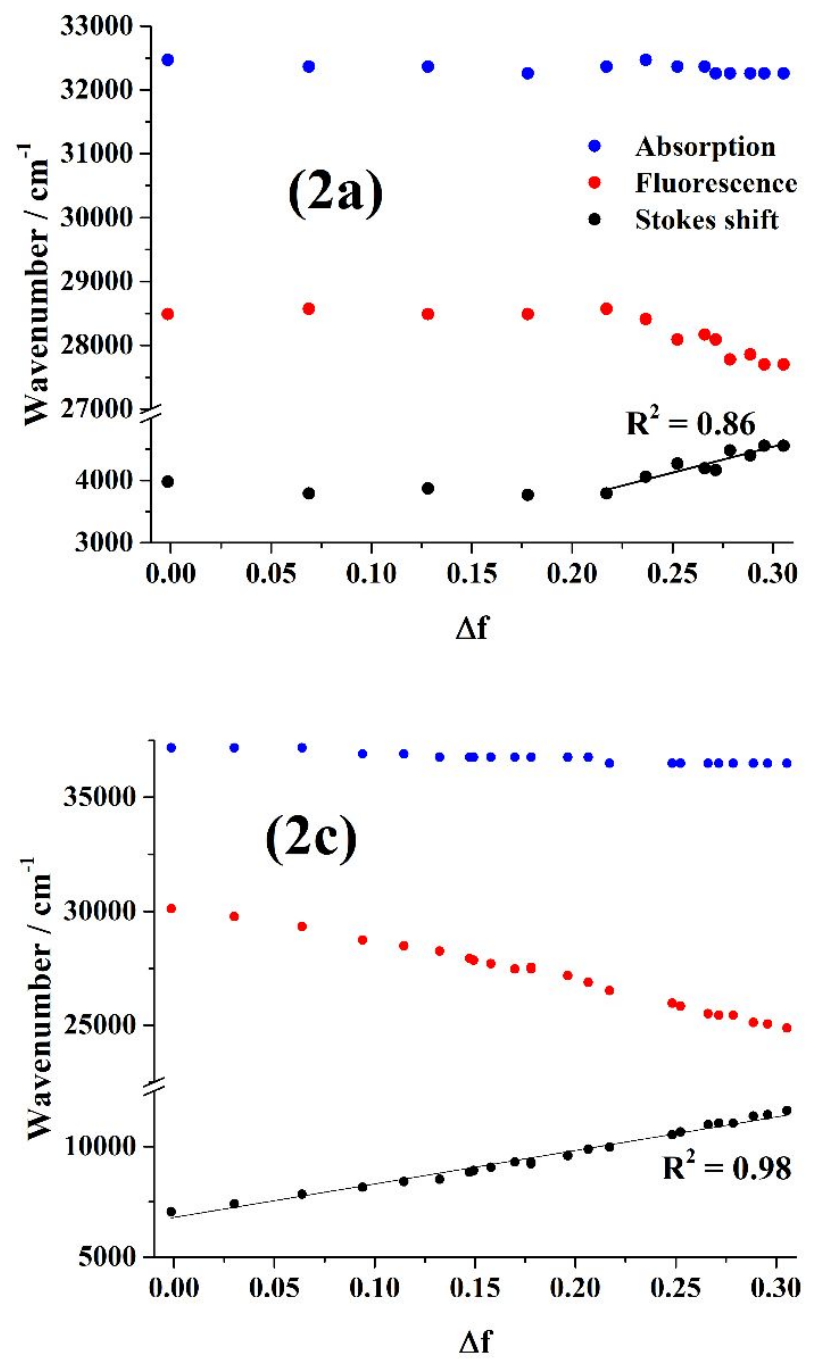

Figure 6. Lippert-Mataga plots of compounds 2a-d.

In the case of $\mathbf{2 a}$, hexane-dichloromethane mixtures do not present significant variations in the positions of the absorption and fluorescence maxima, but this effect is indeed observed in dichloromethane-acetonitrile mixtures. This dual solvatochromic behavior, of inexistent solvatochromism in low polar solvents but evident in more polar mixtures, could be originated by the formation of excited states of different nature in each regime. This is the case of some fluorophores like Neutral Red and PRODAN, that in low polarity media are associated to locally excited (LE) states whose dipolar moment does not vary significantly with respect to the ground state whereas high polarity solvents give rise to lower energy ICT states. ${ }^{58,59}$

Linear plots were obtained for the second regime of $2 a\left(R^{2}\right.$ $=0.86)$, for $\mathbf{2 b}\left(R^{2}=0.97\right)$ and $\mathbf{2 c}\left(R^{2}=0.98\right)$, demonstrating that the Lippert-Mataga model accurately describes the behavior of these systems and that no specific solvent effects are apparently present in aprotic solvents. On the contrary, $\mathbf{2 d}$ does not present any significant solvatochromic effect, as was
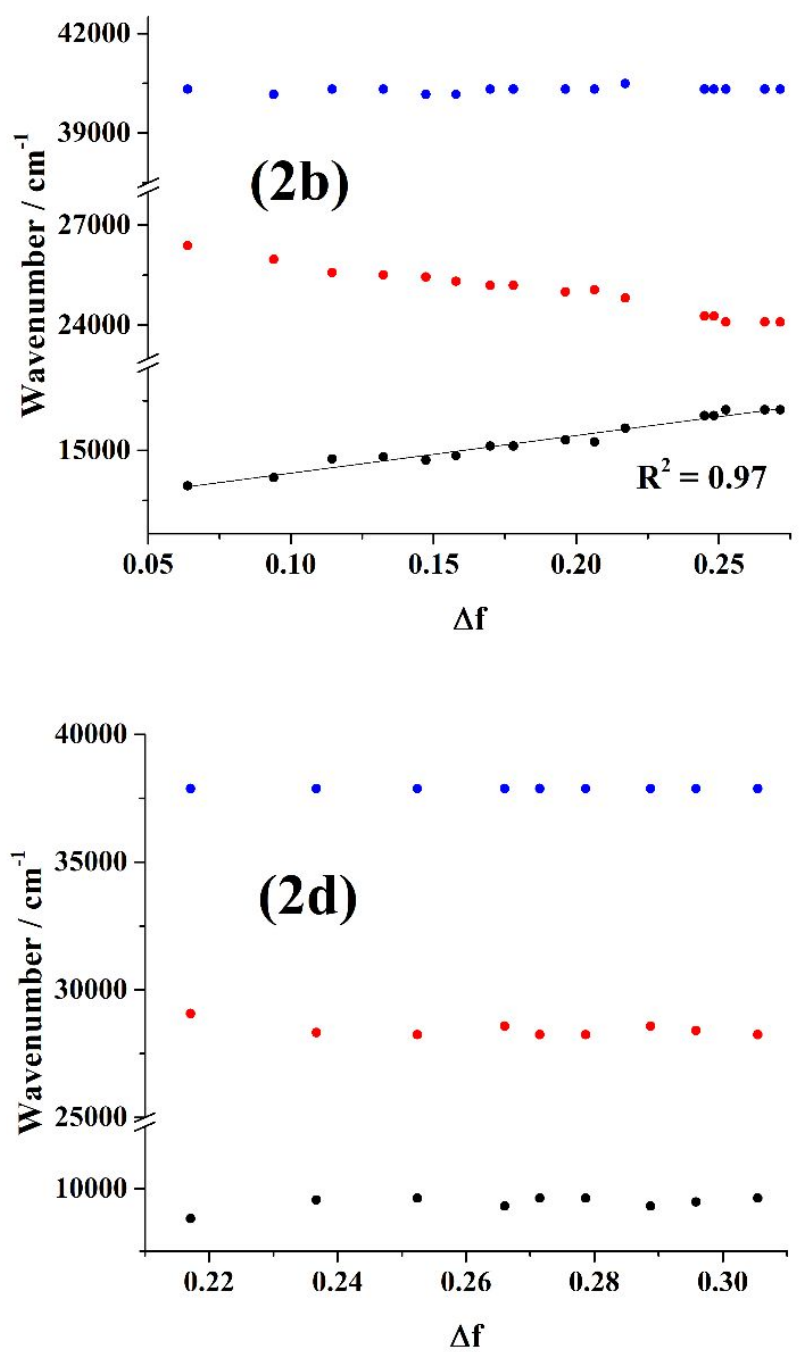

already expected from the initial emission spectra in dichloromethane and acetonitrile.

The changes in dipole moments $\Delta \mu$ were calculated as 10.8 D for $\mathbf{2 a}, \mathbf{2} .6 \mathrm{D}$ for $\mathbf{2 b}$ and $14,5 \mathrm{D}$ for $\mathbf{2 c}$, with errors estimated in around $10 \%$ considering both the standard deviations of Lippert plots and the approximation in Onsager radius. The radii were obtained as the average value between the ones calculated for compounds $\mathbf{1 b}$ and $\mathbf{1 c}(5,2 \AA \pm 0,3 \AA) .{ }^{17}$ The dipole moments are similar to the one obtained for compound $\mathbf{1 c}$ and significantly larger than those of compounds $\mathbf{1 a}$ and $\mathbf{1 b}$, and show an increase of ca. $2 \mathrm{D}$ with each replacement of an amino group for an isocyanide.

\section{Conclusions}

The photophysical properties of four simple nitrogenated Tröger's bases were studied, including three dissymmetrical compounds $\mathbf{2 a}, \mathbf{2 c}$ and $\mathbf{2 d}$ and a new asymmetrical derivative $\mathbf{2} \mathbf{b}$ with amino and isocyano substituents. The NMR and IR spectra 
of this compound showed that spectroscopic properties result 6 mainly as the superposition of those of the dissymmetrical 7 analogues, but with a certain degree of communication between both ends of the TB scaffold, as was already observed by our group for diformamide $\mathbf{2} \mathbf{d}$. $^{32}$

This communication was not so evident regarding the optical properties of the TBs, which indicate the absence of intramolecular charge transfer between the amino donor group and the isocyano acceptor group in the extremes of $\mathbf{2 b}$. Instead, an ICT state can be proposed between the isocyano group and a central nitrogen of the diazocinic core both in $\mathbf{2} \mathbf{b}$ and $\mathbf{2 c}$, as suggested by the observed solvatochromic effect, band broadening and large Stokes shifts.

A spin and symmetry allowed ${ }^{1} \pi \pi^{*}$ transition ascribed to the TB skeleton is responsible for the main absorption band in the UV region, but a red-shifted band and the emission spectrum are substantially dependent on the substituents. In addition, the fluorescence quantum yields of the TBs studied presented non negligible values, consistent with those of the previously reported analogues.

The results presented herein constitute one of the first approaches to the investigation of the photophysical and structural properties of simple Tröger's bases. This knowledge is of paramount importance in order to fully understand and design more complex systems that profit of the unique geometry and features of TBs, which are taken advantage of in numerous fields such as supramolecular chemistry and molecular recognition among others. In fact, in our group we are working in the development of TB-based ligands for the preparation of luminescent lanthanide complexes, where the TB acts not only as a geometrical scaffold but also in some cases as the antenna, with very promising results.

\section{Conflicts of interest}

There are no conflicts to declare.

\section{Acknowledgements}

This work was supported by Agencia Nacional de Promoción Científica y Tecnológica (PICT 2013-2331 to J.A.R.) and Universidad de Buenos Aires (UBACyT 20020130100826BA to J.A.R.).

\section{References}

1 C. Pardo, I. Alkorta and J. Elguero, Tetrahedron Asymmetry, 2006, 17, 191-198.

2 S. Sergeyev, Helv. Chim. Acta, 2009, 92, 415-444.

3 J. Artacho and K. Wärnmark, Synthesis (Stuttg)., 2009, 3120-3126.

4 C. Pardo, M. Ramos, A. Fruchier and J. Elguero, Magn. Reson. Chem., 1996, 34, 708-710.

5 L. Mosca, J. Čejka, B. Dolenský, M. Havlík, M. Jakubek, R. Kaplánek, V. Král and P. Anzenbacher, Chem. Commun., 2016, 52, 10664-10667.
L. Xu, X. Yan and C. Yuan, RSC Adv., 2018, 8, 35289-35293. C. Yuan, Y. Zhang, H. Xi and X. Tao, RSC Adv., 2017, 7, 55577-55581.

8 B. R. Manda, M. Alla, R. J. Ganji and A. Addlagatta, Eur. J. Med. Chem., 2014, 86, 39-47.

9 S. Shanmugaraju, C. Dabadie, K. Byrne, A. J. Savyasachi, D. Umadevi, W. Schmitt, J. A. Kitchen and T. Gunnlaugsson, Chem. Sci., 2017, 8, 1535-1546.

10 I. Neogi, S. Jhulki, A. Ghosh, T. J. Chow and J. N. Moorthy, Org. Electron. physics, Mater. Appl., 2014, 15, 3766-3772. C. Yuan, J. Li, H. Xi and Y. Li, Mater. Lett., 2019, 236, 9-12. B. Dolenský, J. Elguero, V. Král, C. Pardo and M. Valík, Adv. Heterocycl. Chem., 2007, 93, 1-56.

Ö. V. Rúnarsson, J. Artacho and K. Wärnmark, European J. Org. Chem., 2012, 7015-7041.

14 M. Valík, R. M. Strongin and V. Král, Supramol. Chem., 2005, 17, 347-367.

R. Yuan, M. qi Li, J. biao Xu, S. ying Huang, S. liang Zhou, P. Zhang, J. juan Liu and H. Wu, Tetrahedron, 2016, 72, 40814084.

F. Vögtle, Reizvolle Moleküle der Organischen Chemie, B. G. Teubner, 1989.

17 D. M. P. Aroche, J. M. Toldo, R. R. Descalzo, P. F. B.

Gonçalves and F. S. Rodembusch, New J. Chem., 2015, 39, 6987-6996.

18 A. Dömling, Chem. Rev., 2006, 106, 17-89.

19 M. L. Bode, D. Gravestock and A. L. Rousseau, Org. Prep. Proced. Int., 2016, 48, 89-221.

20 D. Rácz, M. Nagy, A. Mándi, M. Zsuga and S. Kéki, J. Photochem. Photobiol. A Chem., 2013, 270, 19-37. R. Ramozzi, N. Chéron, B. Braïda, P. C. Hiberty and P. Fleurat-Lessard, New J. Chem., 2012, 36, 1137-1140. D. N. Mehta-Hurt, J. A. Korn, A. K. Gutberlet and T. S. Zwier, J. Phys. Chem. A, 2015, 119, 2863-2877.

A. R. Muirhead, A. Hartford, K. Huang and J. R. Lombardi, J. Chem. Phys., 1972, 56, 4385-4393.

W. Wang, X. Sun, J. Qu, X. Xie, Z. H. Qi, D. Hong, S. Jing, D. Zheng, Y. Tian, H. Ma, S. Yu and J. Ma, Phys. Chem. Chem. Phys., 2017, 19, 31443-31451.

T. H. Webb and C. S. Wilcox, J. Org. Chem., 1990, 55, 363365.

C. Pardo, E. Sesmilo, E. Gutiérrez-Puebla, A. Monge, J. Elguero and A. Fruchier, J. Org. Chem., 2001, 66, 16071611.

B. Dolenský, M. Valík, D. Sýkora and V. Král, Org. Lett., 2005, 7, 67-70.

J. Jensen, J. Tejler and K. Wärnmark, J. Org. Chem., 2002, 67, 6008-6014.

M. Havlík, B. Dolenský, M. Jakubek and V. Král, European J. Org. Chem., 2014, 2798-2805.

30 P. A. Lanza, D. Dusso, C. L. Ramirez, A. R. Parise, C. A. Chesta, E. L. Moyano and D. M. A. Vera, European J. Org. Chem., 2019, 2019, 7644-7655. M. Nagy, D. Rácz, S. L. Kovács, L. Lázár, P. P. Fehér, M. Purgel, M. Zsuga and S. Kéki, J. Photochem. Photobiol. A Chem., 2016, 318, 124-134.

32 L. Trupp, S. L. Laurella, M. C. Tettamanzi, B. C. Barja and A. 
C. Bruttomesso, J. Mol. Struct., 2018, 1157, 434-443.

33 U. Kiehne, T. Weilandt and A. Lutzen, Org. Lett., 2007, 9, 1283-1286.

34 K. Heinze and V. Jacob, Eur. J. Inorg. Chem., 2003, 39183923.

35 A. Jarzebski, C. Bannwarth, C. Tenten, C. Benkhäuser, G. Schnakenburg, S. Grimme and A. Lützen, Synthesis (Stuttg)., 2015, 47, 3118-3132.

36 M. D. Cowart, I. Sucholeiki, R. R. Bukownik and C. S. Wilcox, J. Am. Chem. Soc., 1988, 110, 6204-6210.

37 J. Elguero, A. Fruchier, T. Mas and C. Pardo, Magn. Reson. Chem., 2005, 43, 665-669.

38 M. Demeunynck, C. Fontaine and J. Lhomme, Magn. Reson. Chem., 1999, 37, 73-76.

39 C. L. Ramírez, C. Pegoraro, L. Trupp, A. Bruttomesso, V. Amorebieta, D. M. A. Vera and A. R. Parise, Phys. Chem. Chem. Phys., 2011, 13, 20076-20080.

40 J. G. Polisar, L. Li and J. R. Norton, Tetrahedron Lett., 2011, 52, 2933-2934.

41 B. Stuart, Infrared Spectroscopy: Fundamentals and Applications, Wiley, 2004.

42 J. Coates, Interpretation of Infrared Spectra, A Practical Approach, Encyclopedia of Analytical Chemistry, Wiley, 2006.

43 J. A. Dean, Lange's Handbook of Chemistry, McGraw-Hill, 15th edn., 1999.

44 Roeges and N. G., A Guide to the Complete Interpretation of Infrared Spectra of Organic Structures, Wiley, New York, NY, 1994.

45 H. Lindemann and L. Wiegrebe, Ber. Dtsch. Chem. Ges., 1930, 63, 1650.

46 N. V. Sidgwick, Chem. Rev.

47 J. U. Nef, Justus Liebigs Ann. Chem., 1892, 270, 267-335.

48 J. U. Nef, Justus Liebigs Ann. Chem., 1899, 309, 126.

49 F. Hof, M. Schär, D. M. Scofield, F. Fischer, F. Diederich and S. Sergeyev, Helv. Chim. Acta, 2005, 88, 2333-2344.

50 S. Sergeyev, M. Schär, P. Seiler, O. Lukoyanova, L. Echegoyen and F. Diederich, Chem. - A Eur. J., 2005, 11, 2284-2294.

51 Z. Li, X. Xu, Y. Peng, Z. Jiang, C. Ding and X. Qian, Synthesis (Stuttg)., 2005, 1228-1230.

52 M. Klessinger and J. Michl, Excited States and Photochemistry of Organic Molecules, VCH, 1995.

53 N. R. Deprez, K. A. McNitt, M. E. Petersen, R. G. Brown and D. E. Lewis, Tetrahedron Lett., 2005, 46, 2149-2153.

54 H. Suzuki, Electronic Absorption Spectra and Geometry of Organic Molecules, Academic Press, 1967.

55 Joseph R. Lakowicz, Principles of Fluorescence Spectroscopy, Springer International Publishing, 3ra edn., 2006.

56 C. Reichardt and T. Welton, Solvents and Solvent Effects in Organic Chemistry, Wiley-VCH, 4ta edn., 2011.

57 Y. Zhao, K. Chen, E. A. Yildiz, S. Li, Y. Hou, X. Zhang, Z. Wang, J. Zhao, A. Barbon, H. G. Yaglioglu and H. Wu, Chem. - A Eur. J., 2020, 1-10.

58 G. Weber and F. J. Farris, Biochemistry, 1979, 18, 30753078.
M. K. Singh, H. Pal, A. C. Bhasikuttan and A. V. Sapre, Photochem. Photobiol., 1998, 68, 32-38. 
Structure of $(S, S)-1 a$ and three-dimensional structure obtained by molecular mechanics using ChemDraw3D.

$64 \times 28 \mathrm{~mm}(600 \times 600 \mathrm{DPI})$ 
<smiles>Cc1cc(N)cc2c1N1Cc3cc(N)cc(C)c3N(C2)c2c(C)cc(N)cc2C1</smiles>

$2 a$

2b<smiles>Cc1cc(N=C=O)cc2c1N1Cc3cc(N=CN)cc(C)c3N(C2)c2c(C)cc(NC=O)cc2C1</smiles>

Chart 1. Structure of compounds 2a-d.

$84 \times 47 \mathrm{~mm}(1200 \times 1200 \mathrm{DPI})$ 
Scheme 1. Synthetic routes used for the preparation of TBs $2 a-$ d. i) (CH2O)n, TFA, 48 h, r.t., $87 \%$; ii) Fe, $\mathrm{HAcO}, \mathrm{EtOH}, 2 \mathrm{~h}, \Delta, 99 \%$; iii) $\mathrm{CHCl} / \mathrm{EtOH}, \mathrm{KOH}$ (aq.), 6 h, $\Delta, 4 \%$; iv) HCOOH/Ac2O, THF, Et3N, 24 h, r.t. , $96 \%$; v) $\mathrm{POCl} 3, \mathrm{CH} 2 \mathrm{Cl} 2$, Et3N, 15 min, $0{ }^{\circ} \mathrm{C}, 100 \%$. 


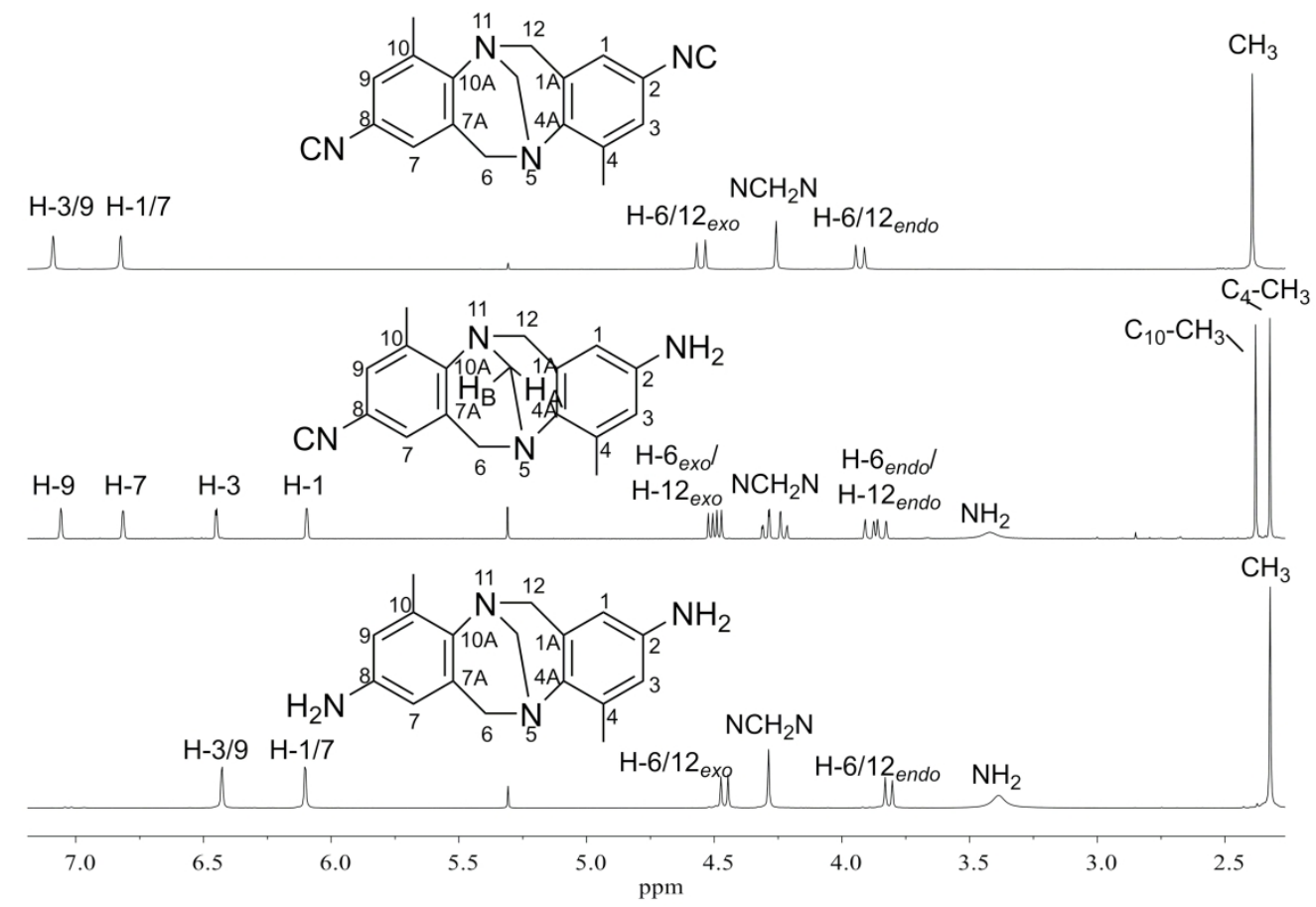

1H NMR spectra of $2 a$ (bottom), $2 \mathrm{~b}$ (middle) and 2c (top) in $\mathrm{CDCl}^{3}(500 \mathrm{MHz}$ ). $148 \times 103 \mathrm{~mm}(600 \times 600 \mathrm{DPI})$ 
Section of the $1 \mathrm{H}$ NMR (top) and COSY (bottom, left) spectra of $2 \mathrm{c}$ in $\mathrm{CDCl} 3(500 \mathrm{MHz}$ ) and threedimensional structure obtained by molecular mechanics using ChemDraw3D (bottom, right). 


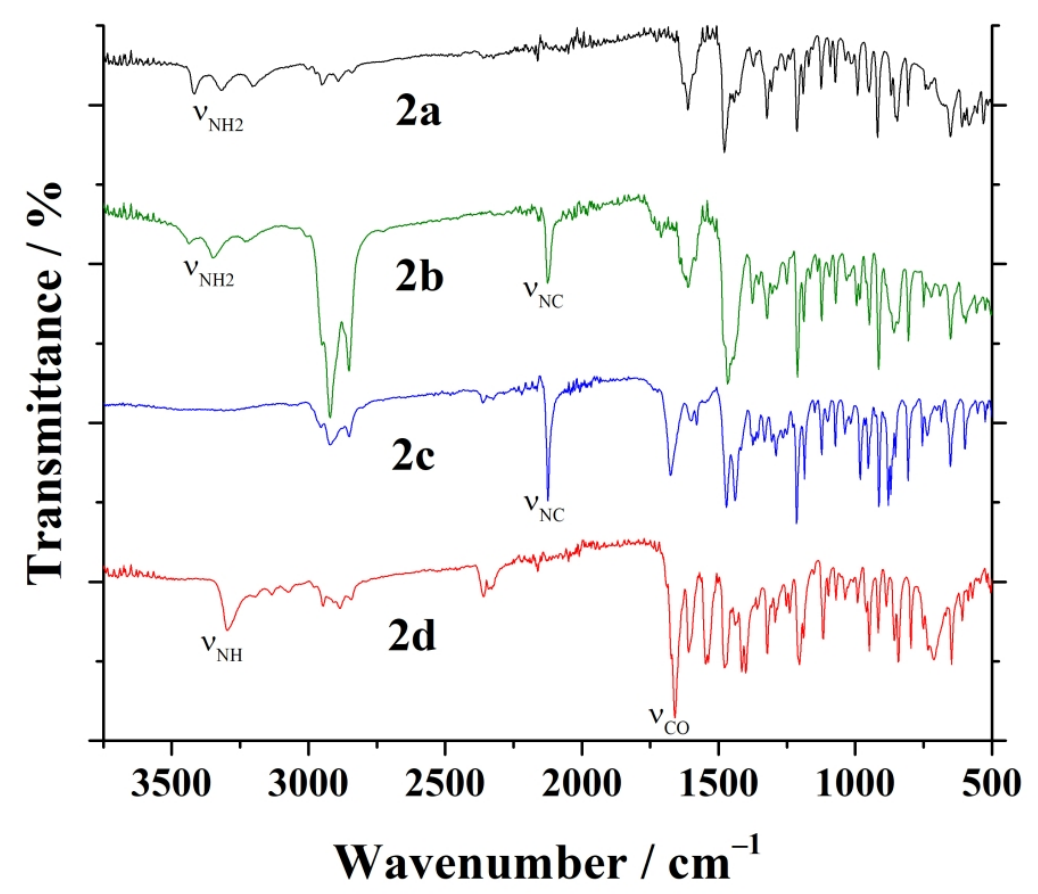

Figure 4. IR spectra of $2 a-d$ (neat, ATR mode).

$272 \times 208 \mathrm{~mm}(300 \times 300$ DPI $)$ 

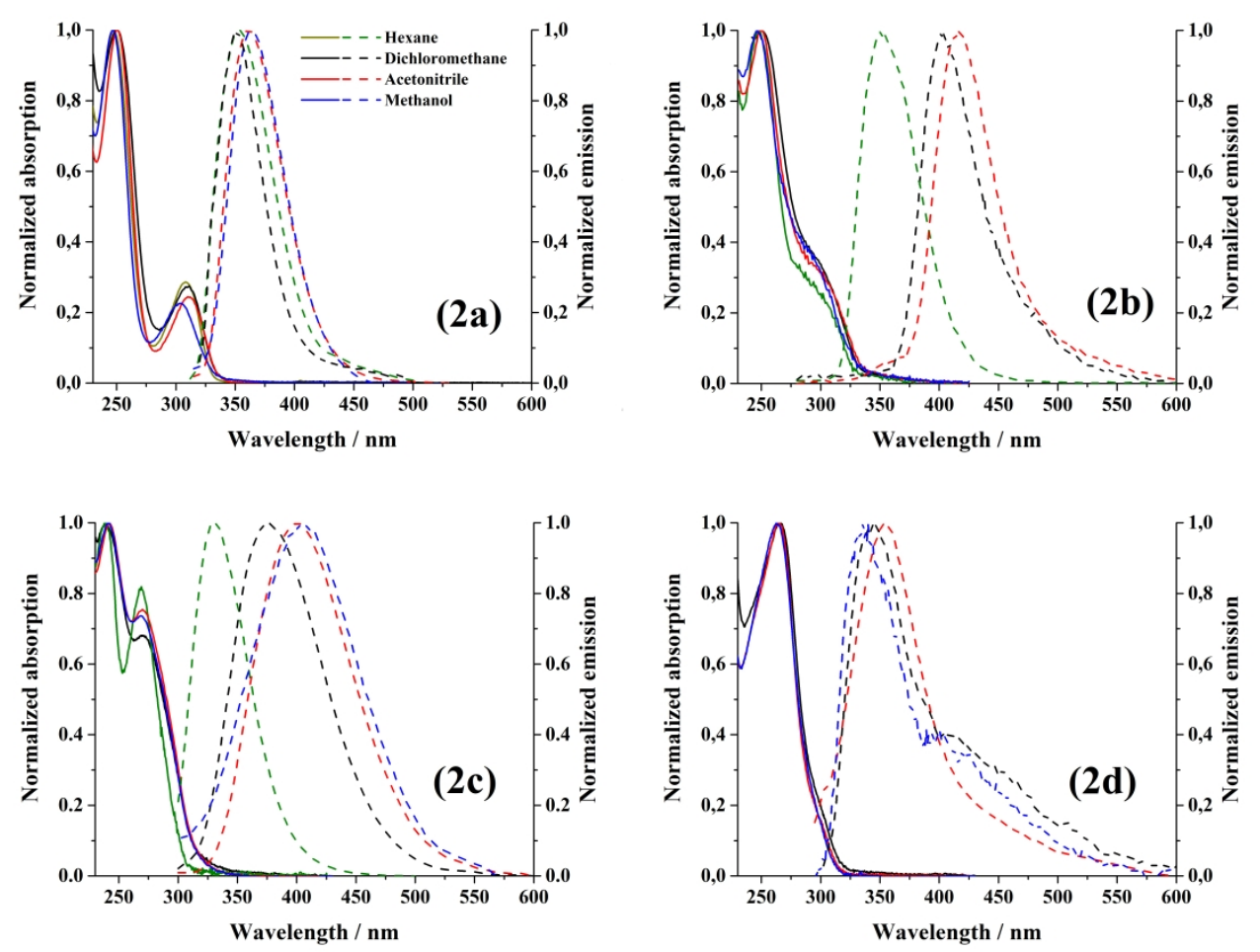

Figure 5. Absorption and emission spectra of compounds $2 a-d$ in different solvents. $544 \times 416 \mathrm{~mm}(300 \times 300 \mathrm{DPI})$ 

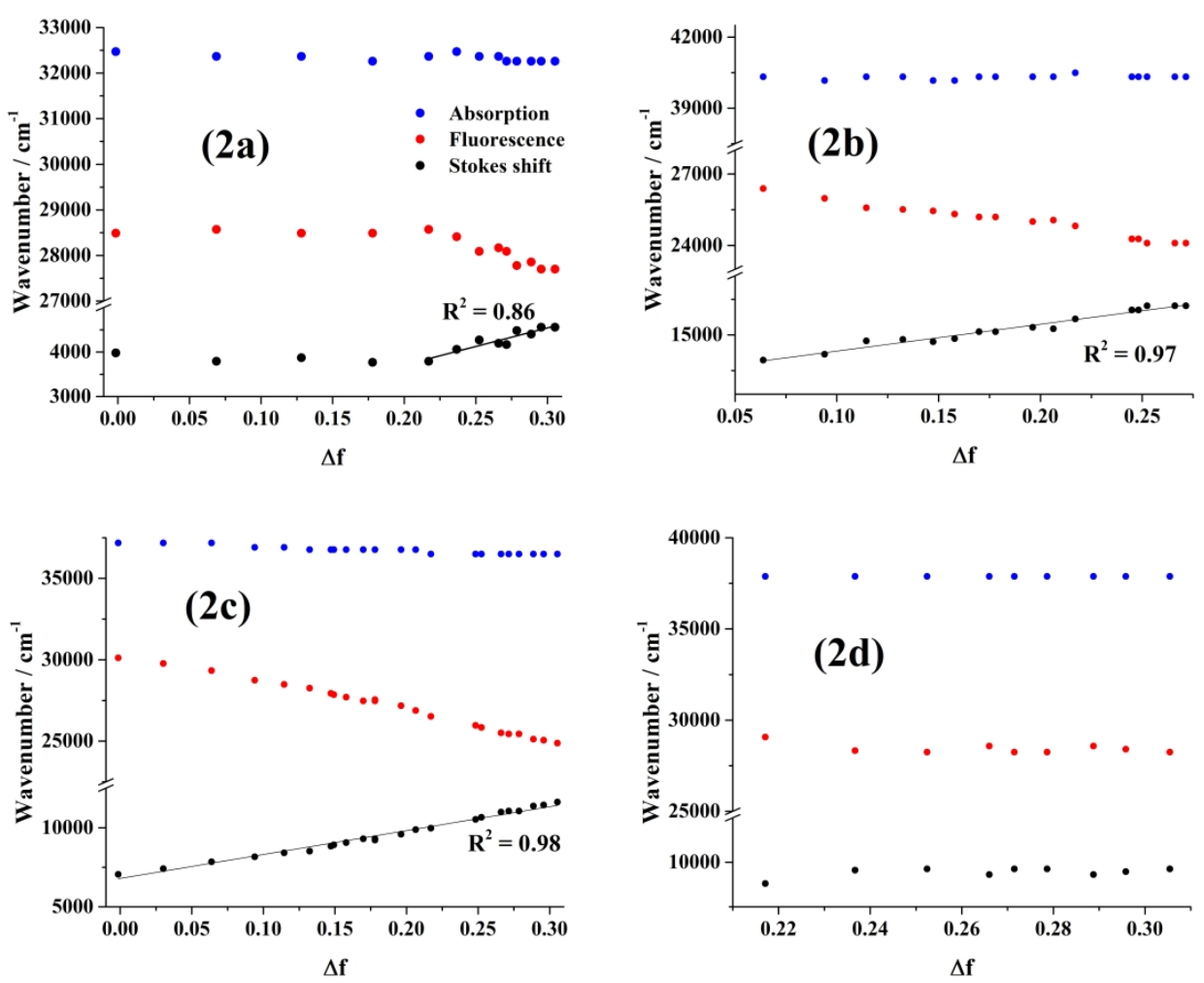

Figure 6. Lippert-Mataga plots of compounds 2a-d.

$513 \times 414 \mathrm{~mm}(300 \times 300$ DPI $)$ 


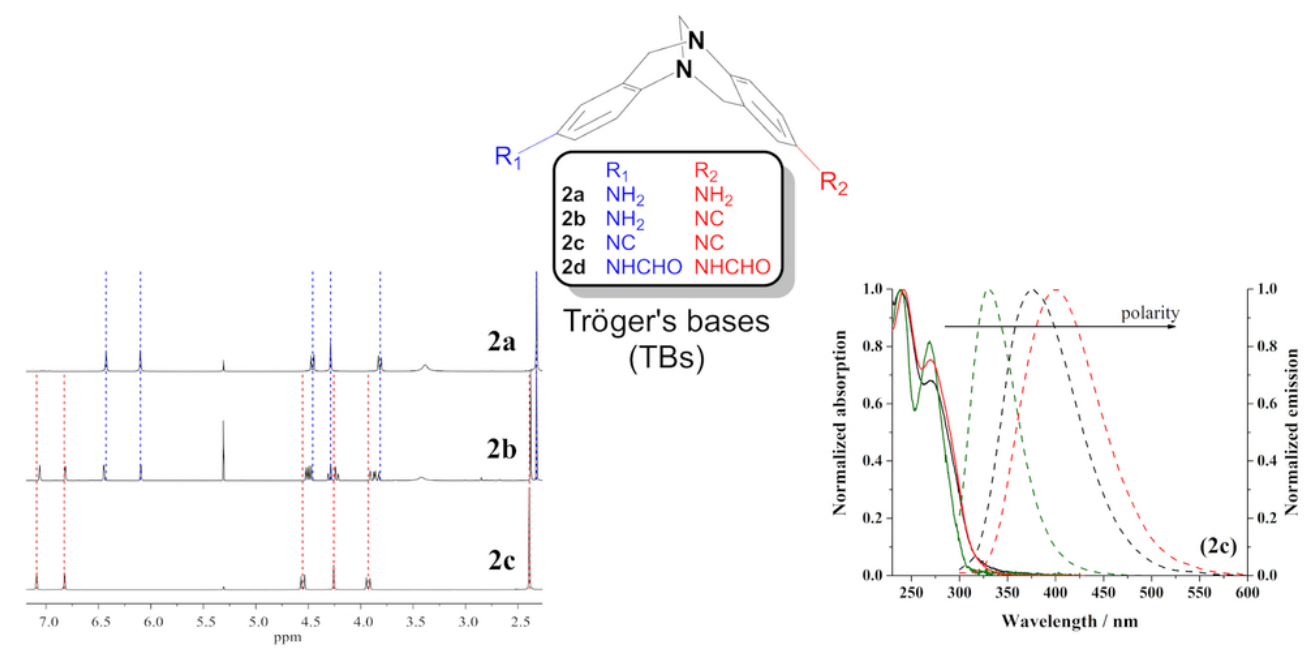

$84 \times 42 \mathrm{~mm}(300 \times 300$ DPI $)$ 
Manuscript ID NJ-ART-04-2020-001988

Title: Simple dissymmetrical and asymmetrical Tröger's Bases: Photophysical and structural characterization

Table of Contents

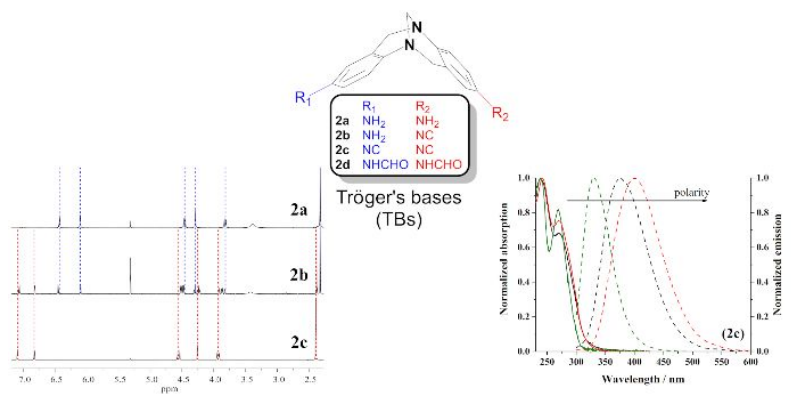

Four TBs were studied by NMR, IR and optical spectroscopies, observing solvatochromic effects and communication between the asymmetric molecule's extremes 
Electronic Supplementary Information (ESI)

\title{
Simple dissymmetrical and asymmetrical Tröger's Bases: Photophysical and structural characterization
}

\author{
Leandro Trupp ${ }^{a b c d}$ Andrea C. Bruttomesso ${ }^{t c d}$ and Beatriz C. Barja*ab \\ a Departamento de Química Inorgánica, Analítica y Química Física \\ Facultad de Ciencias Exactas y Naturales, Universidad de Buenos Aires \\ Int. Güiraldes 2160, Ciudad Universitaria, Buenos Aires, 1428, Argentina \\ E-mail: barja@qi.fcen.uba.ar \\ b Instituto de Química Física de los Materiales, Medio Ambiente y Energía (INQUIMAE) \\ CONICET - Universidad de Buenos Aires \\ Int. Güiraldes 2160, Ciudad Universitaria, Buenos Aires, 1428, Argentina \\ E-mail: barja@qi.fcen.uba.ar \\ Departamento de Química Orgánica \\ Facultad de Ciencias Exactas y Naturales, Universidad de Buenos Aires \\ Int. Güiraldes 2160, Ciudad Universitaria, Buenos Aires, 1428, Argentina \\ d Unidad de Microanálisis y Métodos Físicos Aplicados a Química Orgánica (UMYMFOR) \\ CONICET - Universidad de Buenos Aires \\ Int. Güiraldes 2160, Ciudad Universitaria, Buenos Aires, 1428, Argentina \\ $+\quad$ Deceased, $25^{\text {th }}$ august 2018
}

\section{Contents}

1. Experimental procedures and characterization data $\quad$ S2

2. NMR spectra of $\mathbf{2 b} \quad$ S7

3. Comparison of NMR spectra of $\mathbf{2} \mathbf{b}$ with $\mathbf{2 a}$ and $\mathbf{2 c} \quad \mathrm{S} 10$

4. IR spectra assignment of $\mathbf{2 a - d} \quad$ S11

5. Photophysical data of the UV-vis spectra of $2 a-d \quad S 12$

6. Lifetime measurements of $\mathbf{2 a - c}$ in acetonitrile S13

7. Parameters of the Lippert-Mataga plots of $\mathbf{2 a - c} \quad$ S15 


\section{Experimental procedures and characterization data}

\section{General remarks}

All reagents and solvents were purchased from commercial suppliers and used without further purification. All compounds were characterized by ${ }^{1} \mathrm{H}$ and ${ }^{13} \mathrm{C}$ Nuclear Magnetic Resonance (NMR) spectroscopy using a Bruker Avance II 500 or a Bruker $600 \mathrm{MHz}$ spectrometer. ${ }^{1} \mathrm{H}$ NMR and ${ }^{13} \mathrm{C}$ NMR spectra were supplemented by $2 \mathrm{D}$ gradient selected correlation spectroscopy (COSY), multiplicityedited heteronuclear single quantum coherence (HSQC), heteronuclear multiple bond correlation (HMBC) and phase sensitive nuclear Overhauser effect spectroscopy (NOESYPH) experiments to help with the assignment of signals. All NMR spectra were processed using the MestReNova software. Chemical shifts $(\delta)$ are given in ppm downfield from TMS as the internal standard and coupling constant $(\mathrm{J})$ values are given in $\mathrm{Hz}$. Splitting patterns are abbreviated as follows: singlet (s), doublet (d), multiplet (m), broad singlet (b.s.), doublet of doublets (dd) and complex signal (c.s., mixture of different conformer's peaks that are not possible to integrate separately). ESI-Q-TOFMS measurements were performed with a Bruker micrOTOF-Q II mass spectrometer running in the positive ion mode at $4.5 \mathrm{kV}$ at a desolvation temperature of $200^{\circ} \mathrm{C}$. Fourier transform infrared spectra were recorded on a FTIR Nicolet 8700 in ATR mode.

\section{General procedure and characterization of compounds 2-3}

\section{4,10-dimethyl-2,8-dinitro-6H,12H-5,11-methanodibenzo $[b, f][1,5]$ diazocine (3): 2-methyl-4-} nitroaniline (10.0 g, $0.066 \mathrm{~mol}$ ) was dissolved in trifluoroacetic acid (TFA, $80 \mathrm{ml}$ ) previously cooled in an ice bath and paraformaldehyde $(4.77 \mathrm{~g}, 0.16 \mathrm{~mol})$ was added in portions. The reaction mixture was allowed to reach ambient temperature and was kept with stirring for $48 \mathrm{~h}$ and finally poured into water. The resulting suspension was basified to $\mathrm{pH} 9$ with $\mathrm{NaOH} 20 \%$ and the yellow solid was filtered and resuspended in hot acetone for $20 \mathrm{~min}$. After cooling, the mixture was kept at $-20^{\circ} \mathrm{C}$ for $16 \mathrm{~h}$ and afterwards the solid product was filtered and dried ( $9.79 \mathrm{~g}, 0.029 \mathrm{~mol}, 87 \%$ ). The crude product was pure according to NMR spectroscopic analysis. ${ }^{1}$

${ }^{1} \mathrm{H}$ NMR $\left(600 \mathrm{MHz}, \mathrm{DMSO}-\mathrm{d}_{6}\right): \delta 7.97(\mathrm{~s}, 2 \mathrm{H}, \mathrm{H}-3 / 9), 7.82(\mathrm{~s}, 2 \mathrm{H}, \mathrm{H}-1 / 7), 4.68(\mathrm{~d}$, Jendo,exo $=17.3 \mathrm{~Hz}$, $\left.2 \mathrm{H}, \mathrm{H}-6 / 12_{\text {exo }}\right), 4.37\left(\mathrm{~s}, 2 \mathrm{H}, \mathrm{NCH}_{2} \mathrm{~N}\right), 4.32$ (d, Jendo,exo $\left.=17.3 \mathrm{~Hz}, 2 \mathrm{H}, \mathrm{H}-6 / 12_{\text {endo }}\right), 2.48\left(\mathrm{~s}, 6 \mathrm{H}, \mathrm{CH}_{3}\right)$. ${ }^{13} \mathrm{C}$ NMR (150 MHz, DMSO-d $)$ : $\delta 152.5$ (C-4A/10A), 143.2 (C-2/8), 135.0 (C-4/10), 129.8 (C-1A/7A), 
123.9 (C-1/7), 120.8 (C-3/9), $66.6\left(\mathrm{NCH}_{2} \mathrm{~N}\right), 54.5(\mathrm{C}-6 / 12), 17.3\left(\mathrm{CH}_{3}\right)$. HRMS (ESI): m/z calcd. for $\mathrm{C}_{17} \mathrm{H}_{17} \mathrm{~N}_{4} \mathrm{O}_{4}^{+}$: $341.1244[M+\mathrm{H}]^{+}$; found 341.1259.

\section{4,10-dimethyl-6H,12H-5,11-methanodibenzo $[b, f][1,5]$ diazocine-2,8-diamine (2a): Dinitro-TB 3} $(1.44 \mathrm{~g}, 4.2 \mathrm{mmol})$ and iron powder $(4.76 \mathrm{~g}, 85.3 \mathrm{mmol})$ were suspended in ethanol $(50 \mathrm{ml})$ and acetic acid $(7.0 \mathrm{ml}, 122.5 \mathrm{mmol})$ was added. The mixture was refluxed for $18 \mathrm{~h}$ under nitrogen atmosphere, was poured into water and the excess iron powder was filtered. The aqueous solution was extracted with dichloromethane and the organic phase was washed with sat. aq. $\mathrm{NaHCO}_{3}$ and water, dried over $\mathrm{Na}_{2} \mathrm{SO}_{4}$ and evaporated to dryness. A white solid was obtained, which was pure according to NMR spectroscopic analysis (1.18 g, $4.2 \mathrm{mmol}, 99 \%){ }^{1}$

${ }^{1} \mathrm{H}$ NMR $\left(600 \mathrm{MHz}, \mathrm{CDCl}_{3}\right): \delta 6.41$ (d, $\left.\mathrm{J}_{1,3 / 7,9}=2.0 \mathrm{~Hz}, 2 \mathrm{H}, \mathrm{H}-3 / 9\right), 6.09$ (d, $\left.\mathrm{J}_{1,3 / 7,9}=2.0 \mathrm{~Hz}, 2 \mathrm{H}, \mathrm{H}-1 / 7\right)$, $4.45\left(\mathrm{~d}, \mathrm{~J}_{\text {endo,exo }}=16.7 \mathrm{~Hz}, 2 \mathrm{H}, \mathrm{H}-6 / 12_{\text {exo }}\right), 4.27\left(\mathrm{~s}, 2 \mathrm{H}, \mathrm{NCH}_{2} \mathrm{~N}\right), 3.80(\mathrm{~d}$, Jendo,exo $=16.7 \mathrm{~Hz}, 2 \mathrm{H}, \mathrm{H}-$ 6/12 endo), 3.37 (b.s., $4 \mathrm{H}, \mathrm{NH}_{2}$ ), 2.31 (s, $6 \mathrm{H}, \mathrm{CH}_{3}$ ). ${ }^{13} \mathrm{C} \mathrm{NMR} \mathrm{(150} \mathrm{MHz,} \mathrm{CDCl} 3$ ): $\delta 142.3$ (C-2/8), 137.7 (C-4A/10A), 133.8 (C-4/10), 129.0 (C-1A/7A), 116.3 (C-3/9), 110.4 (C-1/7), $68.1\left(\mathrm{NCH}_{2} \mathrm{~N}\right), 55.4$ (C6/12), $17.0\left(\mathrm{CH}_{3}\right)$. IR (neat): $v^{\sim}=3417$ (w), 3318 (w), 3203 (w) cm $\mathrm{cm}^{-1}(\mathrm{NH})$. HRMS (ESI): m/z calcd. for $\mathrm{C}_{17} \mathrm{H}_{21} \mathrm{~N}_{4}^{+}: 281.1761[\mathrm{M}+\mathrm{H}]^{+}$; found 281.1759.

\section{8-isocyano-4,10-dimethyl-6H,12H-5,11-ethanodibenzo[b,f][1,5] diazocin-2-amine (2b): Diamino-} TB 2a $(0.20 \mathrm{~g}, 0.71 \mathrm{mmol})$ was suspended in chloroform/ethanol 3:1 $(1.3 \mathrm{ml})$ and a solution of potassium hydroxide $(0.44 \mathrm{~g}, 7.9 \mathrm{mmol})$ in water $(2.0 \mathrm{ml})$ was slowly added. The suspension was refluxed for $6 \mathrm{~h}$ and afterwards the reaction mixture was diluted with dichloromethane, washed with water, dried over $\mathrm{Na}_{2} \mathrm{SO}_{4}$ and evaporated to dryness. The crude product was purified using column chromatography on aluminium oxide $\left(\mathrm{CH}_{2} \mathrm{Cl}_{2}\right.$ : petroleum ether). A white solid was obtained, which was pure according to NMR spectroscopic analysis ( $8 \mathrm{mg}, 0.03 \mathrm{mmol}, 4 \%$ ).

${ }^{1} \mathrm{H}$ NMR $\left(500 \mathrm{MHz}, \mathrm{CDCl}_{3}\right): \delta 7.06(\mathrm{~s}, 1 \mathrm{H}, \mathrm{H}-9), 6.82(\mathrm{~s}, 1 \mathrm{H}, \mathrm{H}-7), 6.45\left(\mathrm{~d}, 1 \mathrm{H}, \mathrm{J}_{1,3}=2.3 \mathrm{~Hz}, \mathrm{H}-3\right)$, $6.10\left(\mathrm{~d}, 1 \mathrm{H}, \mathrm{J}_{1,3}=2.3 \mathrm{~Hz}, \mathrm{H}-1\right), 4.51\left(\mathrm{~d}, 1 \mathrm{H}, \mathrm{J}_{\text {endo,exo }}=16.5 \mathrm{~Hz}, \mathrm{H}-12_{\text {exo }}\right), 4.49\left(\mathrm{~d}, 1 \mathrm{H}, \mathrm{J}_{\text {endo,exo }}=17.0\right.$ $\left.\mathrm{Hz}, \mathrm{H}-6_{\text {exo }}\right), 4.30\left(\mathrm{dd}, 1 \mathrm{H}, \mathrm{J}_{\mathrm{A}, \mathrm{B}}=12.6 \mathrm{~Hz}, \mathrm{~J}_{\mathrm{B}, 6-\text { endo }}=1,7 \mathrm{~Hz}, \mathrm{H}-\mathrm{NCH}_{\mathrm{AB}} \mathrm{N}\right), 4.23\left(\mathrm{dd}, 1 \mathrm{H}, \mathrm{J}_{\mathrm{A}, \mathrm{B}}=12.6 \mathrm{~Hz}\right.$, $\mathrm{J}_{\mathrm{A}, 12 \text {-endo }}=1,5 \mathrm{~Hz}, \mathrm{H}-\mathrm{NCH}_{\underline{\mathrm{AB}}} \mathrm{N}$ ), $3.89\left(\mathrm{dd}, 1 \mathrm{H}\right.$, Jendo,exo $=17.0 \mathrm{~Hz}, \mathrm{~J}_{\mathrm{B}, 6-\text { endo }}=1.7 \mathrm{~Hz}, \mathrm{H}-6_{\text {endo }}$ ), 3.84 (dd, 1 $\mathrm{H}, \mathrm{J}_{\text {endo,exo }}=16.5 \mathrm{~Hz}, \mathrm{~J}_{\mathrm{A}, 12-\text { endo }}=1,5 \mathrm{~Hz}, \mathrm{H}-12_{\text {endo }}$ ), 3.42 (b.s., $2 \mathrm{H}, \mathrm{NH}_{2}$ ), 2.38 (s, $\left.3 \mathrm{H}, \mathrm{C}_{10} \mathrm{C}_{\mathrm{H}_{3}}\right), 2.32$ (s, 3 $\mathrm{H}, \mathrm{C}_{4} \mathrm{CH}_{3}$ ). ${ }^{13} \mathrm{C} \mathrm{NMR}\left(125 \mathrm{MHz}, \mathrm{CDCl}_{3}\right.$ ): $\delta 162.5$ (CN), 147.5 (C-10A), 142.6 (C-2), 136.9 (C-4A), 134.5 (C-10), 134.1 (C-4), 129.7 (C-7A), 128.2 (C-1A), 126.5 (C-9), 122.5 (C-7), 121.7 (C-8), 116.6 (C-3), $\left.110.0(\mathrm{C}-1), 67.6\left(\mathrm{NCH}_{2} \mathrm{~N}\right), 55.1(\mathrm{C}-6), 55.0(\mathrm{C}-12), 17.0\left(\mathrm{C}_{4} \mathrm{C}_{3}\right), 16.9\left(\mathrm{C}_{10} \mathrm{C}_{3}\right)_{3}\right) . \mathrm{IR}$ (neat): v $=3438$ 
(w), 3348 (w), 3226 (w) cm $\mathrm{cm}^{-1}(\mathrm{NH}) ; 2125$ (m) cm $\mathrm{cm}^{-1}$ (NC). HRMS (ESI): m/z calcd. for $\mathrm{C}_{18} \mathrm{H}_{19} \mathrm{~N}_{4}{ }^{+}$: $291.3775[\mathrm{M}+\mathrm{H}]^{+}$; found 291.1616.

\section{$N, N^{\prime}-(4,10-$ dimethyl-6H,12H-5,11-methanodibenzo[b,f][1,5]diazocine-2,8-diyl)diformamide (2d):} Acetic formic anhydride was obtained by stirring a mixture of formic acid $(1.3 \mathrm{~mL}, 35 \mathrm{mmol})$ and acetic anhydride $(2.2 \mathrm{~mL}, 23 \mathrm{mmol})$ at $60^{\circ} \mathrm{C}$ for $3 \mathrm{~h}$. This mixture was added dropwise to a solution of diamino-TB 2a $(0,26 \mathrm{~g}, 0.92 \mathrm{mmol})$ and triethylamine $(1,0 \mathrm{~mL})$ in $10 \mathrm{~mL}$ of THF, and the reaction mixture was stirred at room temperature for $24 \mathrm{~h}$. The solution was diluted with ethyl acetate (50 $\mathrm{mL}$ ), washed successively with sat. aq. $\mathrm{KHCO}_{3}$, brine and water, dried over $\mathrm{Na}_{2} \mathrm{SO}_{4}$ and then concentrated under reduced pressure to give a yellow solid $(0.30 \mathrm{~g}, 0.89 \mathrm{mmol}, 96 \%)$. The crude product was pure according to NMR spectroscopic analysis. Further purification using column chromatography on silica gel $\left(\mathrm{CH}_{2} \mathrm{Cl}_{2}: \mathrm{MeOH}\right)$ afforded a white solid. ${ }^{1}$

${ }^{1} \mathrm{H}$ NMR $(500 \mathrm{MHz}, \mathrm{CDCl} 3$ ) $\delta$ 8,52-8,47 (c.s., $1 \mathrm{H}, \mathrm{CHO}, E), 8,29$ (s, $1 \mathrm{H}, \mathrm{CHO}$, Z), 8,02-7,92 (c.s., $1 \mathrm{H}$, $\mathrm{NH}, E), 7,17-7,13$ (m, $1 \mathrm{H}, \mathrm{H}-1 / 7, \mathrm{Z}), 7,06-7,02$ (m, $1 \mathrm{H}, \mathrm{H}-3 / 9, \mathrm{Z}), 7,01$ (b.s., $1 \mathrm{H}, \mathrm{NH}, \mathrm{Z})$, 6,81-6,76 (c.s., $1 \mathrm{H}, \mathrm{H}-3 / 9, E), 6,52-6,47$ (m, $1 \mathrm{H}, \mathrm{H}-1 / 7, E), 4,58-4,50$ (c.s., $\left.2 \mathrm{H}, \mathrm{H}-6 / 12_{\text {exo }}\right), 4,28$ (s, $2 \mathrm{H}$, $\mathrm{NCH}_{2} \mathrm{~N}$ ), 3,97-3,89 (c.s., $2 \mathrm{H}, \mathrm{H}-6 / 12$ endo), 2,41-2,36 (c.s., $\left.6 \mathrm{H}, \mathrm{CH}_{3}\right) .{ }^{13} \mathrm{C} \mathrm{NMR}\left(125 \mathrm{MHz}, \mathrm{CDCl}_{3}\right) \delta$ 162,8 / 162,7 (CHO, E), 158,7 / 158,7 (CHO, Z), 143,6 / 143,4 (C-4A/10A, E), 142,8 / 142,7 (C-4A/10A, Z), 134,9 / 134,9 (C-4/10, E), 133,9 / 133,92 (C-4/10, Z), 132,5 / 132,4 / 132,2 / 132,1 (C-1A/7A, E / Z), 129,4 / 129,3 (C-2/8, Z), 128,7 / 128,6 (C-2/8, E), 120,8 / 120,7 (C-3/9, Z), 120,3 / 120,2 (C-3/9, E), 116,2 / 116,1 (C-1/7, Z), 115,1 / 115,0 (C-1/7, E), 67,6 / 67,6 / 67,5 ( $\mathrm{NCH}_{2} \mathrm{~N}, E$ / Z), 55,2 (C-6/12, Z), 55,1 (C-6/12, E), 17,1 / 17,1 ( $\mathrm{CH}_{3}, E$ / Z). Approx. Z / E overall ratio: 50:50. IR (neat): v = $3298(\mathrm{w})$ (NH); 1660 (s) cm ${ }^{-1}$ (CO). HRMS (ESI): m/z calcd. for $\mathrm{C}_{19} \mathrm{H}_{21} \mathrm{~N}_{4} \mathrm{O}_{2}^{+}$: $337.1659[\mathrm{M}+\mathrm{H}]^{+}$; found 337.1670.

\section{2,8-Diisocyano-4,10-dimethyl-6H,12H-5,11-methanodibenzo[b,f][1,5]}

diazocine

(2c):

Diformamido-TB 2d (63 mg, $0.19 \mathrm{mmol})$ and triethylamine $(0.25 \mathrm{ml})$ were dissolved in dichloromethane $(5 \mathrm{ml})$ and phosphorus oxychloride $(0.05 \mathrm{ml}, 0.53 \mathrm{mmol})$ in $1 \mathrm{ml}$ dichloromethane was added slowly in an ice bath. After $15 \mathrm{~min}$ at $0^{\circ} \mathrm{C}$ no reacting material was observed by TLC, and the reaction mixture was diluted with $100 \mathrm{ml}$ cyclohexane, washed with water and dried over $\mathrm{Na}_{2} \mathrm{SO}_{4}$. A white solid was obtained by evaporation of the solvent, which was pure according to NMR spectroscopic analysis (56 mg, $0.19 \mathrm{mmol}, 100 \%)$.

${ }^{1} \mathrm{H}$ NMR (500 MHz, CDCl $): \delta 7.09$ (d, $\left.\mathrm{J}_{1,3 / 7,9}=1.5 \mathrm{~Hz}, 2 \mathrm{H}, \mathrm{H}-3 / 9\right), 6.82\left(\mathrm{~d}, \mathrm{~J}_{1,3 / 7,9}=1.5 \mathrm{~Hz}, 2 \mathrm{H}, \mathrm{H}-1 / 7\right)$, $4.55\left(\mathrm{~d}, \mathrm{~J}_{\text {endo,exo }}=17.0 \mathrm{~Hz}, 2 \mathrm{H}, \mathrm{H}-6 / 12_{\text {exo }}\right), 4.26\left(\mathrm{~s}, 2 \mathrm{H}, \mathrm{NCH}_{2} \mathrm{~N}\right), 3.93(\mathrm{~d}$, Jendo,exo $=17.0 \mathrm{~Hz}, 2 \mathrm{H}, \mathrm{H}-$ 
6/12 endo), 2.41 (s, $6 \mathrm{H}, \mathrm{CH}_{3}$ ). ${ }^{13} \mathrm{C}$ NMR (125 MHz, CDCl 3 ): $\delta 163.0$ (NC), 146.7 (C-4A/10A), 134.8 (C4/10), 128.9 (C-1A/7A), 126.9 (C-3/9), 122.4 (C-1/7), 122.2 (C-2/8), $67.1\left(\mathrm{NCH}_{2} \mathrm{~N}\right), 54.6(\mathrm{C}-6 / 12)$, $17.0\left(\mathrm{CH}_{3}\right)$. IR (neat): $\mathrm{v}^{\sim}=2123(\mathrm{~s}) \mathrm{cm}^{-1}(\mathrm{NC}) . \mathrm{HRMS}(\mathrm{ESI}): \mathrm{m} / \mathrm{z}$ calcd. for $\mathrm{C}_{19} \mathrm{H}_{17} \mathrm{~N}_{4}^{+}: 301.1448[\mathrm{M}+\mathrm{H}]^{+}$; found 301.1444 .

\section{Photophysical measurements}

UV-vis absorption spectra were measured using a Shimadzu UV-3600 spectrophotometer in 1.00 $\mathrm{cm}$ optical pass quartz cuvettes with teflon caps. Baselines were obtained with pure solvents, slow spectral acquisition speed and $1 \mathrm{~nm}$ of spectral width. Concentrations were adjusted so that absorbances resulted of $0.05-0.40$, in order to obtain acceptable signal/noise ratios and to minimize inner filter effects. Molar absorptivities were obtained from Lambert-Beer plots in each solvent. Even though the standard deviations associated to the linear regressions are lower, a $3 \%$ error is estimated due to solution preparation.

Emission and excitation spectra were obtained using a PTI QuantaMaster QM4 spectrofluorometer in $1.00 \mathrm{~cm}$ optical pass fluorescence quartz cuvettes with teflon caps in right angle geometry. Appropriate excitation and emission wavelengths were chosen for each case, and emission filters were used when necessary. Spectra were acquired with $0.2 \mathrm{~s}$ integration time and $1 \mathrm{~nm}$ steps. Slits were adjusted between 0.25 and $1.00 \mathrm{~mm}$ in order to obtain adequate signal/noise ratios but avoiding saturation of detection. Emission spectra were corrected using the mathematical function provided by the instrumental software.

Fluorescence quantum yield determination was performed using the relative method according to the guidelines suggested by the International Union of Pure and Applied Chemistry (IUPAC) and by Rurak. ${ }^{2,3}$ Low absorbance $(A<0.1)$ solutions were used to avoid inner filter effects and errors produced by an uneven distribution of excited species in the detection volume. In every case the same cuvette was used for sample and reference and the excitation was performed at a wavelength were both compounds presented significant absorption and that allowed full registration of their emission spectra. If possible, an absorption maximum (or minimum) was chosen. Naphthalene in cyclohexane was the selected reference for compounds $\mathbf{2 a}, \mathbf{2 c}$ and $\mathbf{2 d}$, and phenanthrene in ethanol was chosen for $\mathbf{2} \mathbf{b} .{ }^{4,5}$ Quantum yields were obtained from the slope of the linear regression of the graph of the integrated emission intensity v. $1-10^{-A(\lambda)}$, where $A(\lambda)$ is the absorbance at the excitation wavelength. At least four spectra for different absorbances in the $0-0.1$ range were obtained, in 
order to remove spurious light influence and to guarantee emission linearity with respect to absorption.

Fluorescence lifetimes were measured using the TCSPC technique in a HORIBA Jobin Yvon IBH spectrofluorometer equipped with a NanoLED HORIBA Jobin Yvon $282 \mathrm{~nm}$ laser diode with <100 ps pulse width and $1 \mathrm{MHz}$ repetition frequency. The excitation monochromator was set in $282 \mathrm{~nm}$ and the emission monochromator was adjusted for each sample and solvent at its maximum fluorescence wavelength. Slits were set at their maximum aperture in both cases and a WG305 filter and a polarizer in the magic angle were used. Acquisition was performed with a Picosecond Photon Detection Module IBH TBX-04 (1024 channels, 55 ps/channel). The pulse was obtained using a scattering glass set at $45^{\circ}$ instead of the sample with the excitation monochromator set at $287 \mathrm{~nm}$ and with slits fixed to avoid saturation of detection. Once the pulse and decays were registered, deconvolutions were performed using the DAS6 v6.3 - HORIBA Jobin Yvon software. A nonlinear least square method was employed for the fit of the decay data to a mono-exponential equation (A $+B 1 \exp (t / \tau))$, and the quality of the fit was assessed through the value of $\chi^{2}$ and a visual inspection of the autocorrelation function and the residuals.

\section{References}

1 L. Trupp, S. L. Laurella, M. C. Tettamanzi, B. C. Barja and A. C. Bruttomesso, J. Mol. Struct., 2018, 1157, 434-443.

2 A. M. Brouwer, Pure Appl. Chem., 2011, 83, 2213-2228.

3 U. Resch-Genger and K. Rurack, Pure Appl. Chem., 2013, 85, 2005-2013.

4 K. Suzuki, A. Kobayashi, S. Kaneko, K. Takehira, T. Yoshihara, H. Ishida, Y. Shiina, S. Oishi and S. Tobita, Phys. Chem. Chem. Phys., 2009, 11, 9850-9860.

5 W. R. Dawson and M. W. Windsor, J. Phys. Chem., 1968, 3251, 3251-3260. 
2. NMR spectra of $\mathbf{2} \mathbf{b}$

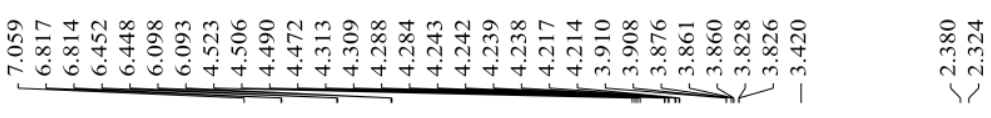

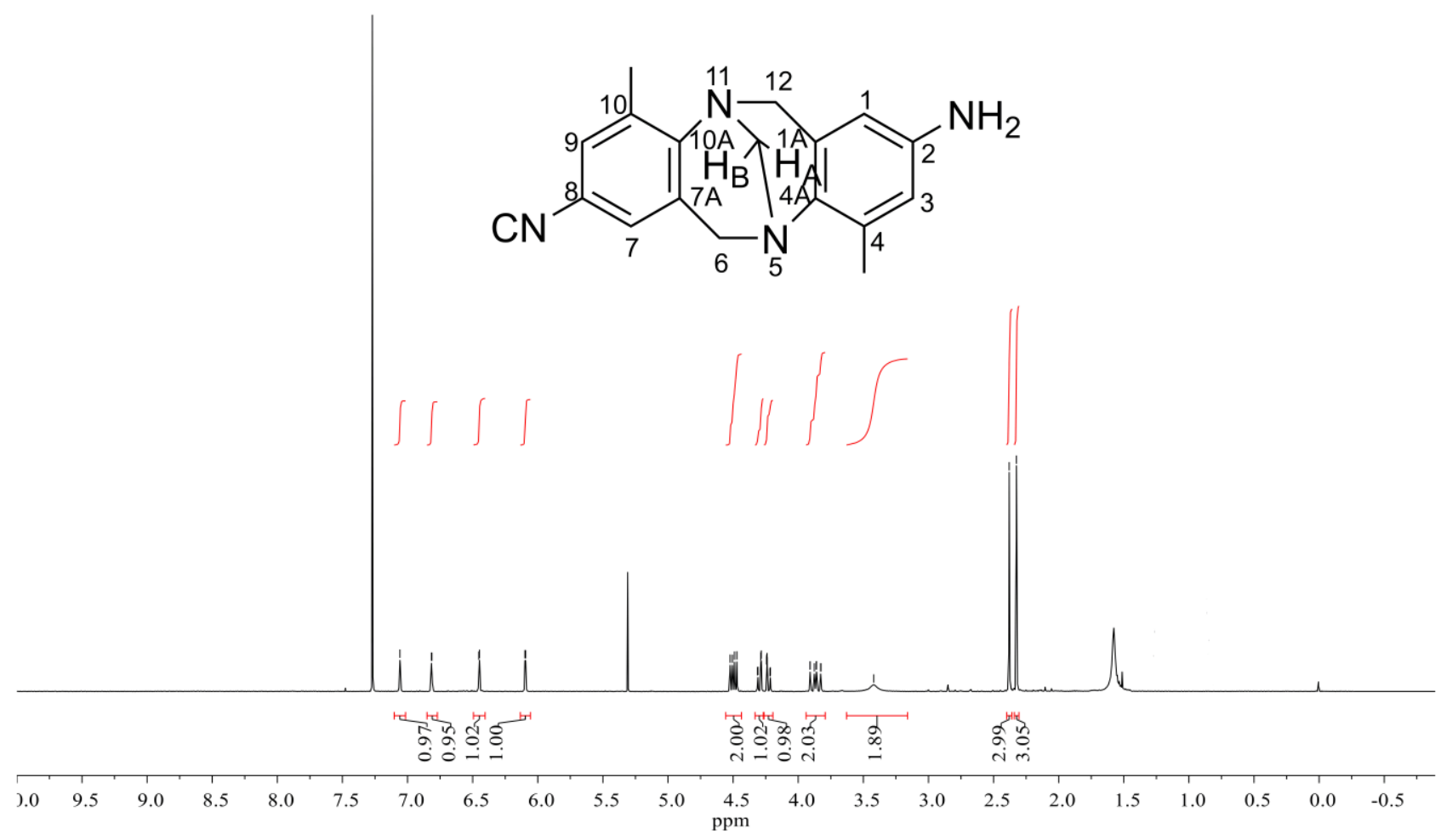

Figure $\mathbf{S 1}$. ${ }^{1} \mathrm{H}$ NMR spectrum of $\mathbf{2 b}$ in $\mathrm{CDCl}_{3}$ at $25^{\circ} \mathrm{C}(500 \mathrm{MHz})$. 


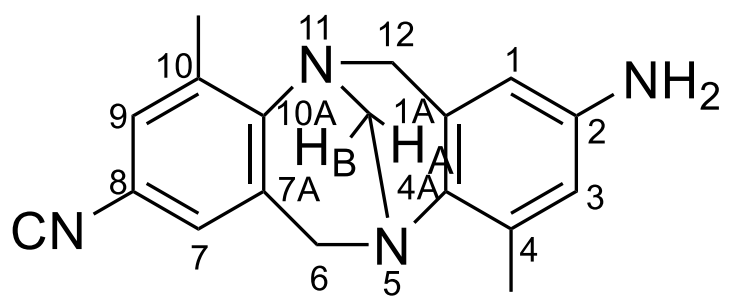

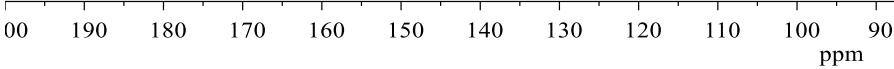

Figure S2. ${ }^{13} \mathrm{C}$ NMR spectrum of $\mathbf{2 b}$ in $\mathrm{CDCl}_{3}$ at $25^{\circ} \mathrm{C}(125 \mathrm{MHz})$.

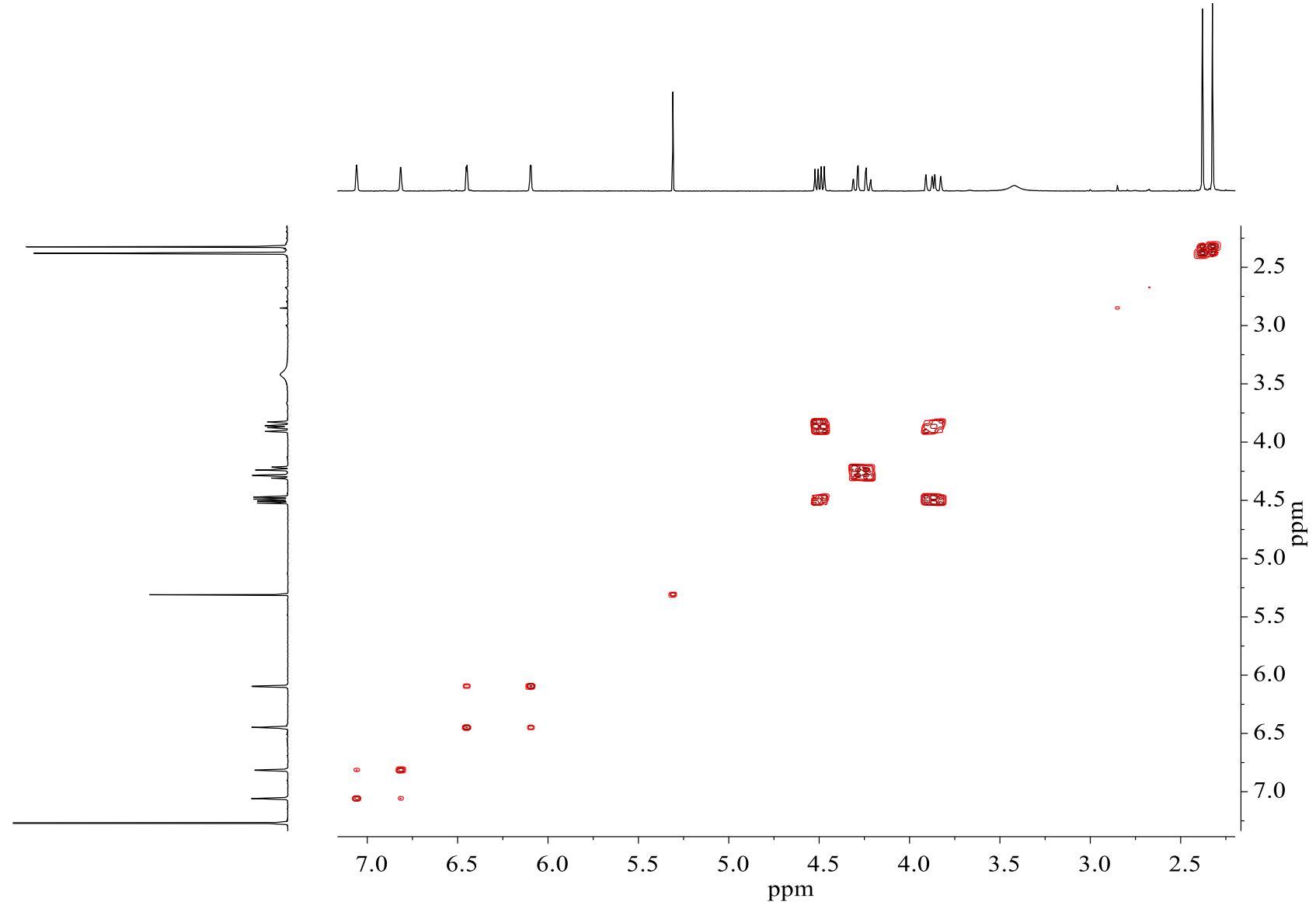

Figure S3. COSY NMR spectrum of $\mathbf{2 b}$ in $\mathrm{CDCl}_{3}$ at $25{ }^{\circ} \mathrm{C}\left(500 \mathrm{MHz}\right.$ for $\left.{ }^{1} \mathrm{H}\right)$. 


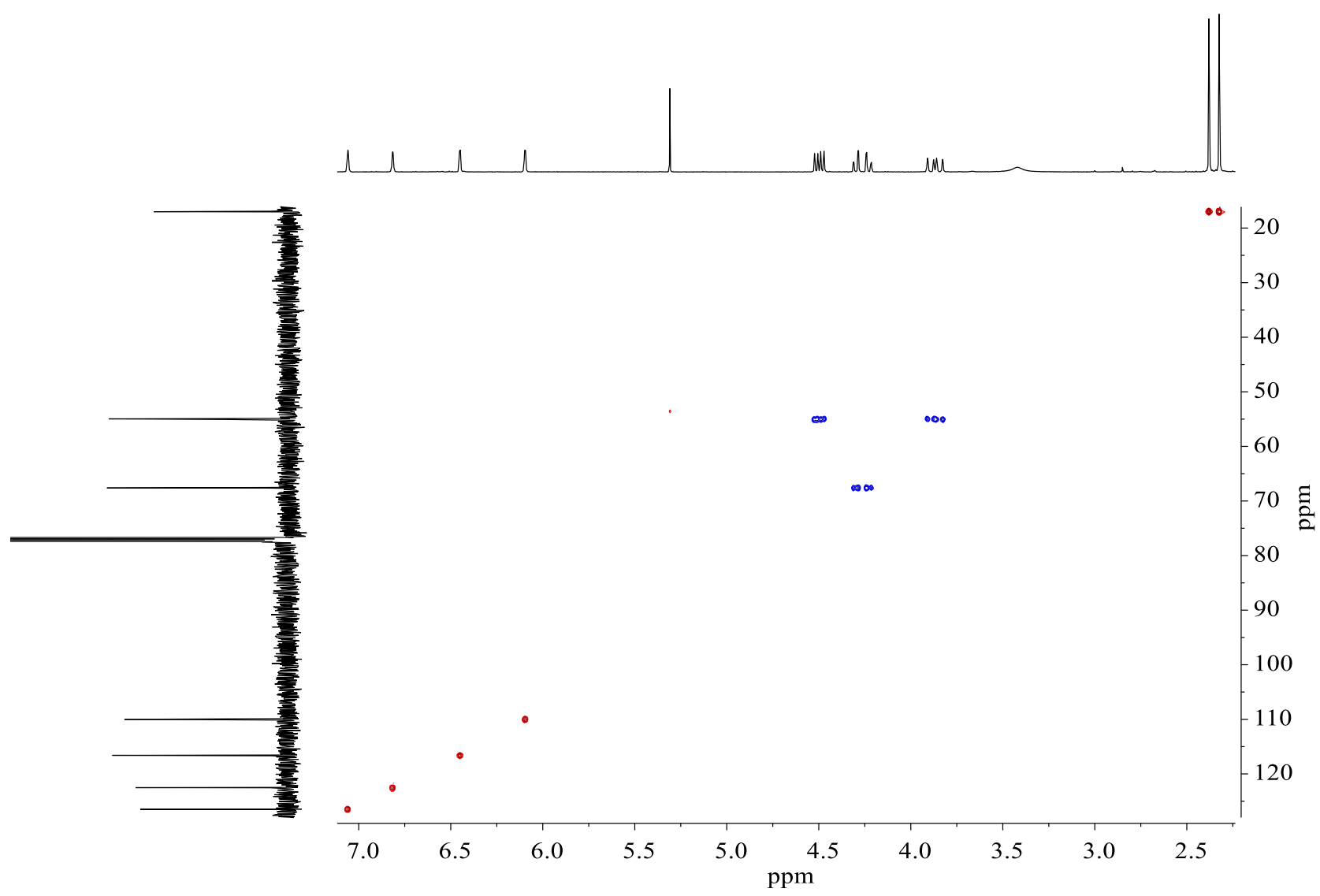

Figure S4. HSQC-DEPT NMR spectrum of $\mathbf{2} \mathbf{b}$ in $\mathrm{CDCl}_{3}$ at $25^{\circ} \mathrm{C}\left(500 \mathrm{MHz}\right.$ for $\left.{ }^{1} \mathrm{H}\right)$.

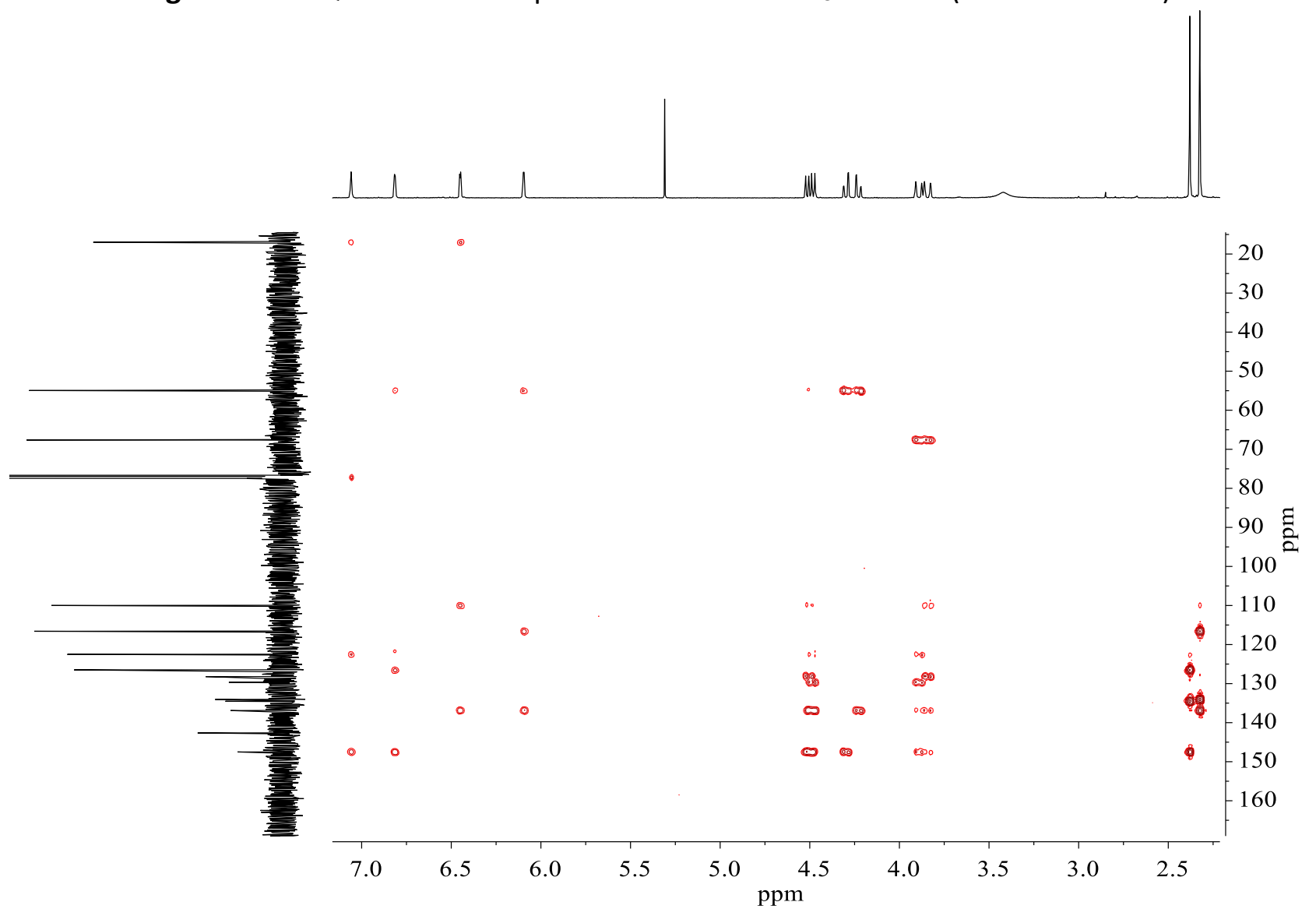

Figure S5. $\mathrm{HMBC}$ NMR spectrum of $\mathbf{2 b}$ in $\mathrm{CDCl}_{3}$ at $25{ }^{\circ} \mathrm{C}\left(500 \mathrm{MHz}\right.$ for $\left.{ }^{1} \mathrm{H}\right)$. 


\section{Comparison of NMR spectra of $\mathbf{2 b}$ with $\mathbf{2 a}$ and $\mathbf{2 c}$}

Table S1. ${ }^{1} \mathrm{H}$ and ${ }^{13} \mathrm{C}$ NMR signals of $2 \mathrm{a}-\mathrm{c}$ and chemical shift difference between the asymmetrical (2b) and dissymmetrical (2a / $\mathbf{2 c}$ ) compounds.

\begin{tabular}{|c|c|c|c|c|c|c|}
\hline & \multicolumn{3}{|c|}{$\delta\left({ }^{1} \mathrm{H}\right) / \mathrm{ppm}$} & \multicolumn{3}{|c|}{$\delta\left({ }^{13} \mathrm{C}\right) / \mathrm{ppm}$} \\
\hline & $2 a / 2 c$ & $2 b$ & $\Delta \delta$ & $2 a / 2 c$ & $2 b$ & $\Delta \delta$ \\
\hline 1 & $6.09^{2 a}$ & 6.10 & 0.01 & $110.4^{2 a}$ & 110.0 & -0.4 \\
\hline 2 & - & - & - & $142.3^{2 a}$ & 142.6 & 0.3 \\
\hline 3 & $6.41^{2 a}$ & 6.45 & 0.04 & $116.3^{2 a}$ & 116.6 & 0.3 \\
\hline 4 & - & - & - & $133.8^{2 a}$ & 134.1 & 0.3 \\
\hline 7 & $6.82^{2 c}$ & 6.82 & 0.00 & $122.4^{2 c}$ & 122.5 & 0.1 \\
\hline 8 & - & - & - & $122.2^{2 c}$ & 121.7 & -0.5 \\
\hline 9 & $7.09^{2 c}$ & 7.06 & -0.03 & $126.9^{2 c}$ & 126.5 & -0.4 \\
\hline 10 & - & - & - & $134.8^{2 c}$ & 134.5 & -0.3 \\
\hline $1 \mathrm{~A}$ & - & - & - & $129.0^{2 a}$ & 128.2 & -0.8 \\
\hline $4 \mathrm{~A}$ & - & - & - & $137.7^{2 a}$ & 136.9 & -0.8 \\
\hline $7 A$ & - & - & - & $128.9^{2 c}$ & 129.7 & 0.8 \\
\hline $10 \mathrm{~A}$ & - & - & - & $146.7^{2 c}$ & 147.5 & 0.8 \\
\hline $6_{\text {endo }}$ & $3.93^{2 c}$ & 3.89 & -0.04 & \multirow{2}{*}{$54.6^{2 c}$} & \multirow{2}{*}{55.0} & \multirow{2}{*}{0.4} \\
\hline $6_{\text {exo }}$ & $4.55^{2 c}$ & 4.49 & -0.06 & & & \\
\hline $12_{\text {endo }}$ & $3.80^{2 a}$ & 3.84 & 0.04 & \multirow{2}{*}{$55.4^{2 a}$} & \multirow{2}{*}{55.1} & \multirow{2}{*}{-0.3} \\
\hline $12_{\text {exo }}$ & $4.45^{2 a}$ & 4.51 & 0.06 & & & \\
\hline \multirow{2}{*}{$\mathrm{NCH}_{2} \mathrm{~N}$} & $4.27^{2 a}$ & 4.23 & -0.04 & $68.1^{2 a}$ & \multirow{2}{*}{67.6} & 0.5 \\
\hline & $4.26^{2 c}$ & 4.30 & 0.04 & $67.1^{2 c}$ & & -0.5 \\
\hline $\mathrm{C}_{10}-\underline{\mathrm{CH}_{3}}$ & $2.41^{2 c}$ & 2.38 & -0.03 & $17.0^{2 c}$ & 16.9 & -0.1 \\
\hline $\mathrm{C}_{4}-\underline{\mathrm{CH}}_{3}$ & $2.31^{2 a}$ & 2.32 & 0.01 & $17.0^{2 a}$ & 17.0 & 0.0 \\
\hline $\mathrm{NH}_{2}$ & $3.37^{2 a}$ & 3.42 & 0.05 & - & - & - \\
\hline NC & - & - & - & $163.0^{2 c}$ & 162.5 & -0.5 \\
\hline
\end{tabular}




\section{IR spectra assignment of $\mathbf{2 a - d}$}

Table S2. IR signals (in $\mathrm{cm}^{-1}$ ) of $\mathbf{2 a - d}$. $v$ : stretching, $\delta$ : in plane deformation, $\gamma$ : out of plane deformation; vs: very strong, s: strong, m: medium, w: weak, vw: very weak, b: broad, ot: overtone, n.d.: not determined

\begin{tabular}{|c|c|c|c|c|}
\hline Assignment & $2 a$ & $2 b$ & 2c & 2d \\
\hline$v_{a} \mathrm{NH}_{2}$ & $3417(w, b)$ & $3438(w, b)$ & - & - \\
\hline$v_{\mathrm{s}} \mathrm{NH}_{2}$ & $\begin{array}{c}3318(w, b) \\
(3203, \text { ot })\end{array}$ & $\begin{array}{c}3348(w, b) \\
(3226, \text { ot })\end{array}$ & - & - \\
\hline$\checkmark \mathrm{NH}$ amide & - & - & - & $\begin{array}{l}3298 \\
(w, b)\end{array}$ \\
\hline$v \mathrm{C}-\mathrm{H}_{\text {aliph. }}$ & $\begin{array}{l}2950,2891 \\
2842(v w, b)\end{array}$ & $\begin{array}{l}2950,2922, \\
2852 \text { (vs, b) }\end{array}$ & $\begin{array}{l}2954,2922, \\
2852(w, b)\end{array}$ & $\begin{array}{c}2942,2885 \\
2843(\mathrm{vw})\end{array}$ \\
\hline$v \mathrm{C}-\mathrm{H}_{\mathrm{arom}}$ & n.d. & n.d. & n.d. & $\begin{array}{c}3194,3134, \\
3072 \text { (vw) }\end{array}$ \\
\hline$v \mathrm{~N} \equiv \mathrm{C}$ & - & $2125(\mathrm{~m})$ & 2123 (s) & - \\
\hline$v \operatorname{CO}(\mathrm{I})$ & - & - & - & $1660(s)$ \\
\hline$\delta \mathrm{NH}_{2}$ & $1612(s, b)$ & $1612(s, b)$ & - & - \\
\hline$\delta-\mathrm{NH}$ - amide & - & - & - & 1608 \\
\hline$\nu \mathrm{C}=\mathrm{C}-\mathrm{C}$ ring range, $\delta \mathrm{CH}_{2}, \mathrm{CH}_{3}$ & $1323-1479$ & $1323-1467$ & 1330-1471 & $1321-1477$ \\
\hline$\delta \mathrm{NH} / v \mathrm{CN}(\mathrm{II})$ & - & - & - & 1547 \\
\hline$\checkmark \mathrm{CN}$ tertiary amine & 1213 & 1213 & 1215 & 1205 \\
\hline$\rho \mathrm{CH}_{3}$ & 1072 & 1072 & 1072 & 1070 \\
\hline$\delta=\mathrm{C}-\mathrm{H}$ & 918 & 914 & 914 & 916 \\
\hline$\gamma=\mathrm{C}-\mathrm{H}$ & 652 & 652 & 652 & 649 \\
\hline$\gamma \mathrm{NH} / \mathrm{CN}$ (amide V) & - & - & - & $712(m, b)$ \\
\hline
\end{tabular}




\section{Photophysical data of the UV-vis spectra of $\mathbf{2 a - d}$}

Table S3. Relevant photophysical data of the UV-vis spectra of TBs 2a-d in different solvents. $\lambda_{\max 1}$ is the wavelength of the principal absorption peak, $\lambda_{\max 2}$ is the wavelength of the red-shifted absorption peak and $\varepsilon_{1}$ and $\varepsilon_{2}$ are the respective molar absorption coefficients.

\begin{tabular}{|c|c|c|c|c|c|}
\hline TB & Solvent & $\lambda_{\max 1} / \mathrm{nm}$ & $\varepsilon_{1}{ }^{[\mathrm{a}]} / \mathrm{M}^{-1} \mathrm{~cm}^{-1}$ & $\lambda_{\max 2} / \mathrm{nm}$ & $\varepsilon_{2}{ }^{[\mathrm{a}]} / \mathrm{M}^{-1} \mathrm{~cm}^{-1}$ \\
\hline \multirow{4}{*}{$2 a$} & Hexane & 247 & {$[b]$} & 308 & [b] \\
\hline & Dichloromethane & 250 & $1.5 \times 10^{4}$ & 310 & $4.1 \times 10^{3}$ \\
\hline & Acetonitrile & 250 & $1.7 \times 10^{4}$ & 310 & $4.2 \times 10^{3}$ \\
\hline & Methanol & 247 & $1.6 \times 10^{4}$ & 304 & $3.7 \times 10^{3}$ \\
\hline \multirow{4}{*}{$2 b$} & Hexane & 250 & {$[b]$} & $292^{[c]}$ & [b] \\
\hline & Dichloromethane & 247 & $1.4 \times 10^{4}$ & $299[c]$ & $4.8 \times 10^{3}$ \\
\hline & Acetonitrile & 250 & $1.6 \times 10^{4}$ & $295^{[c]}$ & $5.3 \times 10^{3}$ \\
\hline & Methanol & 246 & $1.3 \times 10^{4}$ & $286^{[c]}$ & $4.8 \times 10^{3}$ \\
\hline \multirow{4}{*}{ 2c } & Hexane & 239 & [b] & 269 & [b] \\
\hline & Dichloromethane & 243 & $1.6 \times 10^{4}$ & 272 & $1.1 \times 10^{4}$ \\
\hline & Acetonitrile & 242 & $1.4 \times 10^{4}$ & 270 & $1.1 \times 10^{4}$ \\
\hline & Methanol & 241 & $1.3 \times 10^{4}$ & 269 & $9.8 \times 10^{3}$ \\
\hline \multirow{4}{*}{$2 d$} & Hexane & [b] & {$[\mathrm{b}]$} & {$[b]$} & [b] \\
\hline & Dichloromethane & 266 & $2.0 \times 10^{4}$ & - & - \\
\hline & Acetonitrile & 265 & $2.1 \times 10^{4}$ & - & - \\
\hline & Methanol & 263 & $2.2 \times 10^{4}$ & - & - \\
\hline
\end{tabular}

[a] $3 \%$ error is estimated due to sample preparation. [b] Not obtained due to low solubility. [c] Estimated by spectral deconvolution. 
6. Lifetime measurements of $\mathbf{2 a - c}$ in acetonitrile
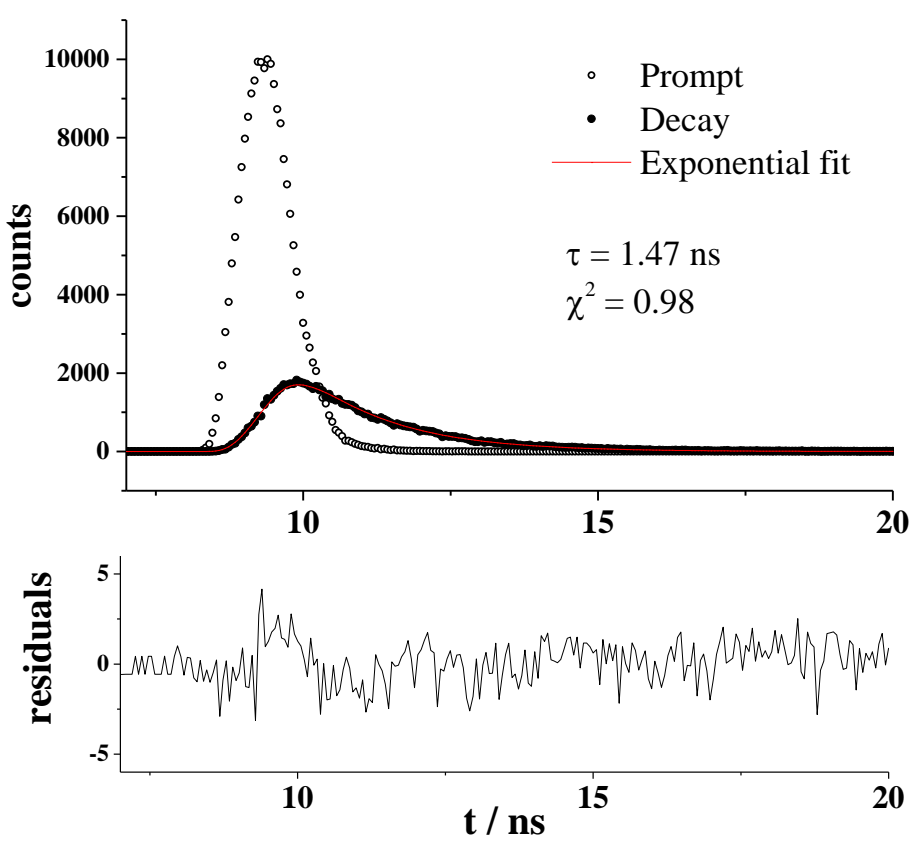

Figure S7. Fluorescence decay of $2 \mathrm{a}$ in acetonitrile $\left(\lambda_{\mathrm{exc}}=282 \mathrm{~nm}, \lambda_{\mathrm{em}}=350 \mathrm{~nm}\right)$
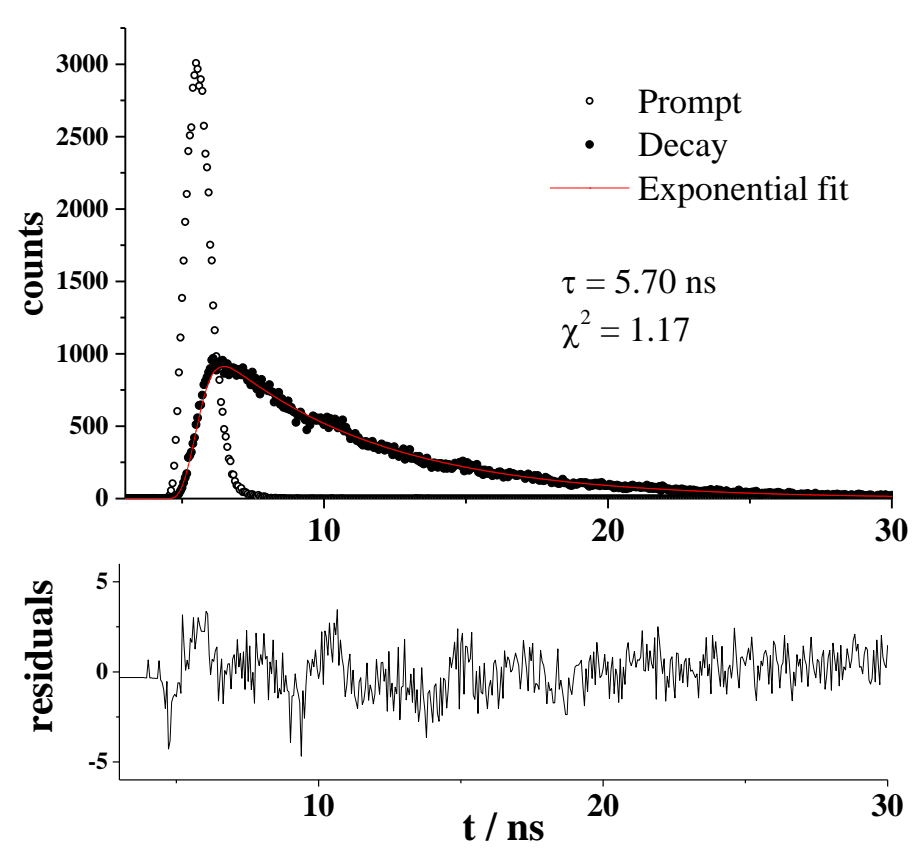

Figure S8. Fluorescence decay of $\mathbf{2 b}$ in acetonitrile $\left(\lambda_{\mathrm{exc}}=282 \mathrm{~nm}, \lambda_{\mathrm{em}}=416 \mathrm{~nm}\right)$ 

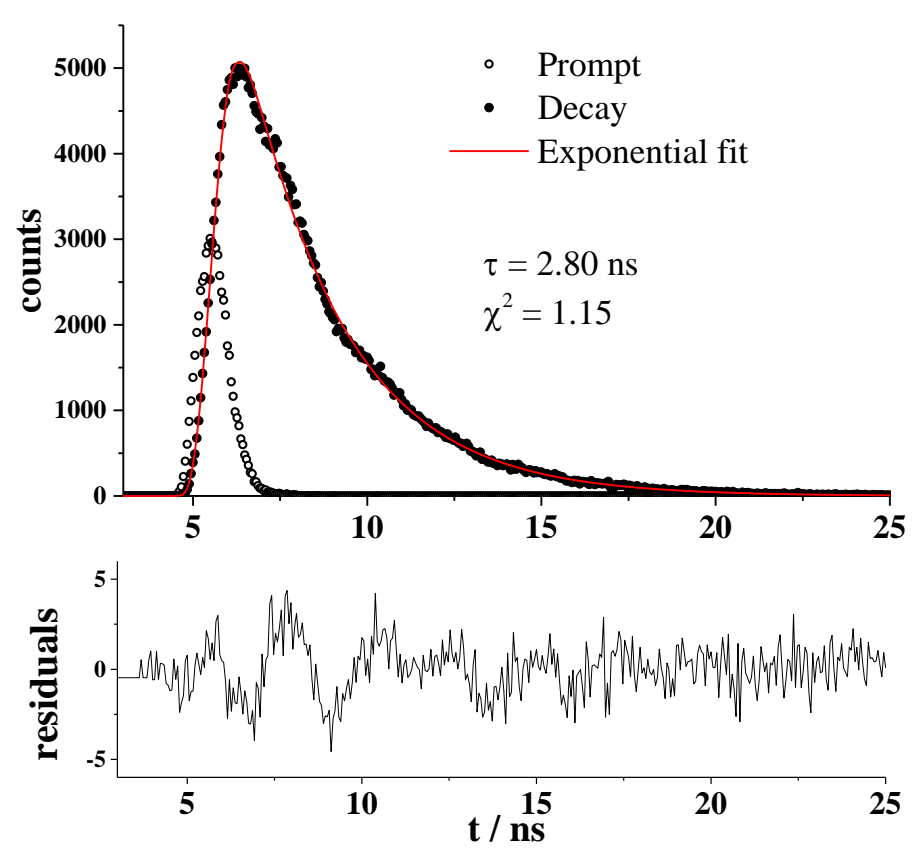

Figure S9. Fluorescence decay of $2 \mathrm{c}$ in acetonitrile $\left(\lambda_{\mathrm{exc}}=282 \mathrm{~nm}, \lambda_{\mathrm{em}}=400 \mathrm{~nm}\right)$

Table S4. Relevant data from lifetime measurements of TBs $2 a-c$ in acetonitrile ( $\lambda_{\text {exc }}=282 \mathrm{~nm}$ ). $\lambda_{e m}$ is the analyzed emission wavelength, $A$ is the offset, B1 is the pre-exponential factor, $\tau$ is the fluorescence lifetime and $\chi^{2}$ is the chi-square of the fit.

\begin{tabular}{|c|c|cc|cc|cc|c|}
\hline \multirow{2}{*}{ TB } & \multirow{2}{*}{$\lambda_{\text {em }} / \mathrm{nm}$} & \multicolumn{2}{|c|}{$\mathrm{A}$} & \multicolumn{2}{|c|}{$\mathrm{B1}$} & \multicolumn{2}{c|}{$\tau / \mathrm{ns}$} & $\chi^{2}$ \\
& & value & SD & value & SD & value & SD & \\
\hline 2a & 350 & 0.55 & 0.05 & 0.01463 & 0.00005 & 1.470 & 0.006 & 0.975 \\
\hline $\mathbf{2 b}$ & 416 & 0.31 & 0.06 & 0.01859 & 0.00006 & 5.70 & 0.02 & 1.171 \\
\hline $\mathbf{2 c}$ & 400 & 0.47 & 0.04 & 0.1200 & 0.0002 & 2.801 & 0.005 & 1.146 \\
\hline
\end{tabular}




\section{Parameters of the Lippert-Mataga plots of $\mathbf{2 a - c}$}

Table S5. Parameters for the linear regressions of the LippertMataga plots of TBs $\mathbf{2 a - c}$. A is the intercept, B is the slope and $R^{2}$ is the $R-$ square of the fit.

\begin{tabular}{|c|cc|cc|c|}
\hline \multirow{2}{*}{ TB } & \multicolumn{2}{|c|}{$\mathrm{A} / 10^{4}$} & \multicolumn{2}{|c|}{$\mathrm{B} / 10^{4}$} & \multirow{2}{*}{$\mathrm{R}^{2}$} \\
& value & SD & value & SD & \\
\hline $\mathbf{2 a}$ & 0.20 & 0.03 & 0.8 & 0.1 & 0.86 \\
\hline $\mathbf{2 b}$ & 1.32 & 0.01 & 1.13 & 0.05 & 0.97 \\
\hline $\mathbf{2 c}$ & 0.680 & 0.008 & 1.51 & 0.04 & 0.98 \\
\hline
\end{tabular}




\section{Dear Dr Balentova and reviewers}

It's our pleasure to receive your e-mail about the comments of manuscript NJ-ART-04-2020-001988. We are very glad that you will consider our revised manuscript. First of all, please convey our best regards to the reviewers. They have put forward a lot of constructive and informative advice and suggestions about improving the manuscript. The advice and suggestions are a great help to our current and further researches. We have taken the reviewer's comments into consideration during revising this manuscript and we have carefully amended the manuscript according to the reviewer's comments. The details about the modifications (highlighted in yellow) in the revised version and the answers to the reviews' questions are shown as follows:

\section{Referee: 1}

1) Figure 1 should be redesigned since it is almost identical to the Figure 1 in one of the author's previous publications (Journal of Molecular Structure, 2018, 1157, 434-443).

Corrected in the manuscript and figure

2) The synthesis of compounds 3,2a and 2d have been reported in Journal of Molecular Structure, 2018, 1157, 434-443, with identical yield\%. The author should clearly point it out in the manuscript.

Corrected: the reference is now included both in the manuscript and in the ESI

3) Compound $2 b$ was synthesized in an awful yield of $4 \%$, which the authors attributed to "the lack of selectivity of the reaction and to the low stability of the product that partially decomposes throughout the chromatographic purification". Therefore, the crude NMR of this reaction should be provided in SI, and the conversion\% or the yield\% using internal standard should be determined from the crude NMR data.

Unfortunately, we don't have crude NMR spectra since the reaction mixture was purified immediately after the reaction by column chromatography. This experiment is at this point impossible to perform, since we will not be able to return to the laboratory probably for some more months. Nevertheless, we think that the complex mixture of reaction including the product $2 \mathrm{~b}$, reagent $2 \mathrm{a}$ and byproduct $2 \mathrm{c}$ (among other compounds, as observed by TLC), would be very difficult to analyze given the similarity of the NMR spectra of $2 b$ with those of $2 a$ and $2 c$, preventing the determination of their relative ratios and in respect to an internal standard. Additional comments regarding this reaction can be seen in response to Referee 2.

4) Although it is not absolutely necessary, the reviewer is of the opinion that $X$-ray single crystal structures of these compounds would be informative data to be included in this manuscript.

Unfortunately, we don't have crystal structures at this moment, and it will be impossible to attempt their obtention for several more months.

\section{Referee: 2}

1) In the introduction, right column, lines 25-28, the authors discuss about the usefulness of TBs in many fields, but do not support the statement with actual references. 


\section{Corrected in the manuscript}

2) Page 2, right column, lines 37-42: the authors justify the low yield (4\%) in the obtainment of $2 b$, pointing out partial decomposition during column chromatography. Is it the acidity of the silica? Have the authors tried alternatives to SiO2? What about the thermal stability of the compound? It seems to be "special" compared to the others and a little bit more feeling for this structure could actually be useful to readers interested in applying that specific molecule.

The column chromatography was performed using aluminum oxide (see ESI) given the acidity of the silica and the fact that isocyanides are often sensitive to acidic conditions. In fact, we had previously investigated this behavior with the diisocyano-TB 2c, which we have attempted to purify in multiple conditions and found that the reported procedure was the most convenient. Aluminum oxide column chromatography was better than silica column chromatography, which resulted in ca. $30 \%$ yields even when the reaction was quantitative and almost instantaneous as we observed by NMR experiments with an internal standard. Unfortunately, the simple extraction procedure was impossible to perform with $2 \mathrm{~b}$ given the presence of multiple compounds in the reaction mixture, and we therefore chose to purify by column chromatography using aluminum oxide. Regarding the thermal stability, we did not do a thorough investigation, but the compound remained unaltered during the measurements at room temperature. Samples were always stored in the freezer to prevent decomposition.

3) Page 3, left column, line 11-12: "Compound 2d was prepared in 96\% yield according to the procedure described previously by our group starting from 2a". Please repeat the reference.

Corrected in the manuscript

4) Would it be possible to increase the font size in the ppm axis of Figures 2 and 3? It is hardly readable. Also, could the authors improve the resolution, or at least increase the thickness, of the NMR traces? The 2D-COSY spectrum could also benefit from increasing its size.

Corrected in the manuscript and figures

5) Also concerning Figure 3: the 3D molecular structure is rotated with respect to the adjacent 2D chemical structure, which, at first glance, can confuse the reader. Perhaps the authors can furnish another $2 D$ representation that better fits with the $3 D$ architecture? Maybe Figure 3 could take the whole width of the page, leaving more freedom to the authors in terms of space?

Corrected in the manuscript and figure

6) Page 4, left column, line 36: the authors correctly refer to Table S2 in ESI. However, they have it wrongly indexed as Table S1 in ESI (as in, there are two consecutive Table S1 in ESI).

Corrected in the ESI

7) Page 5, right column, line 57: they author refer to Table 2, but it should be Table 1.

Corrected in the manuscript

8) Table S3 in ESI is difficult to read, in the sense that it is difficult to associate compounds and solvents at first glance. I suggest the authors restructure Table S3 in a similar way to Table 1 from the main text.

Corrected in the ESI 